\title{
Unknown primary tumour
}

Citation for published version (APA):

van de Wouw, A. J. (2005). Unknown primary tumour. [Doctoral Thesis, Maastricht University]. Maastricht University. https://doi.org/10.26481/dis.20050701aw

Document status and date:

Published: 01/01/2005

DOI:

10.26481/dis.20050701aw

Document Version:

Publisher's PDF, also known as Version of record

\section{Please check the document version of this publication:}

- A submitted manuscript is the version of the article upon submission and before peer-review. There can be important differences between the submitted version and the official published version of record.

People interested in the research are advised to contact the author for the final version of the publication, or visit the DOI to the publisher's website.

- The final author version and the galley proof are versions of the publication after peer review.

- The final published version features the final layout of the paper including the volume, issue and page numbers.

Link to publication

\footnotetext{
General rights rights.

- You may freely distribute the URL identifying the publication in the public portal. please follow below link for the End User Agreement:

www.umlib.nl/taverne-license

Take down policy

If you believe that this document breaches copyright please contact us at:

repository@maastrichtuniversity.nl

providing details and we will investigate your claim.
}

Copyright and moral rights for the publications made accessible in the public portal are retained by the authors and/or other copyright owners and it is a condition of accessing publications that users recognise and abide by the legal requirements associated with these

- Users may download and print one copy of any publication from the public portal for the purpose of private study or research.

- You may not further distribute the material or use it for any profit-making activity or commercial gain

If the publication is distributed under the terms of Article $25 \mathrm{fa}$ of the Dutch Copyright Act, indicated by the "Taverne" license above, 


\section{Unknown Primary Tumour}

\section{PROEFSCHRIFT}

Ter verkrijging van de graad van doctor

aan de Universiteit Maastricht,

op gezag van de Rector Magnificus, Prof. mr. G.P.M.F. Mols, volgens het besluit van het College van Decanen,

in het openbaar te verdedigen

op vrijdag 1 juli 2005 om 14.00 uur

door

Agnès Josephine van de Wouw 


\section{Promotor}

Prof. dr. H.F.P. Hillen

Co-promotores

Dr. R.L.H. Jansen

Dr. E.J.M. Speel

\section{Beoordelingscommissie}

Prof. dr. H.C. Schouten (voorzitter)

Prof, dr. ir. P.A. van den Brandt

Dr. A. de Bruïne

Prof. dr. Ph. Lambin

Prof. dr. P.H.M. de Mulder, UMC St. Radboud Nijmegen 
Süßes Dichten, Lauter Wahrheit,

Fesselt mich in Sympathie

Rein verkörpert Liebesklarheit

Im Gewand der Poesie!

Schumann's Myrthen Lieder op.25 no.6. Lied der Suleika (Goethe)

Ter herinnering aan inijn oma

Voor Aernout,

Floris, Liselotte en Myrthe 
8

4 


\section{Contents}

Chapter 1 General introduction 9

Chapter 2 Epidemiology of unknown primary tumours; incidence 23 and population based survival of 1285 patients in southeast Netherlands, 1984-1992

Chapter $3 \quad$ Clinical and immunohistochemical analysis of patients 33 with unknown primary tumour. A search for prognostic factors in UPT

Chapter 4 Phase III trial of carboplatin, etoposide and paclitaxel compared with 5-fluorouracil and folinic acid in adenocarcinoma of unknown primary tumour

Chapter 5 The unknown biology of the unknown primary tumour; 63 a literature review

Chapter $6 \quad$ Molecular evidence for a clonal relationship between multiple lesions in unknown primary tumour patients

Chapter $7 \quad$ General discussion

Samenvatting

Dankwoord 


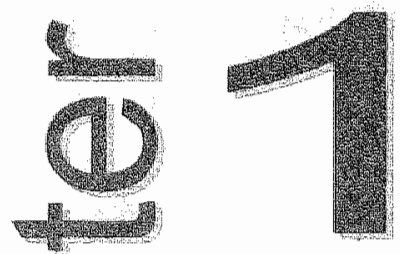

\section{General introduction}

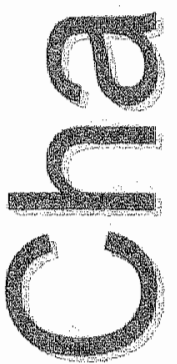


Chapter 1 


\section{Introduction}

Unknown Primary Tumour (UPT) is an intriguing but difficult clinical phenomenon. Patients with UPT are confronted with incurable cancer due to metastases. The fact that the physician does not know the origin of this tumour puts an extra psychological burden on most patients. Clinicians find it difficult to treat UPT because in the current state of knowledge in medical oncology the known primary site appears essential for the correct choice of treatment. Investigators do not know whether UPT is a specific biological entity.

In this thesis, different aspects of UPT (mainly adenocarcinoma of UPT) are discussed in order to improve our knowledge about this tumour, which will hopefully lead to improved survival.

\section{Definition}

UPT is defined as biopsy proven metastasis of a malignancy in the absence of an identifiable primary site after a complete history and physical examination have been carried out, along with basic laboratory studies, chest $X$-ray and additional directed studies indicated by positive findings during the initial workup or a search for a treatable malignancy. ${ }^{1}$ (table 1.1)

Proposals have been made, to introduce a limitation of the time period of the examinations between the first visit and the diagnosis. Thus far no definite time factor' has been integrated into the definition of UPT mainly because a thorough analysis of the patient and the pathological material takes time..$^{2,3}$

Table 1.1 Diagnostic evaluation for UPT.

- Biopsy proven metastatic cancer

- No primary tumour

therefore evaluate by:

- history

- physical examination

- laboratory: basic evaluation

- radiology: chest radiography.

- additional diagnostic tests: indicated by positive findings and/or to find treatable subgroups 
A careful and comprehensive pathological examination of biopsied metastatic lesions is crucial for the diagnosis of UPT. It is very important to recognise lymphomas, melanomas and sarcomas. With improving immunohistochemical panels and molecular tools, the pathologist can increasingly distinguish these malignancies.

UPT is predominantly classified as adenocarcinoma (50-70\%) or poorly differentiated carcinoma (20-30\%). Only $5-8 \%$ is squamous cell carcinoma and $2-3 \%$ undifferentiated malignancy. ${ }^{4-9}$ Neuroendocrine carcinoma $(2-4 \%)$ is often mentioned separately because this entity belongs to a treatable subgroup, that is often regarded and treated as small cell lung carcinoma. ${ }^{10}$

\section{Incidence}

UPT accounts for $0.5-10 \%$ of all newly diagnosed patients with cancer, $4,6,7,11-15$ The wide variation in reported incidences is the result of variation in (1) definition, (2) time and (3) patient selection.

1. In many countries UPT is not identified separately, although the International Classification of Disease of Oncology (ICD-O) allocates the codes 196 to 199 to refer to different localisations of metastatic malignancy of unknown origin. The incidence can be underestimated as well as overestimated by changing definition. Overestimation can be seen when the diagnosis is not microscopically confirmed, for example, in patients with benign diseases or lymphoma. In $20-25 \%$ of patients the diagnosis is not pathologically confirmed. ${ }^{6,11}$ This is a major problem because diagnosis should be based on pathological confirmation. However not proving the diagnosis is such a common practice that one cannot ignore this large group of patients. Lack of histological confirmation can also lead to underestimation: in many countries UPT is only registered as such when confirmed by pathological data, so these patients are not included. Underestimation can also occur when primary sites are 'assigned' to patients on a 'best guess' basis in the absence of definite proof. ${ }^{11,16}$

2 . The lack of histological diagnosis is declining at the present time because patients have better access to medical care, so they are in a better clinical condition when diagnosed. This fact more often leads to histological confirmation, which excludes other diagnoses. The pathologist also has a broader panel of immunohistochemical and molecular markers that can point in the direction of a probable primary tumour. With this specific information, clinicians will more often perform additional studies, which will reveal more primary tumours.

Moreover, sophisticated diagnostic modalities such as spiral CT, MRI and PET scans are available nowadays, which also can identify the primary tumour in a certain fraction of patients. ${ }^{17}$ 
3. Patient selection is also an important factor in declining incidence. An essential part of the research on UPT comes from tertiary referral centres, where incidences found are as low as $0.5 \%-1.8 \%$. ${ }^{7.13}$ This is not only due to intensive clinical and pathological diagnostic management, but also to selection bias up front: patients in poor condition or not willing to undergo further investigations are not referred to these centres.

To investigate what the incidence of UPT is in an unselected population, a population-based study of 1285 patients with UPT was conducted in the Southeast of the Netherlands. The results of this study are shown in Chapter 2.

Clinical behaviour

Though UPT comprises a heterogeneous group of tumours with widely varying natural histories, the clinical picture of UPT demonstrates common typical characteristics (table 1.2). ${ }^{18,19}$

Table 1.2 Clinical behaviour of UPT.

- Short history of non-specific complaints

- Primary remains unidentified in most cases

- $30 \%$ present with over 3 metastatic sites

- Unusual metastatic pattern

- Poor prognosis

Firstly, patients predominantly present with a short history of non-specific complaints (anorexia, weight loss, etc) ${ }^{20}$

Secondly, the primary tumour remains unidentified in most cases throughout the patient's life. Exact figures are missing because different search methods are used (intensive search, clinical follow-up etc.), most data are gathered retrospectively and different populations of UPT are studied. In two studies, the primary tumour site was identified ante-mortem by extensive radiographic and/or endoscopic search in $11-20 \%$ of the patients. ${ }^{19,21}$ In three retrospective studies, the primary tumour was revealed during clinical follow-up after diagnosis in 5-15\%. ${ }^{22-24}$ Even after thorough evaluation at autopsy, only $80 \%$ of the primaries have been found. 9,21

Thirdly, approximately $30 \%$ of patients with UPT present with three or more organs being involved. ${ }^{7,8,12,22,25,26}$ This obviously differs from the percentage of patients with three or more involved organs in metastasised known primary tumours which is below $15 \% .{ }^{27-29}$

Fourthly, an unusual metastatic pattern is reported in some large autopsy studies. $^{9,21.30}$ Differences in metastatic localisation were observed when, at autopsy, the primary tumour was found and the metastatic pattern of UPT was 
compared with the common sites of tumour spread of known primary tumours. A relatively high number of metastases in UPT are found in the kidney, adrenal gland, skin and heart when compared with expected sites of metastases. ${ }^{27}$ In addition, differences in metastatic localisation were observed, when in patients were the primary tumour had been found during autopsy the metastatic pattern of UPT was compared with the common sites of tumour spread of known primary tumours. ${ }^{21}$ In our small group of autopsied patients in whom the primary was found we found no aberrant metastatic pattern. (Chapter 3). Selection bias is an obvious concern in any study based on autopsy data; over $50 \%$ of patients with UPT are not autopsied. However, in two retrospective studies patient characteristics and tumour-specific parameters of autopsied and non-autopsied patients were compared and did not differ from each other, making a significant selection bias unlikely. ${ }^{13.22}$

Finally , patients with UPT, with the exclusion of treatable subgroups, have a very poor prognosis. $6,9.14,19,31$

In Chapter 3 we present among other things the clinical findings of 70 patients with adenocarcinoma of unknown primary in a general hospital.

\section{Prognostic factors}

In order to determine which UPT patients to treat, it is important to estimate the prognosis of the individual patient. One should recognise patients belonging to favourable subgroups, but it is also important to identify patients who are most likely to benefit from therapy. Such patients can be selected using prognostic models by van der Gaast and Culine. ${ }^{26,32}$ The most important prognostic factors established today are performance status, serum lactate dehydrogenase and serum alkaline phosphatase. In Chapter 3 a clinical and immunohistochemical study is described verifying these prognostic factors in a Dutch population. A search is also conducted for new prognostic factors by analysing the correlation of specific immunohistochemical alterations in UPT cells with the unique clinical features of UPT patients.

\section{Survival and treatment}

In unselected populations, patients with UPT have a poor prognosis of 3 to 5 months, with less than $20 \%$ of patients alive one year after diagnosis. ${ }^{6,9,14,19,31}$ Past studies made it clear that some patients respond better to specific treatment than others. Therefore treatable subgroups have a better prognosis when given specific treatments (table 1.3). 
Table 1.3 Treatable subgroups.

- Patients with squamous cell carcinoma (SCC) involving the upper or mid cervical lymph nodes

- Patients with squamous carcinoma involving the inguinal lymph inodes

- Female patients with axillary lymph node metastases

- Women with peritoneal carcinomatosis

- Men with skeletal metastases and/or increased Prostate Specific Antigen

- Poarly differentiated carcinoma

- Poorly differentiated neuroendocrine tumours

- Adenocarcinoma presenting as single metastatic focus

1. Patients with squamous cell carcinoma (SCC) involving the upper or midcervical lymph nodes. In such patients, a primary tumour should be suspected in the head and neck region. Optimal initial evaluation includes a thorough examination of the oropharynx, hypopharynx, nasopharynx, larynx and upper oesophagus by direct vision and fiber optic nasopharyngolaryngoscopy, with biopsy of any suspected area. Patients with SCC of unknown primary should be treated as having locally advanced SCC of the head and neck. Treatment with radiation to the pharyngeal axis and bilateral neck, radical neck dissection, or a combination of these modalities has resulted in long-term, disease-free survival in $40-67 \%$ of cases. ${ }^{33-43}$ Only limited experience is available on chemoradiation in patients with cervical SCC of unknown primary. ${ }^{44,45}$

2. Patients with squamous carcinoma involving the inguinal lymph nodes. Patients should be examined carefully in the genital and anorectal areas. Inguinal dissection and/or radiotherapy and/or chemotherapy may lead to long-term survival. ${ }^{46-48}$

3. Female patients with axillary lymph node metastases. Breast cancer should be suspected in these women. Mammography is the first examination that should be given. However, when it is not helpful in making a diagnosis, bilateral breast magnetic resonance imaging (MRI) is used as a standard approach to evaluate the breasts. ${ }^{49,50}$ These women should be treated as having stage II breast cancer. Primary therapy should include either modified radical mastectomy or axillary lymph node dissection, followed by radiation therapy of the breast and adjuvant systemic therapy. ${ }^{51-55}$ The primary tumour will be identified in $44-82 \%$ of patients when mastectomy is performed. ${ }^{52,53,55}$

4. Women with peritoneal carcinomatosis. These women often have either occult ovarian carcinoma or multifocal extraovarian carcinoma or peritoneal papillary serous carcinoma. When treated as having stage III ovarian carcinoma, complete response to treatment and long-term, disease-free survival are reported. ${ }^{56}$ 
5. Men with skeletal metastases and/or increased prostate specific antigen. These men should be treated as having metastasised prostate cancer with hormonal manipulation.

6. Poorly differentiated carcinoma. Patients with one or more of the following characteristics -young age, male gender, predominant tumour localisation in the mediastinum or retroperitoneum, presence of $12 \mathrm{p}$ chromosomal gain, elevated serum levels of beta-human chorionic gonadotropin or alpha fetoprotein- resemble those with (extragonadall) germ cell tumours. For this reason, these patients should be treated according to the guidelines established for poor prognosis germ cell tumours. ${ }^{57-59}$

7. Poorly differentiated neuroendocrine tumours. Low-grade tumours identified as carcinoids or islet tumours of unknown primary should be managed as metastatic tumours of these types with known sites. The more aggressive, metastasised, poorly differentiated neuroendocrine tumours are more likely to be occult small cell (lung) carcinoma or metastasised anaplastic carcinoid tumours. This entity is noteworthy for its responsiveness to chemotherapy. When treated with a cisplatin-based regimen or a regimen used in small cell lung carcinoma overall response rates of over $75 \%$ may be reached; patients may also have complete responses and long-term survival. ${ }^{10,60,61}$

8. Adenocarcinoma presenting as single metastatic focus. In occasional patients, only a single metastatic lesion is identified after a complete staging evaluation. If no evidence of additional disease can be found, resection of the solitary lesion should be considered, if technically feasible. Local treatment sometimes results in long disease-free intervals. In some instances (e.g., after resection of a solitary brain metastasis), local radiation therapy may also be appropriate to maximize the chance of local control. ${ }^{62,63}$

Unfortunately, most patients do not belong to one of these favourable subgroups. To date no specific therapeutic regimen exists for these patients, and though many chemotherapeutic trials have been performed, best supportive care still seems a good alternative for these patients.

In some recent, mostly phase II studies with patients selected from poor prognostic groups, a median survival of $8-13$ months was reached. ${ }^{7,8,64-73}$ Hainsworth et al. treated 55 patients with paclitaxel, carboplatin and etoposide. $^{72}$ Twenty-five of 53 assessable patients had major objective responses to treatment (seven complete responses). The actuarial median survival time for the entire group was 13.4 months. This schedule appeared effective and tolerable. However, because this was a phase if study performed in a tertiary referral centre, selection probably played a major role. We therefore initiated a phase $I I I$ study in the treatment of adenocarcinoma of 
unknown primary using carboplatin, etoposide and paclitaxel (CEP) as compared to folinic acid and 5-Fluorouracil (FUFA) on a continuous basis. The objective of this study was to determine whether treatment with CEP improves survival, response and toxicity profile in patients with ACUP compared to treatment with FUFA. The results of this study are shown in Chapter 4.

\section{Biological behaviour}

Whether UPT is a separate entity in which the metastatic phenotype is supported by specific genetic alterations is as yet unknown. Understanding the basic biology of UPT can shed light on this issue and, moreover, can have a direct impact on clinical care. A review of the literature on genetic and phenotypic features of UPT is given in Chapter 5.

In order to start to understand UPT, an attempt is made to assess molecular evidence for a clonal relationship between the various metastases within one patient and the primary tumour. Microsatellite, immunohistochemical, comparative genetic hybridisation and fluorescence in situ hybridisation analyses on multiple tumours in patients with UPT were performed. The results are shown in Chapter 6.

\section{Conclusion}

UPT is still an unknown tumour in many aspects. For improving the poor prognosis of this tumour a better understanding is needed. To achieve this several studies were performed and described in this thesis. 


\section{References}

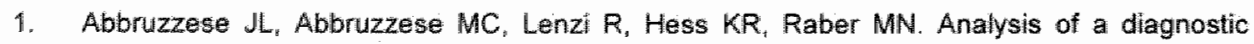
strategy for patients with suspected tumors of unkmown origin. $J$ Clin Oncol 1995;13: 2094-103.

2. Barista I, Celik I, Gullu I, Hayran $\mathbb{M}_{\mathrm{a}}$, Akova $M$. Integrating the time factor into the definition of metastasis of uniknown origin. J Nat Cancer Inst 1996;88.51.

3. Abbruzzese ل $L$, Abbruzzese MC, Lenzi R, Raber MN, Hess KR. Are time or intensity factors important to the definition of metastases of unknown origin? J Natl Cancer Inst 1996:88: 462-3.

4. Lembersky $\mathrm{BC}$, Thomas LC. Metastases of unknown primary site. Med Clin North Am 1996;80:153-71.

5. Daugaard G. Unknown primary tumours. Cancer Treat Rev 1994:20:119-47.

6. Altman $E$. Cadman $E$. An analysis of 1539 patients with cancer of unknown primary site. Cancer 1986;57:120-4.

7. Abbruzzese JL, Abbruzzese MC. Hess $K R$, Raber MN. Lenzi R, Frost $P$. Unknown primary carcinoma: natural history and prognostic factors in 657 consecutive patients. $\mathrm{J}$ Clin Oncol $1994: 12: 1272-80$

8. Hess KR, Abbruzzese MC, Lenzi R, Raber MN, Abbruzzese JL. Classification and regression tree analysis of 1000 consecutive patients with unknown primary carcinoma. Clin Cancer Res 1999:5:3403-10.

9. Le Chevalier T, Cvitkovic E, Caille P, Harvey J, Contesso G, Spieimann M, Rouesse J. Early metastatic cancer of unknown primary origin at presentation. A clinical study of 302 consecutive aulopsied patients. Arch Intern Med 1988;148:2035-9.

10. Hainsworth JD, Johnson DH, Greco FA. Poorly differentiated neuroendocrine carcinoma of unknown primary site. A newly recognized clinicopathologic entity. Ann Intern Med 1998:109: 364-71.

11. Muir C. Cancer of unknown primary site, Cancer 1995;75:353-6.

12. van de Wouw AJ, Janssen-Heijnen ML, Coebergh JW, Hillen HFP. Epidemiology of unknown primary tumours; incidence and population-based survival of 1285 patients in Southeast Netherlands, 1984-1992. Eur J Cancer 2002;38;409-13.

13. Blaszyk H, Hartmann $A_{4}$ Bjornsson $J$. Cancer of unknown primary: clinicopathologic correlations. APMIS 2003;111:1089-94.

14. Levi $F, T e V C$, Erler $G$, Randimbison L, La Vecchia $C$. Epidemiology of unknown primary tumours. Eur J Cancer 2002;38:1810-2.

15. Krementz ET, Cerise EJ, Foster DS, Morgan LR Jr. Metastases of undetermined source. Curr Probl Cancer 1979:4:4-37.

16. Steckel RJ, Kagan AR. Metastatic tumors of unknown origin. Cancer $1991 ; 67: 1242-4$

17. Pavlidis N, Briasoulis E, Hainsworth J, Greco FA. Diagnostic and therapeutic management of cancer of an unknown primary. Eur J Cancer 2003:39:1990-2005

18. Leonard RJ. Nystrom JS. Diagnostic evaluation of patients with carcinoma of unknown primary tumor site. Semin Oncol 1993;20:244-50.

19. Kirsten $F$, Chi $\mathrm{CH}$, Leary JA, Ng AB, Hedley DW, Tattersall MH. Metastatic adeno or undifferentiated carcinoma from an unknown primary site-natural history and guidelines for identification of tireatable subsets. Q J Mled 1987:62: 143-61.

20. Didolkar MS, Fanous N, Elias EG, Moore RH. Metastatic carcinomas from occult primary tumors A study of 254 patients. Ann Surg 1977; 186:625-30.

21. Nystrom JS, Weiner JM, Heffelfinger-Juttner J, Inwin LE, Bateman JR, Wolf RM. Metastatic and histologic presentations in unknown primary cancer. Semin Oncol 1977;4:53-8. 
22. van de Wouw AJ, Jansen RL, Griffioen AW, Hillen HF. Clinical and immunohistochemical analysis of patients with unknown primary tumour. A search for prognostic factors in UPT Anticancer Res 2004:24:297-301.

23. Hamilton CS, Langlands AO. ACUPS (adenocarcinoma of unknown primary site): a clinical and cost benefit analysis. Int J Radiat Oncol Biol Phys 1987:13:1497-503.

24. Stewart JF, Tattersall MH, Woods RL, Fox RM. Unknown primary adenocarcinoma: incidence of overinvestigation and natural history. BMJ 1979;1:1530-3.

25. Abbruzzese JL, Raber MN. Clinical Oncology. MD Abelhoff, JO Armitage, AS Lichter,.JE Niederhuber. (ed.), (Churchill Livingstone, New York, Edinbrough, London, Melbourne, Tokyo) 2001:1833-45.

26. Culine $S$, Kramar $A$, Saghatchian $M$, Bugat $R$ " Lesimple $T$, Lortholary $A$, Merrouche $Y$; Laplanche $A$, Fizazi $K_{n}$ French Study Group on Carcinomas of Unknown Primary. Development and validation of a prognostic model to predict the length of survival in patients with carcinomas of an unknown primary site. J Clin Oncol 2002;20:4679-83.

27. Gilbert HA, Kagan AR. Metastases: incidence, detection, and evaluation without histologic contirmation. In: Weiss $L$, ed. Fundamental. aspects of metastasis. Amsterdam, North Holland. 1976: 385-405

28. End results section, B.b. N.C.I. End results in cancer. US dept of health, education and welfare publication 4. 1972. Government printing office. (Report)

29. Abrams HL, Spiro R, Goldstein N. Metastases in carcinoma: analysis of 1000 autopsied cases. Cancer 1950;3:74-85.

30. Mayordomo JI, Guerra JM, Guijarro C, Garcia-Prats MD, Gomez A, Lopez-Brea M, Gonzalez $R$, Hergueta $P$, Lopez-Pino MA, Martinez-Tello F, et al. Neoplasms of unknown primary site: a clinicopathological study of autopsied patients. Tumori 1993;79:321-4

31. Markman M. Metastatic adenocarcinoma of unknown primary site: analysis of 245 patients seen at The Johns Hopkins Hospital from 1965-1979. Med Pediatr Oncol 1982;10:569-74.

32. van der Gaast $A$, Verweij J, Planting AS, Hop WC, Stoter $G$. Simple prognostic model to predict survival in patients with undifferentiated carcinoma of unknown primary site. $J$ Cilin Oncol 1995;13:1720-5.

33. Barrie $J R_{n}$ Knapper $W H$, Strong EW. Cervical nodal metastases of unknown origin. Am J Surg $1970: 120: 466-70$.

34. Carison LS, Fletcher GH, Oswald MJ. Guidelines for radiotherapeutic techniques for cervical metastases from an unknown primary. Int J Radiat Oncol Biol Phys 1986:12:2101-10.

35. Jesise $\mathrm{RH}$, Perez $\mathrm{CA}$, Fletcher $\mathrm{GH}$. Cervical lymph node metastasis: unknown primary cancer. Cancer 1973,31:854-9.

36. Reddy SP. Marks JE. Metastatic carcinoma in the cervical lymph nodes from an unknown primary site: results of bilateral neck plus mucosal irradiation ws. ipsilateral neck irradiation. Int J Radiat Oncol Biol Phys 1997;37:797-802.

37. Spiro RH, De Rose G. Strong EW. Cervical node metastasis of occult origin. Am J Surg 1983:146:441-6.

38. Yang $Z Y$, Hu YH, Yan $J H_{\text {, }}$ Cai WM, Qin $D X, X u G Z$, Wu XL. Lymph node metastases in the neck from an unknown primary. Report on 113 patients. Acta Radiol Oncol 1983,22:17-22,

39. Fernandez JA, Suarez C. Martinez JA, Llarente JL, Rodrigo JP, Alvarez JC. Metastatic squamous cell carcinoma in cervical lymph nodes from an unknown primary tumour: prognostic factors. Clin Otolaryngol 1998;23:158-63.

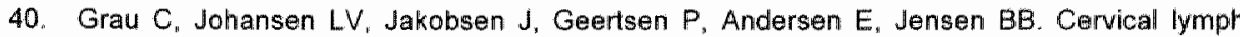
node metastases from unknown primary tumours. Results from a national survey by the Danish Society for Head and Neck Oncology. Radiother Oncol 2000;55:121-9. 
41. Colletier PJ, Garden AS, Morrison WH, Goepfert H, Geara F, Ang KK. Postoperative radiation for squamous cell carcinoma metastatic to cervical lymph nodes from an unknown primary site: outcomes and pattems of failure. Head Neck 1998:20:674-81.

42. Erkal HS, Mendenhall WM, Amdur RJ, Villaret DB, Stringer SP. Squamous cell carcinomas metastatic to cervical lymph nodes from an unknown head-and-neck mucosal site treated with radiation therapy alone or in combination with neck dissection. Int J Radiat Oncol Biol Phys 2001; $50: 55-63$

43. Medini E. Medini AM. Lee CK, Gapany $M$, Levitt SH. The management of metastatic squamous cell carcinoma in cervical lymph nodes from an unknown primary. Am J Clin Oncal $1998: 21: 121-5$.

44. Smith $S$, Argiris A, Stenson K. Combined modality therapy with chemoradiation for squamous cell carcinoma of the head and neck from an occult primary. Proc Am Soc Clin Oncol 2002. (Abstract)

45. Jeremic B, Djuric LJ, Jewremovic S, Stanisavljevic B, Milojevic LJ, Mijatovic LJ. Metastatic squamous cell carcinoma of an unknown primary tumor localized to the neck. $J$ Chemother $1992 ; 4: 41-5$.

46. Zaren $H A_{a}$ Copeland $E M$ III. Inguinal node metastases. Cancer 1978:41:919-23.

47. Guarischi $A_{\text {, Keane }} T \downarrow$, Elhakim $T$. Metastatic inguinal nodes from an unknown primary neoplasm. A review of 56 cases. Cancer 1987;59:572-7.

48. Rasponi A, Costa A, Clemente C, Merson M, Marchini S, Andreoli C. Lymphnodal metastases from unknown primary tumors. Neoplasma 1982;29:631-8.

49. Schorn C, Fischer U, Luftner-Nagel S, Westerhof JP, Grabbe E. MRI af the breast in patients with metastatic disease of unknown primary. Eur Radiol 1999:9:470-3.

50. Henry-Tillman RS, Harms SE, Westbrook KC, Korourian S, Klimberg VS. Role of breast magnetic resonance imaging in determining breast as a source of unknown metastatic lymphadenopathy. Am J Surg 1999;178:496-500.

51. Foroudi $F$, Tiver KW. Occult breast carcinoma presenting as axillary metastases. Int J Radiat Oncal Biol Phys 2000;47:143-7.

52. Patel d, Nemoto $T$, Rosner D, Dao TL. Pickren JW. Axillary lymph node metastasis from an occult breast caincer. Cancer 1981:47:2923-7.

53. Merson $M$, Andreola $S$, Galimberti $V$, Bufalino R, Marchini $S$, Veronesi U. Breast carcinoma presenting as axillary metastases without evidence of a primary tumor. Cancer 1992;70: 504-8.

54. Ellerbroek $N$, Holmes $F$, Singletary E, Evans $H$, Oswald M, McNeese M. Treatment of patents with isolated axillary nodal metastases from an accult primary carcinoma consistent with breast origin. Cancer 1990;66:1461-7.

55. Ashikari $R$, Rosen PP, Urban $\Downarrow A$, Senoo T. Breast cancer presenting as an axiliary mass. Ann Surg 1976;183:415-7.

56. Muggia FM, Baranda J. Management of peritoneal carcinomatosis of unknown primary tumor site. Semin Oncol 1993:20:268-72.

57. Motzer RJ, Rodriguez E Reuter VE, Bosl GJ, Mazumdar M, Chaganti RS. Molecullar and cytogenetic studies in the diagnosis of patients with poorly differentiatted carcinomas of unknown primary site. J Clin Oncol 1995:13:274-82

58. van der Gaast A, Venweij J, Henzen-Logmans SC, Rodenburg CJ. Stoter G. Carcinoma of unknown primary: identification of a treatable subset? Ann Oncoll 1990;1:119-22.

59. Hainsworth JD, Johnson $\mathrm{DH}$, Greco FA. Cisplatin-based combination chemotherapy in the treatment of poorly differentiated carcinoma and poorly differentiated adenocarcinoma of unknown primary site: results of a 12-year experience. J Clin Oncol 1992,10:912-22.

60. van der Gaast A, Verwey J, Prins E, Splinter TA. Chemotherapy as treatment of choice in extrapulmonary undifferentiated small cell carcinomas. Cancer 1990;65:422-4. 
61. Moertel CG, Kvols LK, O'Connell MJ, Rubin w. Treatment of neuroendocrine carcinomas with combined etoposide and cisplatin. Evidence of major therapeutic activity in the anaplastic variants of these neoplasms. Cancer 1991;68:227-32.

62. Nguyen LN, Maor MH, Oswald M. Brain metastases as the only manifestation of an undetected primary tumor. Cancer 1998:83:2181-4.

63. Salvati $M$, Cervoni $L$, Raco $A$. Single brain metastases from unknown primary malignancies in CT-era. J Neurooncol 1995;23:75-80.

64. Hainsworth JD, Greco FA. Management of patients with cancer of unknown primary site. Oncology (Huntingt) 2000;14:563-74.

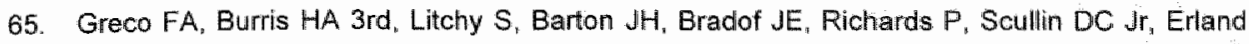
JB, Morrissey LH. Hainsworth JD. Gemcitabine, carboplatin, and paclitaxel for patients with carcinoma of unknown primary site: a Minnie Pearl Cancer Research Network study: $\mathrm{j}$ Clin Oncol 2002;20:1651-6.

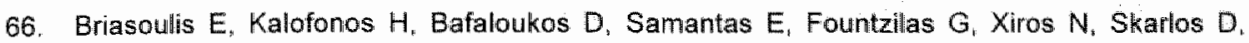
Christodoulou $C$, Kosmidis $P$. Pavlidis $N$. Carboplatin plus paclitaxel in unknown primary carcinoma: a phase il Hellenic Cooperative Oncology Group Study. J Clin Oncol 2000;18: $3101-7$.

67. Pouessel D, Culine $S$, Becht $C$, Ychou $M$, Romieu $G$, Fabbro M, Cupissol D. Pinguel $F$. Gemcitabine and docetaxel as front-line chemotherapy in patients with carcinoma of an unknown primary site. Cancer 2004; 100:1257-61.

68. Culine S, Fabbro M, Ychou M, Romieu G, Cupissol D, Pujol H. Chemotherapy in carcinomas of unknown primary site: a high-dose intensity policy. Ann Oncol 1999;10:569-75.

69. Greco FA, Erland JB, Morrissey LH, Burris HA 3rd, Hermann RC, Steis R, Thampson D, Gray J. Hainsworth JD. Carcinoma of unknown primary site: phase II trials with docetaxel plus cisplatin or carboplatin. Ann Oncol 2000;11:211-5.

70. Greco FA, Burris HA 3rd, Erland JB, Gray JR, Kalman LA, Schreeder MT, Hainsworth JD. Carcinoma of unknown primary site. Cancer 2000;89:2655-60.

71. Greco FA, Gray J, Burris HA 3rd, Erland JB, Morrissey LH, Hainsworth JD. Taxane-based chemotherapy for patients with carcinoma of unknown primary site. Cancer $J 2001 ; 7: 203-12$.

72. Hainsworth JD, Erland JB, Kalman LA, Schreeder MT, Greco FA. Carcinoma of unknown primary site: treatment with 1 -hour paclitaxel, carboplatin, and extended-schedule etoposide. $\mathrm{J}$ Clin Oncol 1997;15:2385-93.

73. Lenzi R, Hess KR, Abbruzzese MC. Raber MN, Ordonez NG, Abbruzzese Jl. Poorly differentiated carcinoma and poorly differentiated adenocarcinoma of unbiknown origin: favorable subsets of patients with unknown-primary carcinama? J Clin Oncol 1997:15: $2056-66$. 


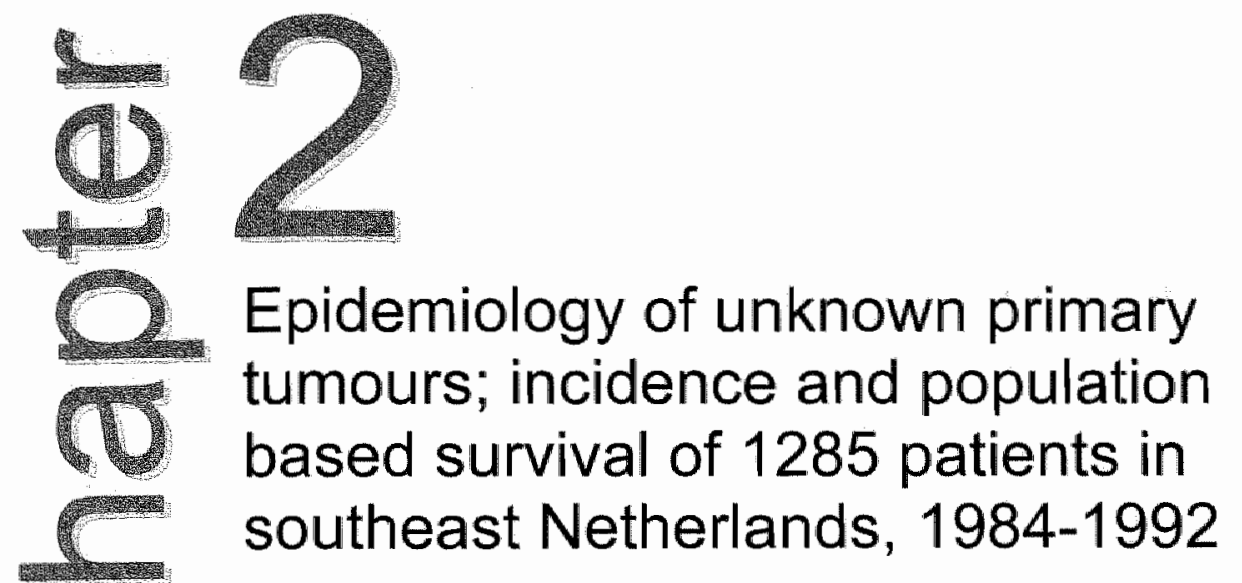

AJ van de Wouw, MLG Janssen-Heijnen, JWW Coebergh, HFP Hillen Eur J Cancer 2002;38:409-13 
wather 2 


\section{Abstract}

\section{Background}

Patients with an unknown primary tumour (UPT) represent 5 to $10 \%$ of all new cancer patients. Data on survival and prognostic factors of UPT are based on selected patient series from specialised institutions. Population-based data on incidence, histology and determinants of survival for patients with UPT are not available.

\section{Patients and methods}

All patients diagnosed with UPT between 1984 and 1992 and entered in the population-based Eindhoven Cancer Registry for Southeast Netherlands were included. Follow-up of vital status is complete up to 1999.

\section{Results}

1285 patients were registered. In 1024 patients the diagnosis was confirmed histopathologically: $479(47 \%)$ had adenocarcinoma, $453(44 \%)$ poorly differentiated carcinoma (PDC) or adenocarcinoma (PDA), 76 (7.4\%) squamous cell carcinoma and 16 patients $(1.6 \%)$ had an undifferentiated malignant neoplasm. In $26 \%$ of these patients with UPT the tumour was already widely disseminated at presentation. The majority of patients $(67 \%)$ received only supportive treatment. The median survival was 11 weeks and only $15 \%$ were still alive one year after diagnosis. Favourable subgroups comprised young patients and patients with metastases localised in lymph nodes. In 261 cases the diagnosis was made clinically. These patients were evaluated separately. They were older than the biopsy-confirmed patients, received less cancer therapy and their prognosis was even worse (median survival of 7 weeks).

In a comparison with data from a tertiary referral centre in the USA our patients were older, received less therapy and had a poorer prognosis. Demographics of our favourable subgroup resembled the patients from the American study. The differences were most likely caused by the difference in patient population.

\section{Conclusion}

We have demonstrated in a population-based study that the prognosis for patients with UPT is more unfavourable than suggested in most clinical studies. 


\section{Introduction}

UPT is defined as biopsy proven metastasis of a malignancy in the absence of an identifiable primary site after complete history and physical examination, basic laboratory studies, chest $X$-ray and additional directed studies indicated by positive findings during the initial work-up. ${ }^{1}$ Modern cancer management relies heavily on recognition of the primary tumour; thus the absence of a primary site poses major diagnostic and therapeutic problems.

Patients with an unknown primary tumour represent 5 to $10 \%$ of all new cancer patients. $^{2,3}$ The diagnosis was ranked as the eighth most frequent site of cancer in one large series. ${ }^{4}$ Approximately 2500 new patients are diagnosed annually in the Netherlands giving an age-standardised incidence rate of 6.7 per $10^{5}$ for males and 5.3 per $10^{5}$ for females. ${ }^{5}$ It is more common than nonHodgkin lymphoma.

In most clinical studies the prognosis for patients with UPT was generally poor. Median survival from the time of diagnosis ranged from 5 to 11 months, and less than $25 \%$ of patients survived beyond one year. ${ }^{6,7}$ Treatable subgroups comprising approximately $30 \%$ of the total group can be recognised. ${ }^{3}$ However, for the majority of patients with UPT effective therapy does not exist. Since data on prognostic factors of UPT and most survival figures are usually obtained from specialised institutions, they may be only of limited relevance. We therefore report on incidence, histological findings, survival and prognostic factors for an unselected group of patients with UPT, treated in general hospitals and entered in the Eindhoven Cancer Registry for Southeast Netherlands between 1984 and 1992. We compared these data with results reported for a specialised institute in the USA. ${ }^{6}$

\section{Materials and methods}

The Eindhoven Cancer Registry was started in 1955 as part of a program for nationwide cancer registration. It served an area of about $2500 \mathrm{~km}^{2}$ with almost one million inhabitants (almost $7 \%$ of the Dutch population). Access to specialised care was easy as a result of relatively short distances to the eight hospitals, ample supply of health services and a sickness insurance system without major financial obstacles. The Eindhoven Cancer Registry provides full documentation on all forms of cancer in this region. ${ }^{8}$ The data are retrieved via four different routes. Routine reports on all patients submitted by the Departments of Pathology and Radiotherapy are checked. Periodic active and direct collection of data from patient records in all hospitals is achieved in cooperation with the medical records offices as well as direct contact with secretarial offices of surgical departments. Finally cross-checks with 
specialised departments of the Radboud University Hospital in Nijmegen are carried out. Active follow-up was accomplished in cooperation with municipal population administrations in four rounds in 1987, 1991, 1994 and 1999. Deathcertificates cannot be tracked in the Netherlands.

From the database in question 1285 new UPT patients were diagnosed during the period 1984-1992. All patients were coded according to the International Classification of Diseases of Oncology, 9th edition, codes 196 to 199 (ICD-O). These codes refer to different localizations of metastasis of an unknown primary malignancy. They are used when at the time of diagnosis and initial treatment, the tumour origin remains unknown to the physician. The series includes 1024 patients with microscopically confirmed metastatic malignancies as well as 261 patients with only a clinical diagnosis. The latter group was evaluated separately because it not fulfilled today's accepted definition of UPT. We did not exclude these patients because the high percentage $(20 \%)$ of clinical diagnosis demonstrated that it was common practice, especially among the elderly, not to perform a biopsy but to diagnose UPT only on the basis of clinical signs and symptoms.

The pathological reports came from three regional laboratories. Patients were divided into 4 subgroups: adenocarcinoma, poorly differentiated carcinoma (PDC) and poorly differentiated adenocarcinoma (PDA), squamous cell carcinoma and undifferentiated malignant neoplasm.

Incidence was calculated per 100,000 person-years and age-adjustment occurred according to the European Standardized Population. Survival was calculated from date of diagnosis, which is the date on which the biopsy was performed or the patient was hospitalised. Estimates of the survival distribution of patients were constructed using the method of Kaplan and Meier. 9 Differences between survival curves for various patient subgroups were evaluated for statistical significance with the log-rank test.

As a reference we used data from the largest series of UPT patients in literature, reported by Abbruzzese et al ${ }^{6}$ In this series clinical data on 657 consecutive patients with unknown primary carcinoma referred to the M.D. Anderson Cancer Center, Houston, USA between 1987 and 1992 were evaluated.

\section{Results}

In the period from 1984 to 1992 in 1285 patients UPT was diagnosed (1024 by biopsy; 261 clinically) and registered with the Eindhoven Cancer Registry, about $4 \%$ of all cancer patients in this period. Most patients were seen by an internist or pneumologist ( $63 \%$ and $15 \%$, respectively).

The demographical and histological characteristics of the biopsy-proven 1024 patients are listed in table 2.1. 
Table 2.1 Characteristics of patients with unknown primary tumour; distribution according to age, gender and histology.

1024 patients with biopsy-confirmed UPT (this study):

la 131 patients who survived more than 1 year; (this study):

Il 261 patients with clinical diagnosis UPT (this study);

III 657 patients with UPT (Abbruzzese et al 1994)

\begin{tabular}{|c|c|c|c|c|c|c|c|c|}
\hline & \multicolumn{6}{|c|}{ Present series } & \multirow{2}{*}{\multicolumn{2}{|c|}{$\begin{array}{c}\text { MD Anderson } \\
\text { III }\end{array}$}} \\
\hline & \multicolumn{2}{|c|}{1} & \multicolumn{2}{|c|}{ la } & \multicolumn{2}{|c|}{$\|$} & & \\
\hline & $n$ & $(\%)$ & $\mathrm{n}$ & $(\%)$ & $n$ & $(\%)$ & $\mathrm{n}$ & $(\%)$ \\
\hline & 1024 & $(100)$ & 131 & $(100)$ & 261 & $(100)$ & 657 & $(100)$ \\
\hline \multicolumn{9}{|l|}{ Age,years } \\
\hline$<40$ & 32 & (3) & 3 & (2) & 2 & (1) & 65 & $(10)$ \\
\hline $40-49$ & 70 & (7) & 16 & (12) & 5 & (2) & 98 & (15) \\
\hline $50-59$ & 191 & (19) & 31 & $(24)$ & 22 & (8) & 175 & $(27)$ \\
\hline $60-69$ & 303 & (30) & 47 & $(36)$ & 63 & (24) & 208 & (32) \\
\hline$\geq 70$ & 428 & (42) & 34 & (26) & 169 & (65) & 111 & $(17)$ \\
\hline \multicolumn{9}{|l|}{ Gender } \\
\hline male & 546 & (53) & 57 & (44) & 148 & $(57)$ & 353 & $(54)$ \\
\hline fermale & 478 & (47) & 74 & $(56)$ & 113 & (43) & 304 & $(46)$ \\
\hline \multicolumn{9}{|l|}{ Histologic diagnosis } \\
\hline adenocarcinoma & 479 & $(47)$ & 44 & $(34)$ & & & 255 & (39) \\
\hline PDCIPDA & 453 & $(44)$ & 70 & $(53)$ & & & 320 & $(49)$ \\
\hline squamous Carcinoma & 76 & $(7)$ & 14 & (11) & & & 38 & (6) \\
\hline malignant neoplasm & 16 & (2) & 3 & (2) & & & 44 & (6) \\
\hline
\end{tabular}

$\mathrm{PDC}=$ poorly differentiated carcinoma; $\mathrm{PDA}=$ poorly differentiated adenocarcinoma

The mean age was 66 years and there was a slight male predominance. Adenocarcinoma and poorly differentiated carcinoma/ poorly differentiated adenocarcinoma were the most common histological diagnoses. The presenting sites of metastasis identified pathologically, radiographically, or by physical examination are listed in table 2.2. Metastases were found most frequently in the liver, followed by the lung or pleura and lymph nodes. In $26 \%$ of patients the tumour had already metastasised to 3 or more sites at the time of diagnosis. In the majority of cases $(67 \%)$ only supportive treatment was given. Chemotherapy, radiotherapy or surgery was provided in $5 \%, 14 \%$ and $5 \%$ of cases, respectively; $4.4 \%$ received combination therapy. Only $1 \%$ of patients received hormonal therapy (table 2.3 ).

In January 1999, 979 patients had died, 20 were lost to follow-up and 25 patients were still alive. The median survival for the biopsy-proven group was 11 weeks, with only 152 patients (15\%) alive one year after diagnosis (figure 2.1). 
Table 2.2 Sites of metastasis in patients with unknown primary tumour.

11024 patients with biopsy-confirmed UPT (this study);

la 131 patients who survived more than 1 year (this study);

II 261 patients with clinical diagnosis UPT (this study):

III 657 patients with UPT (Abbruzzese et al 1994)

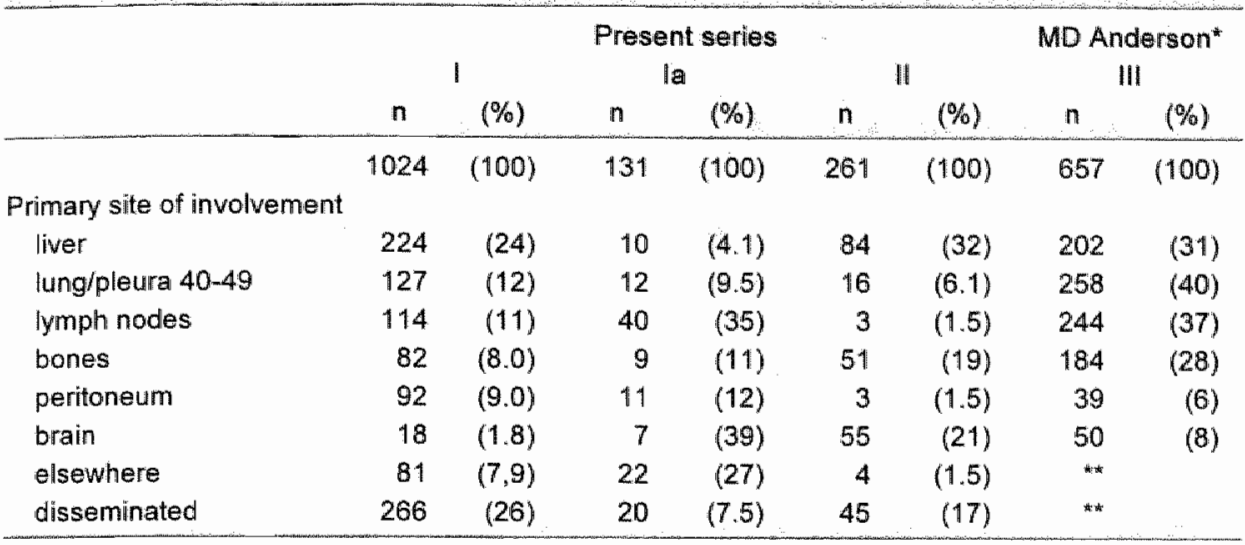

* $60 \%$ of patients presented with more than one metastatic site, "** Not separately mentioned

Table 2.3 Primary therapy for patients with unknown primary tumour.

I 1024 patients with biopsy-confirmed UPT (this study);

la 131 patients who survived more than 1 year (this study);

II 261 patients with clinical diagnosis UPT (this study);

III 657 patients with LIPT (Abbruzzese et al 1994)

\begin{tabular}{|c|c|c|c|c|c|c|c|c|}
\hline & \multicolumn{6}{|c|}{ Present series } & \multirow{2}{*}{\multicolumn{2}{|c|}{$\begin{array}{c}\text { MD Anderson* } \\
\text { III }\end{array}$}} \\
\hline & \multicolumn{2}{|r|}{1} & \multicolumn{2}{|c|}{ Ha } & \multicolumn{2}{|c|}{$\| I$} & & \\
\hline & $n$ & $(\%)$ & $n$ & $(\%)$ & $n$ & $(\%)$ & $n$ & $(\%)$ \\
\hline & 1024 & $(100)$ & 131 & $(100)$ & 261 & $(100)$ & 657 & $(100)$ \\
\hline \multicolumn{9}{|l|}{ Therapy } \\
\hline supportive care & 688 & $(67)$ & 50 & $(38)$ & 202 & $(77)$ & 67 & (10) \\
\hline radiotherapy & 147 & (14) & 32 & $(24)$ & 46 & $(18)$ & 189 & (29) \\
\hline surgery & 51 & (5) & 13 & $(10)$ & 2 & $(0.8)$ & 77 & (12) \\
\hline chemotherapy & 53 & (5) & 3 & (2) & 1 & $(0.4)$ & 324 & (49) \\
\hline hormone therapy & 11 & (1) & 2 & (2) & 2 & $(0.8)$ & & \\
\hline combination & 45 & (4) & 25 & (19) & 1 & $(0.4)$ & & \\
\hline unknown & 29 & (3) & 6 & (5) & 7 & $(2.6)$ & & \\
\hline
\end{tabular}

"Only the primary treatment modality

Favourable subgroups comprised young patients i $<50$ years) and patients with lymph node metastases (table 2.4). Patients with brain metastases as well as patients with an undifferentiated malignant neoplasm appeared to live longer, but random variation ( $n=18$ and $n=16$ ) could have played a role. 
The 261 patients with only a clinical diagnosis differed from biopsy-confirmed patients in being older, receiving less cancer therapy and having a shorter median survival of 7 weeks (figure 2.1).

Patients treated at the MD Anderson were younger, received in almost all cases some sort of therapy and lived longer. About $40 \%$ had lymph node localisation "but it is unknown whether this was the only site of presentation.

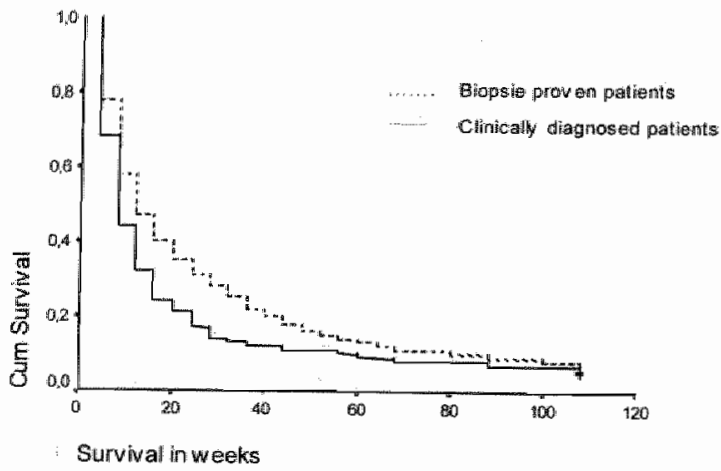

Figure 2.1 Survival functions.

Table 2.4 Median duration of survival of 1024 new patients with biopsy-confirmed UPT, according to age, histology and site of metastases.

\begin{tabular}{lcc}
\hline Variable & No. of patients (\%) & Median survival (weeks) \\
\hline Age, years & $32(3.1)$ & 20 \\
$<40$ & $70(6.8)$ & 24 \\
$40-49$ & $191(19)$ & 12 \\
$50-59$ & $303(30)$ & 9 \\
$60-69$ & $428(42)$ & 5 \\
$\geq 70$ & & \\
Histological diagnosis & $479(47)$ & 10 \\
adenocarcinoma & $453(44)$ & 11 \\
PDC/PDA & $76(7.4)$ & 14 \\
squamous cell carcinoma & $16(1.6)$ & 20 \\
malignant neoplasm & & \\
Site of involvement & $244(24)$ & 4 \\
liver & $127(12)$ & 6 \\
lung/pleura & $114(11)$ & 34 \\
lymph nodes & $82(8)$ & 12 \\
bones & $92(9)$ & 5 \\
peritoneum & $18(11.8)$ & 28 \\
brain & $81(7.9)$ & 20 \\
elsewhere & $266(26)$ & 9 \\
disseminated & &
\end{tabular}

$P D C=$ poorly differentiated carcinoma; $P D A=$ poorly differentiated adenocarcinoma 


\section{Discussion}

In a population-based study we found that $4 \%$ of all new cancer patients were diagnosed as having UPT. In our registry this is the 6th most common malignant presentation among men and women. ${ }^{8}$ Overall survival is very poor in the biopsy-proven group, with a median of 11 weeks and a 1-year survival rate of $15 \%$ and even worse in the clinical diagnosed group ( 7 weeks).

Comparison with a large clinical study of patients with UPT in a tertiary referral hospital revealed similarities with respect to histopathological findings, malefemale ratio, favourable prognostic factors (young age, squamous cell carcinoma and lymph node metastases). ${ }^{6}$ However our patients were older: $42 \%$ versus $17 \%$ were over 70 years old and $10 \%$ versus $25 \%$ under 50 years of age. Approximately $30 \%$ of the patients in our study received anti-cancer therapy. In most clinical studies, $50-90 \%$ of patients received some sort of treatment. ${ }^{6,7}$ Median survival was 11 weeks which was far worse than the 11 months mentioned by Abbruzzese and also worse than the 5 months reported by others. ${ }^{2,3,6,7}$ According to age and lymph node involvement these patients were similar to the favourable subgroup from our series who survived for more than one year.

The shorter survival could be caused by less treatment of mainly older patients in our study. Studies performed in the south of the Netherlands and in the state of Arizona (USA) have shown that the chance of not being treated for cancer or receiving less intensive treatment was higher among the elderly than in younger patients. ${ }^{10,11}$

The high percentage $(20 \%)$ of clinical diagnosis demonstrates that it was common practice, especially among the elderly, not to perform a biopsy but to diagnose UPT only on the basis of clinical signs and symptoms. The short survival probably supports this diagnosis for this particular group of patients.

In order to treat and advise patients with UIPT properly it is important to be aware of the common behaviour of the disease. We have demonstrated in a population-based study that the prognosis of patients with UPT is more unfavourable than most clinical studies have suggested. 


\section{References}

1 Hillen HF. Unknown primary tumours. Postgrad Med $J 2000 ; 76: 690-3$.

2 Greco FA, Hainsworth JD. Cancer of unknown primary site. DeVita VT Jr, Hellman $S$, Rosenberg $S A_{*}$ (eds), editors. Cancer. Principles and practice of oncology. ed 5 . Philadelphia PA Lippincott 1995;2072-92.

3 Lembersky BC, Thomas LC. Metastases of unknown primary site. Med Clin North Am 1996; 80:153-71.

4 Krementz ET, Cerise E』, Foster DS, Morgan LR. Metastases of undetermined source. Curr Probl Cancer 1979;4:4-37.

5 Visser O, Coebergh JWW, Sichouten LJ. Incidence of cancer in the Netherlands 1993. Netherlands Cancer Registry Utrecht.

6 Abbruzzese $\mathrm{J}$, Abbruzzese MC, Hess KR, Raber MN, Lenzi R, Frost P. Unknown primary carcinoma: natural history and prognostic factors in 657 consecutive patients. $J$ Clin Oncol 1994:12:4272-80.

7 Altman E, Cadman E. An analysis of 1539 patients with cancer of unknown primary site. Cancer $1986 ; 57: 120-4$.

8 Coebergh $J W$, Heijden vd LH, Janssen-Heijnen MLG. Cancer incidence and survival in the Southeast of the Netherlands (1955-1994). Lecturis BV Eindhoven 1996.

9 Kaplan EL, Meier P. Non-parametric estimation from incomplete observations. I Am Stat Assoc 1958:53:457-81.

10 de Rijke JM, Schouten LJ, Schouten HC, Jager JJ, Koppejan $A G$, wan den Brandi PA. Agespecific differences in the diagnostics and treatment of cancer patients aged 50 years and older in the province of Limburg, The Netherlands. Ann Oncoll 1996:7:677-85.

11 Goodwin JS, Hunt WC. Samet JM. Determinants of cancer therapy in elderly patients. Cancer $1993 ; 72: 594-601$. 


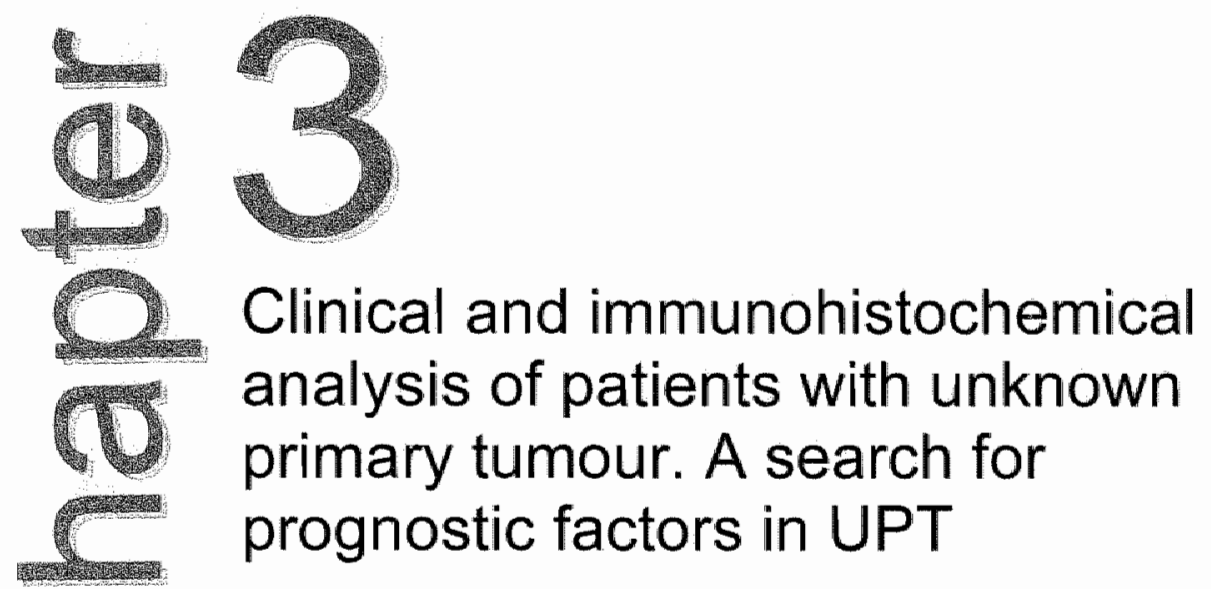

AJ van de Wouw, RLH Jansen, AW Griffioen, HFP Hillen Anticancer Research 2004;24:297-301 
Chander 


\section{Abstract}

\section{Background}

The unknown primary tumour (UPT) is an intriguing clinical phenomenon in approximately $5 \%$ of all new diagnosed patients with cancer. To evaluate a correlation between the specific immunohistochemical alterations in UPT cells and the unique clinical features of UPT patients, to define the natural history of UPT and to verify prognostic factors, we undertook a detailed clinical and immunohistachemical analysis of patients with the diagnosis of adenocarcinoma of UPT.

\section{Results}

Patients with UPT present with a short history and have a poor prognosis. Univariate analysis was performed with clinical, biological and immunohistochemical variables. Patients with a higher age ( $>60$ years), a poor performance score (2-3), liver metastases or more than two organ sites involved, or patients with elevated LDH-levels, were found to have worse prognosis. We confirm that the prognostic model published by Culine, is a valuable model for the prediction of prognosis in patients with UPT. IImmunohistochemical detection of proliferation (MIB-1), p53, vascular endothelial growth factor-A, CD34, CD44v6 and HER-2/neu indicated that these factors were of no prognostic value.

\section{Conclusion}

In conclusion, patients with UPT have a very poor median prognosis of 12 weeks. Prognostic favourable factors are young age, good performance status, no liver metastases and normal LDH level. We found no relationship with immunohistochemical factors. 


\section{Introduction}

Unknown primary tumour (UPT) is defined as biopsy-proven metastasis of a malignancy in the absence of an identifiable primary site after a complete history and physical examination have been carried out, along with basic laboratory studies, chest $X$-ray, and if indicated, additional symptom-directed studies: ${ }^{1.3}$ The diagnosis of an UPT is made in approximately $5 \%$ of all newly diagnosed patients with cancer. ${ }^{2-4}$ UPT is predominantly classified as adenocarcinoma $(50-60 \%)$ or poorly-differentiated adenocarcinoma or carcinoma $(30-40 \%)$. Only $5-8 \%$ of the UPT are a squamous cell carcinoma and $2-5 \%$ an undifferentiated malignancy. ${ }^{2-4}$ In some patients the primary tumour becomes apparent after several months. If patients are autopsied, the primary is found in $60-80 \% .5$ in most clinical studies the prognosis for patients with UPT is poor except for treatable subgroups. Median survival from the time of diagnosis ranges from 3 to 11 months, depending on the selection of patients. $3.4,7,8$

At present, different theories exist to describe the heterogeneous UPT syndrome. UPT may be considered as metastases in patients in whom the primary tumour has not been found and did not result in clinical signs. Otherwise UPT may represent a separate group of cancers with genetic and phenotypic characteristics or even unusual primary tumours mimicking metastatic disease (in case of one identified tumour site). Advances in understanding the basic biology of UPT can have a direct impact on clinical care. As we described earlier, only scant information exists on the biological characteristics of UPT. ${ }^{9}$

Since UPT is an aggressive type of tumour with a high metastatic potential, a high expression of p53, MIB-1, VEGF and CD $44 \mathrm{v} 6$ and a high microvessel density might be expected. To evaluate a correlation of specific immunohistochemical alterations in UPT cells with the unique clinical features of UPT patients, to define the natural history of UPT and to verify prognostic factors, we undertook a detailed clinical and immunohistochemical analysis of patients with the diagnosis of adenocarcinoma of UPT.

\section{Patients and methods}

\section{Patients}

From 1990 to 1996, all consecutive patients with an adenocarcinoma of unknown primary were analysed in the St. Elisabeth Hospital in Tilburg, the Netherlands. The data of patients were obtained from the national pathological computerised archive (Pathologisch Anatomisch Landelijk Geautomatiseerd Archief), from our hospital and from the Eindhoven Cancer Registry (codes 196 
to 199 (CD-O). In this way 160 patients were selected. However, after reviewing the clinical charts of these patients, only 72 patients were biopsyproven adenocarcinoma of UPT (of the other 88 patients in $^{2} 5$ the primary tumour became known, for 20 patients no histology was available and for 13 patients only cytology was available). After reviewing the histological data, 2 biopsies were not adenocarcinoma. So 70 patients were selected according to the following criteria: clinical and histological material available, an adenocarcinoma and no primary tumour existing at the time of diagnosis. The clinical and histological information on all patients was entered into a computerised database and analysed by SPPS for Windows, version 10; SPSS Inc, Chicago, IL, USA.

\section{Immunohistochemical staining}

Next to immunohistochemical prognostic factors, we also performed analysis of HER-2/neu receptor, for this can have therapeutic consequences. ${ }^{10}$

From the routine formalin-fixed paraffin-embedded archival tumour blocks, slides of $3 \mu \mathrm{m}$ thickness were prepared. Immunohistochemical staining was performed using mouse monoclonal antibody against MIB-1 (Dianova" Hamburg, Germany; 1:100, one-hour incubation at room temperature), mouse monoclonal antibody against p53 (D07, DAKO A/S, Denmark, 1:200, two-hour incubation at room temperature), mouse monoclonal antibody against CD34 (NCL-END, Novocastra Laboratories, Newcastle, UK; $1: 50$ ), mouse monoclonal antibody against VEGF (MAB293, R\&D Systems, UK) and mouse monoclonal antibody against CD44v6 (R\&D Systems, 1:1000, one-hour incubation at room temperature) as described by the manufacturer. Staining for HER-2/neu was performed using an automated stainer (DAKO, Carpentaria, CA, USA) and the polyclonal Her-2 antibody NonHercepTest (DAKO) in conjunction with 20 minutes of antigen retrieval $\left(60^{\circ} \mathrm{C}\right)$ in a steam bath.

\section{Immunohistochemical score}

Immunohistochemical countings were analysed as continuous data for MIB-1, p53 and CD44v6. The cut-off values used in this study were defined as follows. MIB-1 staining greater than 20 was regarded as high expression. ${ }^{11}$ Tumours were considered p53-positive when more than $10 \%$ of cells showed positive staining. ${ }^{12}$ The tumour was considered CD44v6-positive when more than $5 \%$ of tumour cells showed CD44v6 expression. ${ }^{13,14}$ Also other cut-off points were analysed for MIB-1, p-53 and CD44v6. The intensity of staining for VEGF was graded on a scale of 0 to $3+$, with 0 representing no detectable stain and $3+$ representing the strongest stain under a $200 x$ field. ${ }^{15.16}$ Microvessel density was measured by selecting the highest vascularised areas at low power and counting the microvessels using a $200 x$ magnification. The MVD was expressed as the number of vessels $/ \mathrm{mm}^{2}$. The criteria for microvessel 
recognition were the same as described by Vermeulen et al. ${ }^{\text {it }}$ At least $2 \mathrm{~mm}^{2}$ tumour were evaluated and the median value (56 vessels $/ \mathrm{mm}^{2}$ in this study) was used as cut-off value. HER-2/neu staining was quantified using the following scale: 0 , no membrane staining; $1+$, barely perceptible light membranous rimming that may not totally encircle the cell membrane; $2+$, light to moderate membranous rimming that totally encircles the membrane; $3+$, moderate to strong rimming that totally encircles the membrane. Tumours were considered to overexpress HER-2/neu if membrane staining of $2+$ or $3+$ intensity was present.

Two investigators scored all slides independently.

\section{Statistical analysis}

Survival was calculated from the date of diagnosis, which was the date on which the biopsy was performed. Estimates of the survival distribution of patients were made using the method of Kaplan and Meier. Differences between survival curves for various patient subgroups were assessed by the log-rank test. Multivariate analysis was done by Cox-regression analysis according to a backward stepwise selection.

\section{Results}

The 70 patients with biopsy-proven adenocarcinoma of unknown primary (ACUP) represent $1.9 \%$ of the total patient population with malignancies presented in the Sint Elisabeth Hospital in Tilburg. The Netherlands. The demographic characteristics and clinical findings are listed in table 3.1. The UPT patients with adenocarcinoma were elderly patients. At presentation one third were already in a poor condition with performance status 2 or worse and over $20 \%$ of patients had more than 2 organs involved, predominant the liver. Less than $50 \%$ of the patients received cancer-related therapy (table 3.1).

The patients presented with general symptoms (not feeling well, weight loss etc.) and/or symptoms related to the metastatic site (dyspnoea, jaundice, palpable lymph node etc.). The duration of the symptoms was not clear.

Radiological and/or endoscopical examinations were performed. In 66 (94\%) patients an X-ray of the thorax and in $62(88 \%)$ patients an ultrasound of the upper abdomen was performed. In $20(64 \%)$ of the women a mammography was done. Neither $48 \mathrm{CT}$-scannings of the thorax and/or abdomen nor 46 analyses of the digestive tract revealed the primary tumour (18 barium enema, 7 coloscopy, 20 gastroscopy, 1 gastric $X$-ray).

In 15 out of 70 patients the primary was identified during follow-up (4) or at autopsy (11). When autopsy was performed the primary was found in all cases. In these patients the appropriate investigation for the particular tumour had 
been performed at diagnosis ( $X$-mammography, CT of the abdomen, CT of the thorax) but did not reveal the primary at that time. The primary tumour was predominantly located in lung (4/15) and pancreas (4/15). Other primary sites were breast (2) bile duct (1), colon (1), stomach (2) and ovary (1).

Table 3.1 Patient characteristics.

\begin{tabular}{llc}
\hline Characteristics & & No. of patients $(\%)$ \\
\hline Age & $40-49$ & $7(10)$ \\
& $50-59$ & $10(14)$ \\
& $60-69$ & $23(33)$ \\
& $\geq 70$ & $30(43)$ \\
& Median & 66 \\
Range & $42-88$ \\
Sex & Male & $39(56)$ \\
Performance Status & Female & $31(44)$ \\
& 0 & $26(37)$ \\
& 1 & $19(27)$ \\
No. organ sites & 2 & $14(20)$ \\
& 3 & $11(16)$ \\
Frimary site & 1 & $35(50)$ \\
& 2 & $15(23)$ \\
Primary tumour & 1 of 2 & $19(27)$ \\
& $\geq 3$ & $30(43)$ \\
& Liver & $10(14)$ \\
& Lung & $9(13)$ \\
& Lymph node & $7(10)$ \\
& Bone & $6(9)$ \\
& Peritoneum & $8(11)$ \\
& Other & $15(21)$ \\
& Nound & $55(79)$ \\
& Yes & $33(47)$ \\
& No & $37(53)$ \\
\hline
\end{tabular}

The metastatic pattern of these tumours seemed not to differ much from metastatic patterns of patients in whom the specific primary tumour was identified at diagnosis. For example pleuritis carinomatosa, adrenal, brain and pulmonary metastases in lung cancer, peritonitis carcinomatosa and liver and bone metastases with a pancreatic primary.

The overall survival of 12 weeks was poor. To evaluate clinical prognostic factors univariate analysis was performed with clinical variables. The worst prognosis was observed in patients older than 60 years, patients with a poor performance score (2-3), patients with liver metastases, patients with more than two organ sites involved and untreated patients (table 3.2). In univariate 
analysis, only lactate dehydrogenase had prognostic relevance among the studied biological parameters. Haemoglobin, alkaline phosphatase, bilirubin and gamma glutamyl transferase showed no significant influence.

Table 3.2 Univariate analysis with clinical variables.

\begin{tabular}{|c|c|c|c|c|}
\hline Variables & & No. of patients & Median survival in weeks & $p$-value \\
\hline \multirow[t]{2}{*}{ Age } & $<60$ & 17 & 30 & \\
\hline & $\geq 60$ & 53 & 12 & 0.016 \\
\hline \multirow[t]{2}{*}{ Sex } & Male & 39 & 12 & \\
\hline & Female & 31 & 13 & 0.226 \\
\hline \multirow[t]{2}{*}{ Performance status } & $0-1$ & 45 & 21 & \\
\hline & $2-3$ & 25 & 6 & 0.000 \\
\hline \multirow[t]{2}{*}{ Liver metastases ${ }^{*}$} & Yes & 30 & 10 & \\
\hline & No & 40 & 13 & 0.039 \\
\hline \multirow[t]{2}{*}{ Lymph nodes. } & Yes & 9 & 65 & \\
\hline & No & 61 & 12 & 0.101 \\
\hline \multirow[t]{2}{*}{ No. of metastatic sites } & $1-2$ & 51 & $\| 7$ & \\
\hline & $\geq 3$ & 19 & 7 & 0.004 \\
\hline \multirow[t]{2}{*}{ Primary tulmour } & Found & 15 & 12 & \\
\hline & Not found & 55 & 13 & 0.506 \\
\hline \multirow[t]{2}{*}{ Treatment } & Yes & 33 & 22 & \\
\hline & No & 37 & 9 & 0.001 \\
\hline
\end{tabular}

* Primary sitte at presentation

In 48 of the 70 patients there was sufficient material to perform additional immunohistochemical staining, to evaluate different immunohistochemical prognostic factors (table 3.3). When 48 patients with immunohistochemical staining were compared to 22 patients without staining, there was no difference in survival, age, sex, performance status, liver metastases or LDH. The only difference was that in the group of 48 patients with immunohistochemicalstaining the primary was found in 14 patients (data not shown). This was because in 11 of these patients autopsy was performed, which provided sufficient material for immuno-histochemical-staining. In an univariate analysis, only MIB-1 dichotomised at $20 \%$ showed a trend to have prognostic value. Strikingly, high proliferation was related to better survival. Looking into this further, 5 out of 7 patients belonging to a treatable subgroup had high MIB-1 staining. All other factors were of no prognostic value. A remarkable observation was made that different metastases within a patient showed a similar expression of the markers.

In a multivariate analysis of clinical and biologic parameters, age, performance status, liver metastases, as well as $L D H$ were of prognostic relevance (table 3.4). 
Table 3.3 Univariate analysis of immunohistochemical parameters.

\begin{tabular}{|c|c|c|c|c|c|}
\hline & No of patients & & No. & Survival in weeks & p-value \\
\hline \multirow[t]{2}{*}{ MB-1 } & 40 & $<20$ & 17 & 11 & 0.07 \\
\hline & & $\geq 20$ & 23 & 13 & \\
\hline \multirow[t]{2}{*}{ P53 } & 48 & $\leq 10$ & 25 & 11 & 0.74 \\
\hline & & $>10$ & 23 & 13 & \\
\hline \multirow[t]{3}{*}{ VEGF } & 46 & 0 & 28 & 12 & 0.38 \\
\hline & & 1 & 6 & 13 & \\
\hline & & $2 / 3$ & 12 & 12 & \\
\hline \multirow[t]{2}{*}{$\operatorname{CD} 34$} & 36 & $\leq 56 / \mathrm{mm}^{2}$ & 19 & 12 & 0.37 \\
\hline & & $>56 / \mathrm{mm}^{2}$ & 17 & 13 & \\
\hline \multirow[t]{2}{*}{ CD $44 v 6$} & 40 & $\leq 5$ & 19 & 42 & 0.95 \\
\hline & & $>5$ & 21 & 14 & \\
\hline \multirow[t]{2}{*}{ HER-2/neu } & & $0 / 1$ & 29 & 12 & 0.47 \\
\hline & & $2 / 3$ & 16 & 13 & \\
\hline
\end{tabular}

Table 3.4 Cox multivariate regression analysis including clinical variables and biological parameters.

\begin{tabular}{|c|c|c|c|}
\hline Variable & & Relative death rate & $p$-value \\
\hline \multirow[t]{2}{*}{ Age } & $<60$ & 1 & 0.04 \\
\hline & $\geq 60$ & 2.6 & \\
\hline \multirow[t]{2}{*}{ Performance status } & $0-1$ & $\|$ & 0.005 \\
\hline & $2-3$ & 6.6 & \\
\hline \multirow[t]{2}{*}{ Organ sites involved } & $1-2$ & 1 & 0.25 \\
\hline & $\geq 3$ & 1.2 & \\
\hline \multirow[t]{2}{*}{ Liver metatsases } & Yes & 1 & 0.006 \\
\hline & No & 2.1 & \\
\hline \multirow[t]{2}{*}{ Lactate dehydrogienase } & Normal & 1 & 0.003 \\
\hline & $>$ Normal & 2.5 & \\
\hline
\end{tabular}

\section{Discussion}

The 70 consecutive patients with biopsy-proven adenocarcinoma of UPT formed $1.9 \%$ of all the malignancies in that period (1990-1996). This is less than the figure of approximately $5 \%$ mentioned in the literature..$^{2-4}$

However, when patients with poorly-differentiated carcinoma, squamous carcinoma and undifferentiated carcinoma were included, as well as the patients with UPT proven by cytology or only a clinical diagnosis, they formed $4.5 \%$ of all the malignancies in that period. It is also important to keep in mind that only patients with a biopsy are included. As found earlier in a population 
based study, these patients have a slightly better prognosis than patients who are clinically diagnosed (11 vs. 7 weeks). ${ }^{4}$

The 70 patients with UPT fit most of the clinical features of UPT as mentioned earlier. ${ }^{1-4,7}$ First they present with a short history of non-specific symptoms. Secondly, in most cases the primary tumour remains unidentified but, if found during life or by autopsy, it is a small asymptomatic tumour, often localised in the lung or pancreas. Thirdly, over $25 \%$ of the patients presented with 3 or more metastases. Fourthly, the prognosis for these unselected patients was very poor with a median survival of 12 weeks, but when patients belonged to a treatable subgroup and were treated the prognosis was much better, as also is mentioned by others. However, new, more effective chemotherapeutic agents are available and in more recent studies, with selected patients from poor prognostic groups, median survival from $9-11$ months is reached, with $>40 \%$ of patients alive 1 year after diagnosis. ${ }^{19-22}$

Independent good prognostic factors were young age, good performance status, no liver metastases and normal LDH-level, as in other studies. ${ }^{2,7.8,23,24}$ In contrast to other studies, alkaline phosphatase and lymph node metastases were of no prognostic value,$^{2,7,8,23}$ When we used the prognostic model presented by Culine et al., the good prognostic group ( $P S=0$ or 1 and no liver metastases) contained 22 patients with a median survival of 26 weeks, the intermediate group (PS>1 or liver metastases) contained 32 patients with a median survival of only 12 weeks and the poor prognostic group ( $P S>1$ and liver metastases) contained 12 patients with a median survival of 4 weeks. ${ }^{24}$ So we can confirm this prognostic model, which seems to be a powerful tool in predicting prognosis in patients with UPT.

In the 15 patients in whom the primary tumour became obvious, we found no unusual metastatic pattern. This is in contrast to earlier studies. ${ }^{6,25,26}$ It should be mentioned, however, that we only could investigate a small group of patients.

Immunohistochemical data were only gathered in $55-60 \%$ of the patients. But these patients formed a representative group of all 70 UPTs, considering age, performance score and survival. We expected overexpression of factors that are correlated to poor prognosis in known primaries, but we did not find any correlation between UPT and any of these factors. The results of other investigators who performed some of these prognostic factors on UPT are contradictive. As Bar-Eli, we found no high expression of $\mathrm{p} 53$, which in contrast to Briasoulis et al. who found overexpression of $p 53$ in $70 \%$ of all patients with UPT ${ }^{27,28}$ The low expression of p53 suggests p53 mutation may not play an important role in the development of this aggressive tumour. However, one should keep in mind that all three studies were performed in small groups (2348 patients) and used different tests. Also a high MVD as a prognostic indicator described earlier by our group could not be confirmed in this study. ${ }^{29}$ 
In conclusion, patients with UPT have a very poor prognosis with a median survival of 12 weeks. Young age, good performance status, the absence of liver metastases and a normal LDH level are favourable prognostic factors. Further research is necessary to answer the question as to whether UPT is a specific entity. Therefore we are performing a study to investigate specific genetic and immunohistochemical alterations in UPT. 


\section{References}

1 Hillen HFP. Unknown primary tumours. Postgrad Med J 2000;76:690-3.

2 Lembersky BC. Thomas LC. Metastases of unknown primary site. Med Clin North Am $1996 ; 80: 153-71$.

3 Greco FA, Hainsworth $J \mathrm{D}$. Cancer of unknown primary site In: DeVita VT Jr, Hellman S, Rosenberg SA: (eds). Cancer: Principles and practice of oncology. ed 6. Philadelphia PA Lippincott. 2000:2072-92.

4 wan de Wouw AJ, Janssen-Heijnen ML, Coebergh JW, Hillen HFP. Epidemialogy of unknown primary tumours: incidence and population-based survival of 1285 patients in Southeast Netherlancis, 1984-1992. Eur J Cancer 2002;38:409-13.

5 Nystrom JS, Weiner JM, Heffelfinger-Juttmer J, Irwin LE, Bateman JR, Wolf RM. Metastatic and histologic presentations in unknown primary cancer. Semin Oncol 1977:4:53-8.

6 Le Chevalier $T$, Cvitkovic E, Caille P. Harvey J Contesso G, Spielmann M. Roulesse J. Early" metastatic cancer of unknown primary origin at presentation. A clinicial study of 302 consecutive autopsied patients. Arch Intern Med 1988;148:2035-9.

7 Abbruzzese $J L$, Abbruzzese MC. Hess $K R_{x}$ Raber MN, Lenzi R, Frost P. Unknown primary carcinoma: natural history and prognostic factors in 657 consecutive patients. $\rfloor$ Clin Oncol $1994: 12: 1272-80$.

8 Altman $E$, Cadman $E$. An analysis of 1539 patients with cancer of unknown primary site. Cancer $1986 ; 57: 120-4$.

9 van de Wouw A.J, Jansen RL, Speel EJ, Hillen HFP. The unknown biclogy of the unknown primary tumour: a literature review. Ann Oncol 2003;14:191-6.

10 Hainsworth JD. Lennington WJ, Greco FA. Overexpression of Her-2 in patients with poorly differentiated carcinoma or poorly differentiated adenocarcinoma of unknown primary site. $\mathrm{J}$ Clin Oncol 2000; 18:632-5.

11 Bonnefoi $H$, Diebold-Berger $S$, Therasse $P$. Hamilton $A$, van de Vijver $M$, MacGrogan $G$, Shepherd L, Amaral $N$, Duval $C$, Drijkoningen $R$, Larsimont $D$. Piccart $M$. Locally advanced/inflammatory breast cancers treated with intensive epirubicin-based neoadjuvant chemotherapy: are there molecular markers in the primary tumour that predict for 5-Year clinical outcome? Ann Oncol 2003;14:406-13.

12 Rosen PP. Lesser ML. Arroyo CD. Cranor M. Borgen P. Nonton L: P53 in node-neglative breast carcinoma: an immunohistochemical study of epidemiologic risk factors histologic features, and prognosis. J Clin Oncol 1995; 13:821-30.

13 Kaufmann M. Heider KH, Sinn HP, von Minckwitz G. Ponta H. Herrich P. CD44 isoforms in prognosis of breast cancer. Lancet 1995;346:502.

14 Friedrichs K, Franke F, Lisboa BW, Kugler G, Gille I, Terpe HJ, Holzel F, Maass H, Gunthert U: CD44 isoforms correllate with cellular differentiation but not with prognosis in human breast cancer. Cancer Res 1995;55:5424-33.

15 Gasparini $G$, Toi M, Gion M, Verderio P. Dittadi $R$, Hanatani M, Matsubara I, Vinante $O$, Bonoldi $E$, Boracchi $\mathbb{P}$, Gatti $C$, Suzuki $H$, Tominaga T. Prognostic significance of vascular endothelial growth factor protein in node-negative breast carcinoma. I Natl Cancer lnst $1997,89: 139-47$

16 Niki $T$, Iba $S$, Tokunou $M$, Yamada $T$. Matsuno $Y$, Hirohashi $S$. Expression of vascular endothelial growth factors $A, B, C$, and $D$ and their Relationships to bymph node status in lung adenocarcinoma. Clin Cancer Res 2000;6:2431-9.

17 Vermeulen PB, Gasparini G, Fox SB, Toi M, Martin L, McCulloch P. Pezzella F, Viale G, Weidner $N$, Harris $A$. Dirix $L Y$. Quantification of angiogenesis in solid human tumours: an international consensus on the methodology and criteria of evaluation. Eur $\mathrm{J}$ Cancer 1996; $32 \mathrm{~A}: 2474-84$ 
18 Rosen PP. Lesser ML. Arroyo CD. Cranor M. Borgen P. Norton L. Immunohistochemical datection of HER2/Neu in patients with axillary lymph node negative breast carcinoma. $A$ study of epidemiologic risk factors, histologic features, and prognosis. Cancer 199575 : $1320-6$

19 Hainsworth JD, Greco FA. Management of patients with cancer of unknown primary site. Oncollogy (Huntingt) 2000; 14:563-74.

20 Hainsworth JD, Burris HA, Calvert SW, Willoutt NT. Scullin DC, Bramham J, Greco FA. Gemcitabine in the second-line therapy of patients with carcinoma of unknown primary site: a phase II trial of the Minnie Pearl Cancer Research Network. Cancer Invest 2001;19:335-9.

21 Greco FA, Burris $H A$, Litchy $S$, Barton $J H_{*}$ Bradof $\rfloor E$, Richards $P$, Scullin $D C J r$, Erland $J B$, Morrissey $L H_{n}$ Hainsworth JD. Gemcitabine, carboplatin, and paclitaxel for patients with carcinoma of unknown primary site: a Minnie Pearl Cancer Research Network Study. J Clin Oncol $2002 ; 20: 1651-6$.

22 Greco FA, Erland JB, Morrissey $L H$, Burris HA, Hermann RC, Steis $R$, Thompson $D$, Gray d, Hainsworth JD. Carcinoma of unknown primary site: phase II trials with docetaxel plus cisplatin or carboplatin. Ann Oncol 2000;11:211-5.

23 van der Gaast $A$, Verweij $\mathbb{J}$, Planting AS, Stoter G. 5-Fluorouracil, doxorubicin and imitomycin C: (FAM) combination chemotherapy for metastatic adenocarcinoma of unknown primary. Eur $J$ Cancer Clin Oncoll 19:8;24:765-8.

24 Culine $S$, Kramar A, Saghatchian M, Bugat R, Lesimple T, Lortholary A, Merrouche $Y$, Laplanche $A$, Fizazi K. Development and validation of a prognostic model to predict the length of survival in patients with carcinomas of an unknown primary site. J Clin Oncol 2002; 20:4679-83.

25 Gilbert HA, Kagan AR. Metastases: incidence, detection, and evaluation without histologic confirmation. Pp. 385-405. In. Weiss.L., ed.Fundamental Aspects of Metastasis. Amsterdam, North-Holland, 1976.

26 Abrams HL, Spiro $R$. Goldstein N: Metastases in carcinoma: analysis of 1000 autopsied cases. Cancer 1950;3:74-85.

27 Bar-Eli M, Abbruzzese JL, Lee-Jackson D. Frost P. P53 gene mutation spectruin in human unknown primary tumors. Anticancer Res 1993;13:1619-23.

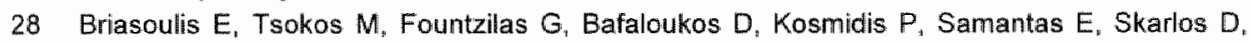
Nicolaides $\mathrm{C}$, Pavlidis $\mathrm{N}$. Bcl2 and p53 protein expression in metastatic carcinoma of unknown primary origin: biologicall and elinical implications. A Hellenic Co- Operative Oncology Group Study. Anticancer Res 1998; $18: 1907.14$

29 Hillen HF, Hak LE, Joosten-Achjanie SR, Arends JW. Microvessel density in unknown primary tumors. Int J Cancer 1997:74:81-5. 


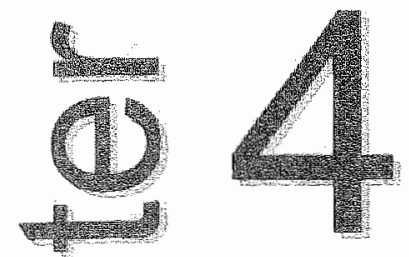

Phase III trial of carboplatin, etoposide and paclitaxel compared with 5-fluorouracil and folinic acid in adenocarcinoma of unknown primary tumour

AJ van de Wouw, HFP Hillen, $C$ van der Heul $Q$ van Hoesel, RLH Jansen Submitted for publication 


\section{Abstract}

\section{Purpose}

We wanted to determine whether treatment with carboplatin, etoposide and paclitaxel (CEP) improved survival, response and toxicity profile in patients with adenocarcinoma of unknown primary (ACUP) compared to treatment with folinic acid (FA) followed by 5-Fluorouracil (FU) in a continuous schedule.

\section{Patients and Methods}

Chemotherapy-naive patients with ACUP were randomly assigned to receive either CEP ( $n=23$; paclitaxel $200 \mathrm{mg} / \mathrm{m}^{2}$ and carboplatin AUC 6 iv on day 1 and etoposide alternating 50 and $100 \mathrm{mg}$ orally on days 1 through 10 , every 3 weeks) or 5-Fluorouracil and folinic acid (FUFA) ( $n=23$; folinic acid $500 \mathrm{mg} / \mathrm{m}^{2}$ followed by FU $2600 \mathrm{mg} / \mathrm{m}^{2}$ iv over 24 hours weekly for 6 weeks every 7 weeks)

\section{Results}

Forty-six patients were enrolled; 23 in each treatment arm. Baseline characteristics were well balanced between both arms. No significant differences in survival were observed. The median survival for the CEP arm was 7.0 vs. 6.4 months for the FUFA arm $(p=0.76)$ and median time to progression was 3.5 vs. 3.3 months $(p=0.79)$. Eighty-three percent $(38 / 46)$ of the above patients were evaluable for response. Complete remission (CR) or partial remission (PR) in CEP vs. FUFA arm was recorded in 30 vs. $9 \%$ $(p=0.036)$ and $C R$ or $P R$ or stable disease $(S D)$ in 60 vs. $48 \%(p=0.14)$. Two drug-related deaths were reported in the CEP and none in the FUFA arm. CEP caused more frequently grade 3 or 4 neutropenia ( 9 vs. 1 patients), thrombocytopenia ( 5 vs. 0 patients) and neutropenic fever (4 vs. 0 patients). Incidences of anaemia and nonhematological adverse events were similar in the two groups.

It was remarkable that $30 \%$ in the CEP and $26 \%$ in the FUFA arm were long survivors.

\section{Conclusion}

This study indicates that the combination of CEP improves response rates but does not prolong overall survival or time to progression and is more toxic compared to FUFA in patients with ACUP. Further more there seems to be a subgroup of patients with ACUP who survive longer, independently of the therapy used. 


\section{Introduction}

Adenocarcinoma of unknown primary (ACUP) is defined as pathologically proven metastases of an adenocarcinoma in the absence of an identifiable primary site after complete history and physical examination, basic laboratory studies, chest $X$-ray and additional directed studies indicated by positive findings during the initial work-up. ${ }^{1}$ Unknown primary tumour accounts for $3-4 \%$ of all newly diagnosed patients with cancer and $60-70 \%$ of these lumours are adenocarcinomas. ${ }^{2-4}$ Treatment of ACUP still is evolving. A minority of patients presents with disease characteristics that have been recognised as favourable, based on responsiveness to therapy and a better prognosis. Favourable subgroups consist of patients with adenocarcinoma in a single peripheral lymph node region or with poorly differentiated (adeno)carcinoma and women with peritoneal carcinomatosis or with axillary nodal metastases and men with osteoblastic metastases. Unfortunately most patients with ACUP do not fit in a favourable subgroup. Many different cisplatin- and/or 5-fluorouracil-based regimens were studied in phase II trials with poor results and a median survival time of 4 to 6 months. A comparison of the results of these trials is difficult because patients with a variety of histological subtypes, variable stage of disease and different characteristics were entered. Overall there seems not much difference in treatment outcome between the different treatment regimens. ${ }^{5}$ The combination chemotherapy of 5-fluorouracil (FU) and folinic acid (FA) is often used. ${ }^{6-9}$ The reason to use this therapy is the relatively low toxicity and the fact that many ACUPs are metastases of primary tumours which show some response to FU. So although formally no standard therapy exists for patients with ACUP we used 5-Fluorouracil and folinic acid (FUFA) as control arm.

Promising results with the new chemotherapeutic agents, such as paclitaxel, vinorelbine and gemcitabine were reported, with median survival rates of 10 to 13 months. Hainsworth et al. treated 55 patients with paclitaxel, carboplatin and etoposide. ${ }^{10}$ Twenty-five of 53 assessable patients had major objective responses to treatment (seven complete responses). The actuarial median survival time for the entire group was 13.4 months. This schedule appeared effective and tolerable. But because this was a phase II study, performed in a tertiary referral centre patient selection probably has an important influence. We therefore initiated a phase III study in the treatment of adenocarcinoma of ACUP using carboplatin, etoposide and paclitaxel (CEP) compared to FUFA in a continuous schedule. The objective of this study was to determine whether treatment with CEP improves survival, response and toxicity profile in patients with ACUP compared to treatment with FUFA. 


\section{Patients and methods}

\section{Patient population}

This multicenter phase III, randomised study was initiated in the University Hospital of Maastricht, the Netherlands in July 1998. Patients with histologically confirmed metastatic adenocarcinoma of unknown primary site were eligible. For the purposes of the study, patients were eligible if the following evaluation did not reveal a primary tumour site: complete history, physical examination, basic laboratory studies, chest X-ray, computed tomography (CT) of the abdomen, and directed radiologic or endoscopic work-up of any symptomatic area.

Patients belonging to favourable subgroups were excluded. These subgroups included women with adenocarcinoma that involved only axillary lymph nodes, women with peritonitis carcinomatosis with adenocarinoma, patients with adenocarcinoma that involved a single tumour site, men with blastic bone metastases and/or an elevated PSA and young ( $<50$ years of age) patients with so-called mid-line tumour.

No previous chemotherapy was allowed. Prior radiotherapy was allowed if it had been terminated at least 4 weeks before starting chemotherapy and if it did not involve more than $25 \%$ of the red bone marrow. Additional entry criteria included Eastern Cooperative Oncology group (ECOG) performance status 0, 1 and 2; measurable disease; adequate bone marrow function (leukocytes $\geq 4.0 \times 10^{9} / \mathrm{l}$, platelets $\geq 100 \times 10^{9} / \mathrm{l}$ ), normal liver function (bilirubin $<25 \mu \mathrm{mol} / \mathrm{l}$ and ASAT and ALAT <3x upper normal limits) and normal renal function (creatinine $<150 \mu \mathrm{mol} / \mathrm{l}$ ). Exclusion criteria were: past or current history of neoplasm other than curatively treated non melanoma skin cancer or in situ carcinoma of the cervix; myocardial infarction within the last three months, congestive heart failure or other severe coexistent medical illness; pregnant or lactating patients; and brain or meningeal metastasis.

\section{Patient assignment}

Eligible patients were randomised centrally by computer to both treatment arms in a 1:1 ratio. A block design was used to ensure equal numbers of patients in each treatment group with or without liver metastases at each clinical centre.

This study was approved by the ethical committees of all institutions and patients were required to give written informed consent before participation.

\section{Treatment}

Patients were treated after randomisation with one of the following chemotherapy regimens. 
Arm A: CEP: paclitaxel $200 \mathrm{mg} / \mathrm{m}^{2}$ by 1-hour intravenous (IV) infusion on day 1. carboplatin at a calculated area under the concentration-time curve (AUC) of 6.0 by 30 minute IV-infusion on day 1 and etoposide $50 \mathrm{mg}$ alternated with 100 ing orally on days 1 through 10 . Before paclitaxel administration, all patients received premedication with dexamethasone $20 \mathrm{mg}$, cimetidine $300 \mathrm{mg}$ (or ranitidine $50 \mathrm{mg}$ ) and clemastine $2 \mathrm{mg}$ given IV 30 minutes before paclitaxel administration. Carboplatin dose was calculated by the Calvert formula (dose = [glomerular filtration rate (GFR)+25]×6). GFR was calculated by the method of Cockcroft and Gault using serum creatinine measurement. ${ }^{11}$ Treatment was administered at 3-week intervals. Toxicity was graded according the first version of the $\mathrm{NClC}$ common toxicity criteria. Patients were re-evaluated after two courses; responding patients and those with stable lesions received two additional courses for a total of four courses of treatment. During the entire four courses of therapy, blood counts were monitored on a weekly basis. The blood count on day 8 was used to modify the etoposide dose if necessary. Dose reductions based on the day- 8 blood counts were as follows: leukocytes $<1.0 \times 10^{9} \%$ or platelets $<75 \times 10^{9} \%$, etoposide was discontinued for the remainder of the course. The blood counts on day 21 were used to modify doses in the subsequent course as follows: leukocytes $\geq 2.5 \times 10^{9} / 1$ and platelets $\geq 75 \times 10^{9} / 1$, all drugs given at full dose; leukocytes $<2.5 \times 10^{9} /$ or platelets $<75 \times 10^{9} / \mathrm{l}$, treatment delayed one week or until leukocytes $>3.0 \times 10^{9} /$ and platelets $>100 \times 10^{9} /$. Patients who met these criteria received full dose treatment. Patients who were hospitalised for treatment of neutropenic fever had $75 \%$ doses of all drugs administered during subsequent treatment courses. Subsequent use of cytokines was at the discretion of the treating physician. Paclitaxel was discontinued in patients who experienced a severe acute hypersensitivity reaction, and the other drugs were continued on schedule.

Arm B: FUFA: Folinic Acid $500 \mathrm{mg} / \mathrm{m}^{2} \mathrm{IV}$ over two hours followed immediately by 5 -Fluorouracil $2600 \mathrm{mg} / \mathrm{m}^{2}$ IV over 24 hours weekly for 6 weeks on day 1,8 , $15,22,29$ and 36. Treatment was administered every 7 weeks. Toxicity was graded according to the first version of the $\mathrm{NClC}$ common toxicity criteria. Patients were re-evaluated after one course; responding patients and those with stable lesions received an additional course for a total of 2 courses. Blood counts were monitored on a weekly basis. The blood counts and toxicity scores were used to modify doses in the subsequent course as follows: leukocytes $<2.0 \times 10^{9} /$, platelets $<75 \times 10^{9} /$, diarrhoea grade $>1$ or mucositis grade $>1$ treatment delayed for at least one week until recovery. Then the patients were re-treated with the full dose again. When patients developed leukocytes $<1.0 \times 10^{9} / /$ or neutropenia and fever, platelets $<25 \times 10^{9} \%$, diarrhoea grade 3 or 4 or mucositis grade 3 or 4 , treatment was delayed until recovery and the next 5-Fluorouracil dose was reduced by $20 \%$. 
In addition if treatment had to be delayed for more than one week the dose had to be reduced by $20 \%$. If in spite of these dose reductions the same toxicity persisted the dose was reduced again by $20 \%$. In case of hand/foot syndrome the dose of 5-Fluorouracil had to be reduced by $20 \%$ and pyridoxine $3 \times 50 \mathrm{mg}$ was administered.

\section{Second line treatment}

In case of progressive disease after an initial response (including symptomatic improvement) retreatment with the same regimen was allowed. Other therapies were up to the attending physician.

\section{Efficacy evaluation}

After completion of therapy, restaging was performed by repeating all studies that were abnormal at the beginning of treatment. All patients were assigned a response category based on WHO-criteria. $\mathrm{CR}$ required the total disappearance of all clinically and radiologically detectable disease for at least 4 weeks. PR required at least a $50 \%$ reduction in the size of all measurable lesions as measured by the product of the greatest length and the greatest width, with no new lesions appearing. Patients with SD had reduction of less than $50 \%$ or increase of less than $25 \%$ in the size of measurable lesions, with no new lesions appearing. Patients with progressive disease had the appearance of any new lesion, or an increase of $25 \%$ or more in the size of any existing measurable lesion. Time to progression (TTP) was measured from the first day of therapy until tumour progression was documented. After completion of all treatment patients were monitored at 3-months intervals until tumour progression occurred. In case of progressive disease after an initial response (including symptomatic improvement) re-treatment with the same regimen was allowed. Follow-up evaluation was performed in all patients until the time of death or July $1,2004$.

\section{Statistical analysis}

The primary objective of the study was to compare overall survival between the two treatment groups on an intention-to-treat basis. Secondary objectives were to compare toxicities, objective response rates, time to progression and quality of life. The study was designed to demonstrate a clinical useful superiority for survival for the CEP treatment, defined as median survival in the CEP-arm 4 months longer than median survival in the FUFA-arm. Using a two-tailed logrank test with $\alpha=0.05$ and a power of 0.80 , a sample size of 60 patients per treatment group would be needed.

All analyses were performed using the SPSS statistical software (SPPS for Windows, version 12; SPSS Inc, Chicago, IL, USA). Differences between 
treatment arms regarding categorical variables were examined with a Chisquare test; for continuous variables, the t-test was used to test the equality of the appropriate means. Survival curves were produced with the Kaplan and Meier method and compared between arms with the stratified log-rank test. ${ }^{12}$

\section{Results}

\section{Patient characteristics}

Between September 1998 and February 2003, 46 patients entered onto this study at 10 treatment centres in the South and Middle of the Netherlands. Twenty-three patients were randomised to receive CEP and 23 to receive FUFA. At the final analysis cut-off date of July 1, 2004 two patients were still alive (one in arm A 26.1+ months, one in arm B 29.4+ months).

Patient characteristics are shown in table 4.1. Characteristics were well balanced across treatment arms. The male-female ratio and the distribution of performance status seemed different but this was not significant.

Table 4.1 Patient characteristics according to treatment group.

\begin{tabular}{llcc}
\hline & & CEP* & FUFA \\
\hline Age in years & Median & 57 & 54 \\
& Range & $24-72$ & $39-71$ \\
Sex & Male/female & $12 / 11$ & $9 / 14$ \\
ECOG performance status & 0 & 4 & 3 \\
& 1 & 13 & 17 \\
No. of metastatic site & 2 & 5 & 3 \\
& 1 & 2 & 6 \\
Dominant site of disease & 2 & 9 & 8 \\
& $>2$ & 11 & 9 \\
& Liver & 13 & 11 \\
& Lung & 3 & 6 \\
& Lymphnodes & 5 & 4 \\
& Skin & 1 & 0 \\
& Bone & 0 & 2 \\
\hline
\end{tabular}

* Of one patient the clinical data were not available

\section{Survival}

Survival curves for both arms are depicted in figure 4.1. The median overall survival was 7 months $(95 \% \mathrm{Cl}, 4.6$ to 9.1$)$ in arm $\mathrm{A}$ and 6.4 months $(95 \% \mathrm{Cl}$, 3.3-9.1) in Arm B. There was no significant difference in overall survival between the two treatment groups ( $\log -r a n k p=0.76)$. 


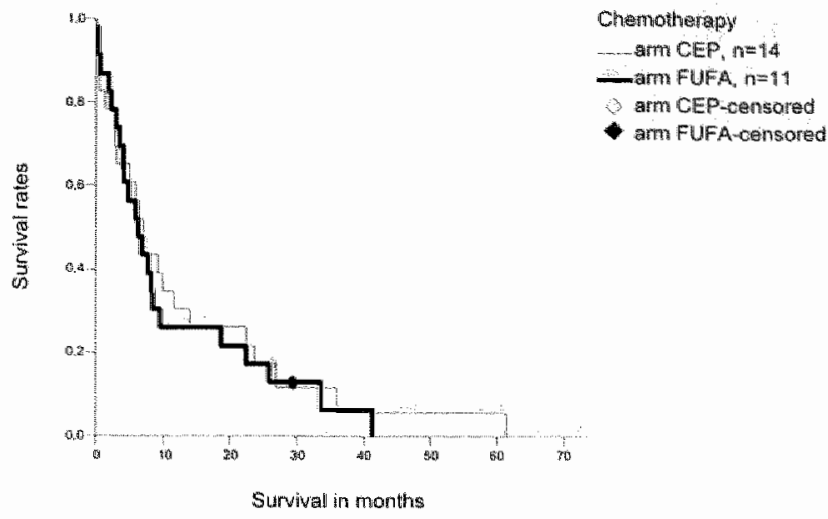

Figure 4.1 Overall survival of the randomly assigned patients according to treatment arm.

TTP curves for both arms are depicted in figure 4.2. Median TTP in the arm with CEP was not different from the median in the arm with FUFA, 3.5 months $(95 \% \mathrm{Cl}, 0-7)$ vs. 3.2 months $(95 \% \mathrm{Cl}, 1.4-5.3 ; \mathrm{p}=0,79)$.

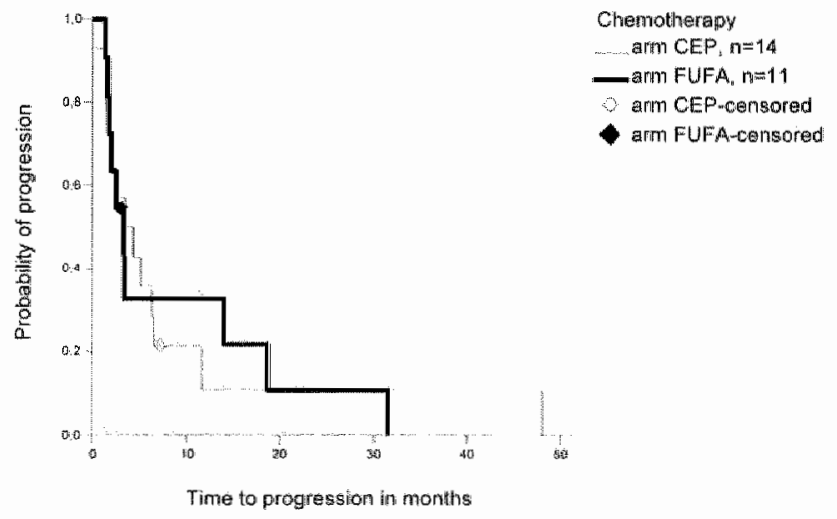

Figure 4.2 Time to progression of the randomly assigned patients according to treatment arm.

Thirteen patients survived more than one year; 7 in the CEP-arm and 6 in the FUFA arm. This group consisted of 7 male and 6 female patients, median age was 56 years, all except 1 had shown response on chemotherapy and performance status is 0 in 3 patients and 1 in 10 patients. In 6 patients liver metastases were present. In 6 patients 2 metastatic sites were involved, and in only 1 were 3 sites involved. The subgroups were too small to evaluate statistically, but it seemed that irrespective of the chemotherapy arm, age, 
performance status and the presence of liver metastases were comparable in patients who survived more than a year compared to all patients. The only difference there seemed to be between the long and the short survivors was the number of metastatic sites (in only 1 out of 13 patients 3 or more sites are involved).

\section{Tumour response}

In the CEP arm 5 patients were not evaluable for response because 2 patients died of progressive disease and 2 patients died of neutropenic fever before evaluation and 1 patient was not evaluated as prescribed by the protocol. The overall response rate by an intent-to-treat analysis was $30 \%(1 \mathrm{CR}, 6 \mathrm{PR})$. In the FUFA arm 3 patients were not evaluable for response because 1 never started therapy because immediately after randomisation he developed symptoms of cerebrall metastases, which were confirmed by computed tomography scan and 2 died of progressive disease before evaluation. The overall response rate was $9 \%$ (no CR, 2 PR). When CR and PR were put together responses were better in CEP ( $p=0.06$ by chi-square test), but when CR, PR and SD were considered as a positive result, response rates were $61 \%$ vs. $48 \%$ and no significant difference was found (Chi-square $p=0.38$ ).

\section{Second line treatment}

Two patients switched from one treatment arm to the other after progression (one from CEP to FUFA and one from FUFA to CEP). Three patients received after an initial response and progression later on the same chemotherapy ( 1 in CEP and 2 in FUFA). Radiotherapy was administered in 10 patients later on, 1 patient was treated with radio-active somatostatine, 1 with anastrozol and 1 with gemcitabine and cisplatin combination chemotherapy.

\section{Toxicity}

In both arms approximately $50 \%$ (12 vs. 11) of the patients completed the full chemotherapeutic course. Reasons for treatment termination were progression (9 vs. 11 patients), drug-related adverse events ( 2 vs. 0 patients) and in the FUFA arm 1 patient never started chemotherapy. In the CEP arm 4 patients died during treatment: 2 treatment related death were due to neutropenic sepsis and 2 were due to progression. In the FUFA arm 2 patients died due to progression. The incidence of haematological toxicity was higher in the CEP arm (table 4.2). Grade 3-4 neutropenia was reported in 9 patients and was complicated by fever or infection in 4 patients (of whom 2 died) in the experimental arm versus 1 patient with neutropenia grade 4 and nil with fever or infection in the control arm. The incidences of grade 3 or 4 nonhematologic adverse events in both groups were ignorable (table 4.2). 
Table 4.2 Treatment-Rellated Toxicity.

\begin{tabular}{lcccc}
\hline & \multicolumn{2}{c}{ CEP (n=23) } & \multicolumn{2}{c}{ FUFA (n=22) } \\
Toxicity & Grade 3 no. & Grade 4 no. & Grade 3 no. & Grade 4 no \\
\hline Leukopenia & 4 & 5 & 0 & 1 \\
Thrombocytopenia & 3 & 2 & 0 & 0 \\
Anaemia & 0 & 1 & 1 & 0 \\
Neuropathy & 1 & 0 & 1 & 0 \\
Diarrhoea & 1 & 0 & 2 & 0 \\
Stomatitis & 0 & 0 & 0 & 0 \\
Fever & 2 & 2 & 0 & 0 \\
\hline
\end{tabular}

\section{Quality of life}

Quality-of-life forms were inadequately registered. In only 11 patients (4 CEP and 7 FUFA) was complete information of baseline and follow up available. No conclusions can be drawn from this sparse information.

\section{Discussion}

ACUP has a poor prognosis and therapeutic options are limited. In our multicentre, randomised, phase III trial we found no statistical significant survival benefit of treatment with CEP when compared to FUFA (7.0 vs. 6.4 months), though overall response rates were better in the CEP arm (30 vs. $9 \%$ ). Patient characteristics were well balanced between treatment arms. Remarkable is that independent of the choice of chemotherapy arm $28 \%$ of the patients survived over one year ( 7 CEP and 6 FUFA). Toxicity was evidently higher in the CEP arm with two toxic deaths. Regretfully quality-of-life scores were not useful, due to the small numbers of patients who completed a baseline and a post baseline form.

A major problem is that the study was closed before reaching the preassigned number of patients. The statistical strength of this study is weakened, with 46 patients differences in survival of less than 6.5 months cannot be shown. Many patients with UPT are already in a poor condition, are not eligible for chemotherapy in a trial by for example elevated liver enzymes and the diagnosis of cancer of unknown primary brings a specific psychological burden. Therefore in general the accrual of these patients in randomised trials is limited. This is probably the reason that this is only the $3^{\text {rd }}$ randomised phase III study ever reported in UPT. ${ }^{13.14}$ Reasons for low accrual beyond the second year of the trial might be the disappointing clinical results in both treatment groups and the problems of toxicity in the CEP arm observed by participating doctors in earlier treated patients. Further possible explanations for the low accrual could be the 
favourable results of taxane and platinum combination in phase 11 trials, the rising use of oral FU and the finding of more primaries by PET-scanning or suggestions by the pathologist.

The other two randomised trials with ACUP comparing doxorubicin and mitomycin $C$ with cisplatin, vinblastine and bleomycin and protracted venous infusion 5-fluorouracil with or without mitomycin $C$ were also small ( 95 and 54 patients) and found no differences in response rate and survival ( $42 \%$ vs. $32 \% ; 18$ vs. 25 weeks and $11.6 \%$ vs. $20 \% ; 4.1$ vs. 3.6 months). ${ }^{13.14}$

In a phase II trial the combination of carboplatin, etoposide and paclitaxel showed promising results, with median survival of 13 months, high response rates $(47 \%)$ and acceptable toxicity rates. ${ }^{10}$ in an updated report on this study, the median survival dropped to 11 months. ${ }^{15}$ in four other studies therapy with a taxane and a platinum combination (docetaxel/cisplatin, docetaxel/ carboplatin, paclitaxel/carboplatin and CEP) accomplished survival rates of 7.4-10 months. ${ }^{16-18}$ In 3 out of 4 of these studies no etoposide was used, but since the start of our study in 1998 others showed that the addition of etoposide to cisplatin seemed not to contribute in the treatment of carcinoma of unknown primary ${ }^{18-21}$. Overall response rates were $22-45 \%$ when a platin and taxane combination was used as therapy for carcinoma of unknown primary, with $0-15 \% \mathrm{CR}^{15-17}$ In all before mentioned studies, toxicity is indicated as well tolerated. ${ }^{15-17}$ However, in 54-63\% of the patients grade $3-4$ neutropenia was reported, $11-17 \%$ of the patients required hospitalisation, and treatment related deaths due to sepsis were mentioned. ${ }^{15,17,22}$

The efficacy of these studies seems to be slightly better than the results we achieved, but there are some important remarks.

- The reported results were from phase II trials, often non-randomised. ${ }^{15-18}$

- Several pathological diagnoses next to adenocarcinoma were allowed in the different studies (poorly differentiated carcinoma, squamous cell carcinoma, neuroendocrine carcinoma). ${ }^{15-17}$ It is known that unknown primary tumours with these types of pathology are far more chemotherapy responsive than adenocarcinoma of unknown primary. Our study only included patients with biopsy-proven adenocarcinoma.

- We were more strict in ruling out "treatable subgroups" ${ }^{15.17}$ Together with women with adenocarcinoma that involved only axillary lymph nodes, patients with squamous carcinoma that involved only cervical or inguinal lymph nodes, men with blastic bone metastases and an elevated PSA and patients with carcinoma that involved a single potentially respectable tumour site, we also excluded women with peritonitis carcinomatosis with adenocarcinoma and young ( $<50$ year old) patients with so-called mid-line tumour. The women with peritonitis carcinomatosis should be treated as having ovarian cancer and up till now that is with carboplatin and paclitaxel. ${ }^{23} \mathrm{Mid}-$ 
line tumours showed a good response and prolongation of survival with platinum-containing therapy. ${ }^{24-26}$

So taking these remarks into account in general our results with CEP are consistent with the results of other studies with taxane-platinum combination.

In older studies FU-based chemotherapy showed median survivals of 3-8 months and response rates of $0-50 \%{ }^{6,9,27,28} \mathrm{~A}$ recent randomised study comparing protracted venous infusion of $F U$ with or without mitomycine $\mathrm{C}$ in UPT reported a median overall survival of 6.6 months and a median failure-free survival of 4.1 months for $5-\mathrm{FU}$ alone. ${ }^{14}$ No significant differences were found between the two treatment groups for survival, nor for response rates. The results we achieved with FUFA seemed to be comparable to these results but adequate evaluation is difficult because different schemes were used, patient sellection was quite different with treatable subgroups included and these studies were except for the last all phase II studies.

An interesting fact is that considering the long survivors, no difference between the two arms was found. There was a trend that long-term survivors had less sites of metastases. In recent studies with all kind of chemotherapy schemes, there is almost always recognisable such a group of $20-40 \%$ of patients surviving longer than a year. ${ }^{15,17,29-32}$ These patients were mostly good responders to therapy. In general CEP is not useful in all patients with ACUP, but may be a new subgroup, which does benefit from this therapy, can be recognised.

Genetic analysis of these tumours, for example, by comparative genomic hybridisation $(\mathrm{CGH})$ and genetic profiling techniques, might give some answers in the future, either by recognising the primary or by predicting sensitivity for specific treatment.

In conclusion this study indicates that the combination of CEP improves response rates but does not prolong overall survival or time to progression and is more toxic in patients with ACUP compared to FUFA. Further more there seems to be a subgroup of patients with ACLP who survive longer, irrespective of the therapy used. 


\section{References}

1. Lembersky BC. Thomas LC. Metastases of uniknown primary site. Med Clin North Am $1996 ; 80: 153-71$

2. van de Wouw, AJ, Janssen Heijnen ML, Coebergh JW, Hillen HFP. Epidemiology of unknown primary tumours; incidence and population-based survival of 1285 patients in Southeast Netherlands, 1984-1992. Eur J Cancer 2002;38:409-13.

3. Muir C. Cancer of unknown primary site. Cancer 1995;75:353-6.

4. Hainsworth JD, Greco FA. Treatment of patients with cancer of an unknown primary site. N Engl J Med 1993;329:257-63.

5. Wan der Gaast A. Chemotherapy in Metastatic Cancer of Unknown Primary. (Dissertation) 1996.

6. Nole F, Colleoni M, Buzzoni R, Bajetta E. Flluorouracil plus folinic acid in metastatic adenocarcimoma of unknown primary site suggestive of a gastrointestinal primary. Tumori 1993 ; $79: 116 \cdot 8$

7. Seymour MT, Johnson PW, Hall MR, Wrigley PF, Slevin ML. Double modulation of 5fluorouracil with interferon alphia $2 \mathrm{a}$ and high-dose leucovorin: a phase I and $\|$ study. $\mathrm{Br} \mathrm{J}$ Cancer 1994:70:719-23.

8. Kelsen D, Martin DS, Colofiore J: Sawyer R, Coit D. A phase II trial of biochemical modulation using $\mathbb{N}$-phosphonacetyl-L-aspartate, high-dose methotrexate, high-dose 5-fluorouracil, and leucovorin in patients with adenocarcinoma of unknown primary site. Cancer 1992;70: $1988-92$

9. Moertel CG, Reitemeier RJ, Schutt AJ, Hahn RG. Treatment of the patient with adenocarcinoma of unknown origin. Cancer 1972;30:1469-72.

10. Hainsworth JD, Erland JB, Kalman LA, Schreeder MT, Greco FA. Carcinoma of unknown primary site: treatment with 1-hour paclitaxel, carboplatin, and extended-schedule etoposide. $J$ Clin Oncol 1997;15:2385-93.

11. Cockcroft DW. Gault MH. Prediction of creatinine clearance from serum creatinine. Nephron $1976 ; 16: 31-41$.

12. Kaplan EL, Meier P. Non-parametric estimation from incomplete observations. J Am Stat Assoc 1958;53:457-81.

13. Miliken ST, Tattersall MH, Woods RL, Coates AS, Levi JA, Fox RM, Raghavan D. Metastatic adenocarcinoma of unknown primary site. A randomized study of two combination chemotherapy regimens. Eur J Cancer Clin Oncol 1987;23:1645-8.

14. Assersohn L, Norman AR, Cunningham D, Iweson T. Seymour M, Hickish T, Massey A, Prior $Y$. Hill ME. A randomised study of protracted venous infusion of 5-fluorouracil (5.FU) with or without bolus mitomycin $\mathrm{C}$ (MMC) in patients with carcinoma of unknown primary. Eur $J$ Cancer 2003:39:1121-8

15. Greco FA, Burris HA III, Erland JB, Gray JR, Kalman LA, Schreeder MT, Hainsworth JD. Carcinoma of unknown primary sile. Cancer 2000;89:2655-60.

16. Greco FA, Erland JB, Morrissey LH, Burris HA III, Hermann RC, Steis $R$, Thompson D, Gray J. Hainsworth JD. Carcinoma of unknown primary site: phase II trials with docetaxel pilus cisplatin or carboplatin. Ann Oncol 2000;11:241-5.

17. Briasoulis $E$, Kalofonos $H$, Bafaloukos D, Samantas E, Fountzilas $G$, Xiros N. Skarlos D, Christodioulou C. Kosmidis P. Pavlidis N. Carboplatin plus paclitaxel in unknown primary carcinoma: a phase II Hellenic Cooperative Oncology Group Study. J Clin Oncol 2000;18: 3101.7

18. Munoz A, Fuente N, Barcelo R, Rubio I, Ferreiro J, Lopez VG. Prognostic and predictive factors of patients with cancer of unknown origin treated with a paclitaxel-based chemotherapy. Med Clin (Barc.) 2004:122:216-8. 
19. Dowell JE, Garrett $A M$, Shyr $Y$, Johnsan DH, Hande KR. A randomized Phase II triall in patients with carcinoma of an unknown primary site. Cancer 2001:91:592-7.

20. Liu JM, Chen YM, Chao Y. Liu SM, Tiu CM, Wu HW. Chiou TC, Hsieh RK, Chan LT, WhangPeng J. Continuous infusion cisplatin and etoposide chemotherapy for cancer of unknown primary site (CUPS) in Taiwan, a region with a high prevalence of endemic viral infections. Jpn J Clin Oncoll 1998;28:431-5.

21. Warner $E$, Goel R, Chang J, Chow W, Verma $S$, Dancey J, Franssen $E$, Dulude $H_{*}$ Girouard $M$. Correia J, Gallant $G$. A multicentre phase II study of carboplatin and prolonged oral etoposide in the treatment of cancer of unknown primary site (CUPS). $\mathrm{Br} J$ Cancer 1998;77: 2376-80.

22. Greco FA, Erland JB, Morrissey LH, Burris HA III, Hermann RC, Steis R, Thompson D, Gray $J$. Hainsworth JD. Carcinoma of unknown primary site: phase II trials with docetaxel plus cisplatin or carboplatin. Ann Oncol 2000;11:211-15.

23. Muggia FM, Baranda J. Management of peritoneal carcinomatosis of unknown primary tumor site. Semin Oncol 1993;20:268-72.

24. Hainsworth JD, Johnson DH, Greco FA. Cisplatim-based combination chemotherapy in the treatment of poorly differentiated carcinoma and poorly differentiated adenocarcinoma of unknown primary site: results of a 12-year experience. $J$ Clin Oncol 1992;10:912-22.

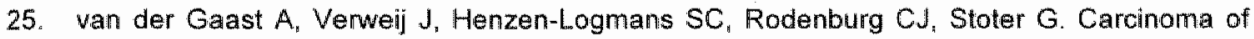
unknown primary: identification of a treatable subset? Ann Oncol 1990;1:119-22.

26. Motzer RJ, Rodriguez E, Reuter VE, Bosl GJ, Mazumdar M, Chaganti RS. Molecular and cytogenetic studies in the diagnosis of patients with poorly differentiated carcinomas of unknown primary site. J Clin Oncol 1995;13:274-82.

27. Markman M. Metastatic adenacarcinoma of unknown primary site: analysis of 245 patients seen at The Johns Hopkins Hospital from 1965-1979. Med Pediatr Oncol 1982;10:569-74.

28. Shildt RA, Kennedy PS, Chen TT, Athens JW, O'Bryan RM, Balcerzak SP. Management of patients with metastatic adenocarcinoma of unknown origin: a Southwest Oncology Group study. Cancer Treat Rep 1983;67:77-9.

29. Culine S, Fabbro M, Ychou M, Romieu G, Cupissol D, Pujol H. Chemotherapy in carcinomas of unknown primary site: a high-dose intensity policy. Ann Oncol 1999;10:569-75.

30. Greco FA, Erland JB, Morrissey LH, Burris HA lll, Hermann RC, Steis R, Thompson D, Gray J. Hainsworth JD. Carcinoma of unknown primary site: phase II trials with docetaxel plus cisplatin or carboplatim. Ann Oncol 2000;11:211-15.

31. Pouessel $D$, Culine $S$, Becht $C$, Ychou $M$, Romieu $G$, Fabbro $M$, Cupissol D, Pinguet $F$. Gemcitabine and docetaxel as front-line chemotherapy in patients with carcinoma of an unknown primary site. Cancer 2004; 100:1257-61

32. Greco FA, Burris HA, II, Litchy S, Barton JH, Bradof JE, Richards P, Scullin DC Jr, Erland JB, Morrissey LH, Hainsworth JD. Gemcitabine, carboplatin, and paclitaxel for patients with carcinoma of unknown primary site: a Minmie Pearl Cancer Research Network study. $₫$ Clin Oncal $2002 ; 20: 1651-6$. 


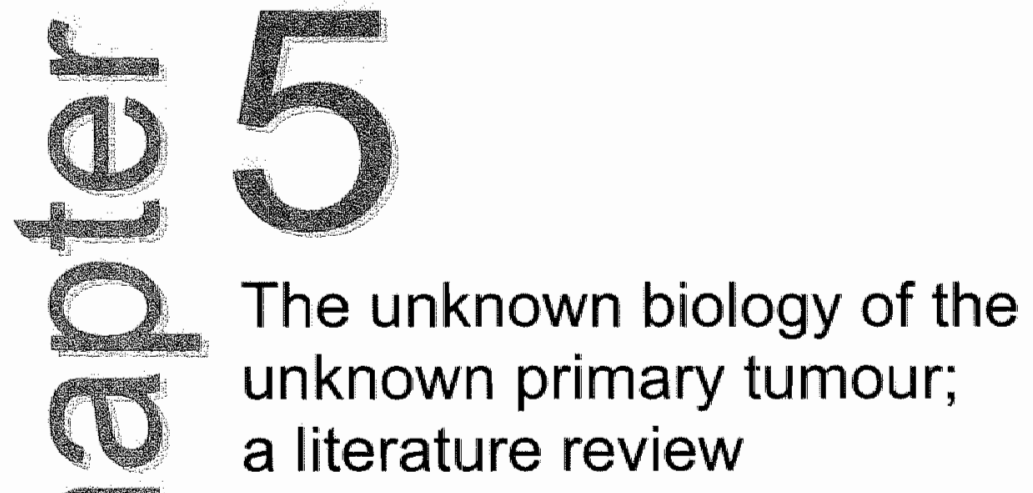

AJ van de Wouw, RLH Jansen, EJM Speel, HFP Hillen Annals of Oncology 2003;14:191-196 


\section{Abstract}

The unknown primary tumour (UPT) is an intriguing clinical phenomenon found in approximately $5 \%$ of all new diagnosed patients with cancer. It is unclear whether UPT forms a biological entity with specific genetic and phenotypic characteristics, or whether it is merely a clinical presentation of metastases in patients in whom the primary tumour cannot be detected and does not result in any visible clinical signs. Understanding the basic biology of UPT may shed light on this issue and, moreover, may have a direct impact on clinical care. A review of the literature revealed only a limited number of publications describing the genetic and phenotypic features of UPT, most of which focus only on the potential of these markers to predict prognosis. The question as to whether the biology of UPT is different from tumours of known primaries therefore remains unanswered. Further insight into the molecular mechanism underlying the oncogenesis of UPT, e.g. by applying newly available DNA and gene profiling microarray techniques, will be necessary to understand its specific biology and to develop more effective treatments. 


\section{Introduction}

The unknown primary tumour (UPT) is an intriguing clinical phenomenon found in approximately $5 \%$ of all newly diagnosed patients with cancer. ${ }^{4-3}$ UPT, alternatively known as cancer of unknown primary (CUP), is defined as biopsy proven metastases of a malignancy in the absence of an identifiable primary site after a complete history and physical examination, basic laboratory studies, chest $X$-ray and additional directed studies indicated by positive findings during the initial work-up. ${ }^{4}$ UPT are predominantly classified as adenocarcinomas $(50-60 \%)$ or poorly differentiated carcinomas or poorly differentiated adenocarcinomas $(30-40 \%)$. Only $5-8 \%$ of the UPT are squamous carcinomas and $2-5 \%$ undifferentiated malignancies. ${ }^{1.2}$

At present, several different explanations have been put forward to describe the heterogeneous UPT syndrome. One such explanation is that UPTs may be considered as metastases in patients in whom the primary has not been found and which did not result in clinical signs of disease. On the other hand, they may represent a separate group of cancers harbouring genetic and phenotypic characteristics that underlie their unique clinical presentation, or alternatively, they may represent unusual primary tumours mimicking metastatic disease (in the case of one identified tumour site).

Advances in understanding the basic biology of UPT can have a direct impact on clinical care. If we regard UPT as common metastases of an unrecognised primary, than the diagnostic evaluation should concentrate on the identification of the primary origin of the tumour. Its identification would lead to a diseasedirected treatment and a better-defined prognosis. Thus, if this is the case, research should focus on developing tools for better detection and/or classification of primary tumours, such as the use of MRI, PET scanning, monoclonal antibody panels and molecular profiling techniques to detect the specific genomic and phenotypic characteristics of the malignant cells involved. In the concept of a specific biology of unknown primary tumours the search for a primary is of minor importance and diagnostic evaluation should focus on the identification of treatable subsets. Treatment should be UPT-specific and the research should focus on the metastatic genotype and phenotype and on the detection of specific biochemical or molecular targets for the treatment of UPT. Thus, it is of great importance to understand the relationship between genotype, phenotype and the biological behaviour of UPT. 


\section{Clinical features}

Although UPT forms a heterogeneous group of tumours with widely varying natural histories, the clinical picture of UPT demonstrates common typical characteristics.

First . patients predominantly present with a short history of non-specific complaints (anorexia, weight loss, etc). In most cases, the primary tumour remains unidentified during the patient's lifetime, but if found during their lifetime or by autopsy, it is a small asymptomatic tumour often localised in lung or pancreas. ${ }^{2,5}$ Even after thorough evaluation at autopsy, only $80 \%$ of the primaries have been found. ${ }^{6,7}$ Secondly, approximately $30 \%$ of patients with UPT present with three or more organs involved. ${ }^{3.9}$ This obviously differs from the percentage of patients with three or more involved organs in metastasised known primaries, which is below $15 \% .^{10-12}$ Thirdly, an unusual metastatic pattern was reported by Nystrom et al. and by Chevalier et $a f^{6,7}$

A relative high number of metastases in UPT are found in kidney, adrenal gland, skin and heart, when compared with expected sites of metastases. ${ }^{10}$ in addition, in patients where the primary had been found during autopsy, differences in metastatic localisation were observed, when the metastatic pattern of UPT was compared with the common sites of tumour spread of known primary tumours. Fourth, the identification of the primary tumour by intensive radiological and/or endoscopic examination, by PET-scan or by immunohistochemistry did not seem to improve survival in the majority of UPT patients mainly due to lack of alternative therapeutic strategies. ${ }^{13-19}$

With the exception of some treatable subgroups, UPT usually exhibits a relatively high resistance to available chemotherapy. ${ }^{1,20-24}$ However new chemotherapeutical agents seem more effective. ${ }^{25,26}$

Patients with UPT have a very poor prognosis of 3 to 4 months in an unselected population with less than $25 \%$ of patients alive one year after diagnosis. ${ }^{3,27,28}$ In more recent studies with highly selected patients from the poor prognostic groups, median survival from 9 to 11 months is reached with over $40 \%$ alive one year after diagnosis. ${ }^{29 \cdot 33}$

\section{Biological features}

A Pub Med search from 1970 untill now revealled only a limited number of publications describing genetic and phenotypic features of UPT and most of them only described their potential as prognostic factors. An overview of the literature will be given below and is summarised in table 5.1. 


\section{Chromosomal abnormalities}

Until now relatively few studies on chromosomal abnormalities in UPT were performed. In an attempt to define unique characteristics of UPT, Abbruzzese et al. developed a research program aimed at evaluating the karyotypic changes common to UPT. ${ }^{34.35}$ They were able to determine the karyotype of 13 from 30 UPT. In 12 of the analysed cell lines were abnormalities detected of the short arm of chromosome 1 amongst others. These abnormalities included deletion of $1 p$, translocations, isochromosome $1 q$ and evidence for gene amplification. These changes are consistent with earlier descriptions of chromosome $1 \mathrm{p}$ abnormalities in advanced malignancy in general as described among others by Atkin. ${ }^{36,37}$

Table 5.1. Biological features of UPT.

\begin{tabular}{lcc}
\hline & Percent & Reference \\
\hline $\begin{array}{l}\text { Chromosomal pattern } \\
\text { chromosome 1q abnormalities }\end{array}$ & & 22 \\
i(12p) in poorly differentiatted carcinoma & & 25 \\
aneuploidy & $70 \%$ & 30 \\
Oncogenes & & \\
c-myc & $96 \%$ & 49 \\
ras & $92 \%$ & 49 \\
c-erB-2 & $65 \%$ & 49 \\
c-erB-2 in PDC/PDA & $11 \%$ & 50 \\
bcl-2 & $40 \%$ & 51 \\
p53 immunohistochemistry & & 51 \\
p53 SSCP/PCR & $53 \%$ & 58 \\
Tumour suppressor genes & $26 \%$ & 64 \\
\hline
\end{tabular}

$\mathrm{PDC}=$ poorly differentiated carcinoma $: \mathrm{PDA}=$ poorly differentiated adenocarcinoma

Motzer et al determined by karyotyping the frequency of specific abnormalities of chromosome 12 , in patients with UPT. ${ }^{38,39}$ The hypothesis was that patients with undifferentiated carcinoma of unknown primary responding to cisplatinbased chemotherapy have unrecognised germ cell tumours and that $i(12 p)$ is a specific chromosomal marker characterizing germ cell tumours. Twelve $(30 \%)$ patients had increased $12 \mathrm{p}$ copy numbers or a deletion of the long arm of chromosome 12. This proved to be predictive for response. Complete responses to cisplatin-based therapy were achieved in patients with specific chromosomal aberrations associated with germ cell tumour and objective responses were achieved in $75 \%$ of these patients compared with $17 \%$ of patients without these aberrations. Summersgill et al. and Ilson et al. found a 
similar association. ${ }^{40,41}$ So in undifferentiated carcinoma of unknown primary $i(12 p)$ is correlated with a good response to platin-based chemotherapy, though lack of $i(12 p)$ does not exclude response. Because i(12p) occurs in over $80 \%$ of the germ cell tumours and only sparsely in a few other lesions (acute leukemia, embryonal rhabdo-myosarcoma and neuroepithelioma) determination of $i(12 p)$ is being used as a diagnostic tool for extragonadal germ cell tumour. ${ }^{42}$

\section{Aneuploidy}

Aneuploidy is now a well-recognised phenomenon, in 70 to $90 \%$ of solid tumours. ${ }^{43,44}$ There is increasing evidence that for many carcinomas such as breast, prostate and colorectal cancer a diploid DNA content is associated with a better prognosis. ${ }^{45}$ In order to determine favourable subgroups Hedley et al. measured the cellular DNA content of tumour biopsies of 152 patients with metastatic adenocarcinoma or undifferentiated carcinoma of unknown primary. ${ }^{46}$ Aneuploidy was found in $70 \%$ of the patients, evenly distributed over the two sexes, and there was no obvious relationship to the various patterns of metastatic involvement. Median survival of patients with diploid tumours was 4.2 months and for patients with aneupioid tumours 4.8 months. These results indicate that the incidence of aneuploidy in this heterogeneous group of patients is similar to that reported for carcinomas with overt primary. In contrast to many of these tumour types, however, in this single study, patients with metastatic adenocarcinomas of unknown primary that are diploid do not have a more favourable prognosis. ${ }^{47}$

\section{Oncogenes}

The oncogenes ras, c-myc, bcl-2 and HER-2/neu are overexpressed in many solid turmours. Determination of levels of these gene products is considered to be useful as prognostic factor, though reports on c-myc and bcl-2 are often conflicting on this matter. ${ }^{47-54}$

Pavlidis et al. found a high overexpression of c-myc, ras and c-erB-2 in 26 UPT patients by immunoperoxidase technique (respectively 96,92 and $65 \%$ ). ${ }^{55}$ They found neither further relationship with histological or clinical parameters nor a diagnostic or prognostic value of this overexpression.

Hainsworth et al. evaluated 100 tumour species of poorly differentiated adenocarcinoma (PDA) or poorly differentiated carcinoma (PDC) of unknown primary site for HER-2-protein. ${ }^{56}$ Ten $(11 \%)$ tumour species overexpressed HER-2. No major differences in overall response rate to chemotherapy were observed between the patients who overexpressed HER-2 and those who did not. Evaluation of the efficacy of trastuzumab in UPT patients with HER-2 overexpression is indicated.

Briasoulis et al. studied the bcl- 2 expression in 40 UPTs ( $8 \%$ squamous, $36 \%$ adenocarcinoma, $55.5 \%$ PDC).$^{57}$ Staining was evaluated by intensity $(+1$ to +3$)$ 
and percentage of positive cells $(1-100 \%)$. Only staining of $>5 \%$ of tumour cells were interpreted to indicate positive tumour staining. Bcl-2 was expressed in almost half of the tumours. This was not expected because in most studies bcl-2 has been found to be up regulated in premalignant lesions rather than in advanced malignancies and also been associated with a less aggressive phenotype. ${ }^{58,58}$ In this study bcl-2 expression by itself had no prognostic value. When combined with a high expression of p53, there was a trend towards a higher response to platin-based chemo-therapy.

Taxanes could be used in an anti-bcl-2 approach. By prevention of polymerisation or depolarisation of microtubules taxanes cause phosphorylation of bcl-2, leading to apoptotic cell death. ${ }^{60}$ in recent studies paclitaxel is used in combination therapy in UPT with promising results (response rates over $40 \%$ and median survival of 9-11 months) in a phase $\|$ study. 32,33

\section{Tumour suppressor genes}

It is now known that a high number of gene inactivations occur in a wide variety of human cancers, and a number of additional putative tumour suppressor genes have been localised on specific chromosomes. P53 is at the moment the best-known tumour suppressor gene. It can suppress tumour development by arresting the cell cycle or initiating apoptosis. Mutations in p53 occur commonly in human cancers, about $55 \%$ of all human cancers express p 53 established by immunohistochemistry. ${ }^{61-53}$

Briasoulis et al. studied by immunohistochemistry $\mathrm{p} 53$ expression in 47 UPTs. ${ }^{57}$ Staining was evaluated by intensity $(+1$ to +3$)$ and percentage of positive cells (1-100). P-53 was expressed in over $70 \%(33 / 47)$ of the tumours. Assessed by immunoreactivity index 25 tumours (53\%) expressed a high and $22(47 \%)$ a low immunoreactivity index. In this study p-53 expression by itself had no prognostic value. When combined with a high expression of bcl-2, there was a trend towards a higher response to platin-based chemotherapy.

Bar-Eli et al. investigated the frequency of p53 mutations in a series of 15 UPT biopsies and 8 cell lines established from UPT. ${ }^{64}$ Mutations in the conserved regions of the p53 gene were analysed by single-strand conformation polymorphism analysis of exons $5-9$ and were verified by direct DNA sequencing of polymerase chain reaction products. In 6 of $23(26 \%)$ patients with UPT the p53 gene were mutated. So although UPT represent bad prognostic tumours the frequency of p53 mutations is relatively low in this study. Therefore they suggest that p53 mutations may not play a major role in the development and progression of UPT. This in contrast to our data of microsatellite analysis, we found in $90 \%$ of the metastases loss of heterozygoty ( $\mathrm{LOH}$ ) of $17 \mathrm{p} 13$ (TP53), so we think there is a relation between p53 mutation
and UPT. 
The difference in the results of p53 studies probably is explained by discordance between immunohistochemical and genetic molecular methods, which may occur in $25 \%$ of tumors. ${ }^{62}$ Two reasons are mentioned. First $20 \%$ of the mutations occur outside the hot spot region (exon 5-9). ${ }^{66}$ On the other hand, the fact that the same monoclonal antibodies can detect both wild and "mutated" protein makes it difficult to distinguish the proportion of each protein. ${ }^{67}$

No association was detected between positive vs. negative immunodetection of p53 and any of the clinicopathological parameters studied. However, patients with a high immunoreactivity index for $\mathrm{p}-53$ and $\mathrm{bcl}-2$ tended to respond better to platin-based chemotherapy.

No research has been performed yet on metastasis-suppressor genes, which seem to play an important role in regulating the growth of disseminated cancer cells at secondary site. ${ }^{68}$

\section{Microvessel density}

There is strong evidence that angiogenesis measured as microvessel density (MVD) correlates with the incidence of metastases in several solid tumors. ${ }^{69}$ In search for a specific biological role of angiogenesis in the metastatic phenotype of the UPT our laboratory compared the MVD in liver metastases of UPT with MVD in liver metastases of colon and breast tumors. ${ }^{70}$ No differences were found between the MVD in liver metastases of UPT and kmown primaries, both showed a high degree of visualization. As in other solid tumours, a high MVD was correlated with short survival in univariate as well as in multivariate analysis.

\section{Discussion}

Mutual clinical features of widespread metastases in uncommon sites and a primary tumour that remains asymptomatic support the paradigm of a specific clinical entity. Whether UPT demonstrates a specific biology with mutual genetic characteristics is still unclear.

Only few studies have tried to identify the unique biological characteristics of UPT. Except for karyotypic abnormalities of the short arm of chromosome 1, as found in many metastatic solid tumours, no further consistent similarities have been found. The finding of aneuploidy in $70 \%$ of UPT and the frequency of c-myc, HER-2/neu, bcl-2 expression and p53 mutation is probably not different from known primary tumours. Most of these items have the same prognostic power in UPT as in metastatic tumours with an overt primary.

It is hypothesised that in UPT the primary acquires a metastatic phenotype soon after transformation and stays small either by inborn errors within the 
primary leading to involution or an extremely slow growth rate, or by metastases inhibiting the growth of the primary tumour. ${ }^{14,35,71}$ There are also suggestions that aggressive tumour cells can leave a relatively mild tumour early and circulate through the blood and form autotrophic, excessive metastases in other organs. ${ }^{72}$ But none of the biological hypotheses is confirmed by results from the literature.

New biological approaches to the dormancy problem in patients may reveal an explanation for the behaviour of UPT. ${ }^{72}$

In conclusion the question whether or not UPT is really different from tumours of known primaries remains unanswered. Further research on the biology of UPT should concern the determination whether this group of tumours share unique genetic, chromosome and/or phenotypic anomalies. It is postulated that new molecular techniques, such as DNA and gene expression profiling as well as proteomics, are going to play an important role in this search. 


\section{References}

1. Greco FA, Hainsworth JD. Cancer of unknown primary site. DeVita VT Jr, Hellman $S$, Rosenberg SA, and (eds). Cancer: Principles and practice of oncology. ed 5. Philadelphia PA Lippincott. 1995: 2072-92.

2. Lembersky BC, Thomas LC. Metastases of unknown primary site. Med Clin Narth Am 1996 ; 80:153-71.

3. van de Wouw AJ, Janssen-Heijnen ML, Coebergh JW, Hillen HF. Epidemiology of unknown primary tumours; incidence and population-based survival of 1285 patients in Southeast Netherlands, 1984-1992. Eur J Cancer 2002;38:409-13.

4. Hillen HF. Unknown primary tumours. Postgrad Med $\sqrt{2000 ; 76: 690-3 .}$

5. Shildt RA, Kennedy PS, Chen TT, Athens JW, O'Bryan RM, Balcerzak SP. Management of patients with metastatic adenocarcinoma of unknown origin: a Southwest Oncology Group study. Cancer Treat Rep 1983;67:77-9.

6. Nystrom JS, Weiner JM, Heffelfinger-juttner J, Inwin LE, Bateman JR, Wolf RM. Metastatic and histologic presentations in unknown primary cancer. Semin Oncol 1977;4:53-8.

7. Le Chevalier T, Cvitkovic E, Caille P. Harvey J, Contesso G. Spielmann M. Rovesse J. Early metastatic cancer of unknown primary origin at presentation. A clinical study of 302 consecutive autopsiled patients. Arch Intern Med 1988;148:2035-9.

8. Abbruzzese JL., Abbruzzese MC, Hess KR, Raber MN, Lenzi $R$, Frost P. Unknown primary carcinoma: natural history and prognostic factors in 657 consecutive patients. J Clin Oncol $1994 ; 12: 1272-80$.

9. Abbruzzese JL, Raber MN. Clinical Oncology. MD Abelhoff, JO Armitage, AS Lichter.JE Niederhuber, (ed.). (Churchill Livingstone, New York, Edinbrough, London, Melboume, Tokyo). 2001:1833-45.

10. Gilbert HA, Kagan AR. Metastases: incidence, detection, and evaluation without histologic confirmation. In: Weiss $L_{\text {, }}$ ed. Fundamental aspects of metastasis Amsterdam, North-Holland. 1976:385-405

11. End results section, Biometry branch National cancer institute. End results in cancer. US dept of health, education and welfare publication 4. 1972. Government printing office. (Report)

12. Abrams HL, Spiro R, Goldstein N. Metastases in carcinoma: analysis of 1000 autopsied cases. Gancer 1950;3:74-85.

13. Stewart JF, Tattersall MH, Woods RL, Fox RM. Unknown prinary adenocarcinoma: incidence of overinvestigation and natural history. BMJ 1979;1:1530-3.

14. Frost Pi, Raber MN, Abbruzzese JL. Unknown primary tumors-are they a unique subgroup of neoplastic disease? Cancer Bull 1987;39:216-8.

15. Karsell PR, Sheedy PF, O'Connell Mu. Computed tomography in search of cancer of unknown origin. JAMA 1982;248:340-3.

16. McMillan $\mathrm{JH}$, Levine E, Stephens RH. Computed tomography in the evaluation of metastatic adenocarcinoma from an unknown primary site. A retrospective sludy. Radiology 1982; 143:143-6.

17. Gamble AR, Bell JA, Ronan JE, Pearson D, Ellis 10 . Use of tumour marker immunoreactivity to identify primary site of metastatic cancer [see comments] BMJ 1993;306:295-8.

18. Kole $A C$, Nieweg OE, Pruim J, Hoekstra HJ, Koops HS. Roodenburg Nl., Vaalburg W. Vermey $A$. Detection of unknown occult primary tumors using positron emission tomography. Cancer 1998:82:1160-6.

19. Lassen U, Daugaard G, Eigtved A, Damgaard K. Friberg L. 18F-FDG whole body positron emission tomography (PET) in patients with unknown primary tumours (UPT). Eur J Cancer $1999 ; 35: 1076-82$ 
20. Bedikian AY, Bodey GP, Valdivieso M. Burgess MA. Sequential chemotherapy for adenocarcinoma of unknown primary. Am J Clin Oncol 1983;6:219-24.

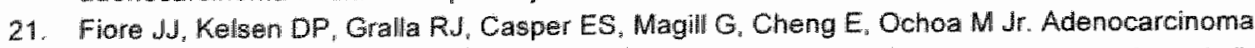
of unknown primary origin: treatment with whdesine and doxorubicin. Cancer Treat Rep 1985; $69.591-4$.

22. Kambtiu SA, Kelsen DP, Fiore $J$, Niedzwiecki $D_{n}$ Chapman $D$, Vinciguerra $V$, Rosenbluth $R$. Metastatic adenocarcinomas of unknown primary site. Prognostic variables and treatment results. Am J Clin Oncol 1990;13:55-60

23. Milliken ST, Tattersall MH, Woods RL, Coates AS, Levi JA, Fox RM, Raghavan D. Metastatic adenocarcinoma of unknown primary site. A randomized study of two combination chemotherapy regimens. Eur $J$ Cancer Clin Oncol 1987,23:1645-8.

24. Moertel CG, Reitemeier RJ, Schuft AJ, Hahn RG. Treatment of the patient with adenocarcinoma of unknown origin. Cancer 1972;30:1469-72.

25. Hainsworth JD, Greco FA. Management of patients with cancer of unknown primary site. Oncology (Huntingt) 2000; 44:563-74.

26. Hainsworth JD, Burris HA, III, Calvert SW, Willcutt NT, Scullin DC, Jr., Bramham J, Greco FA. Gemcitabine in the second-line therapy of patients with carcinoma of unknown primary site: a phase II trial of the Minnie Pearl Cancer Research Network. Cancer Invest 2001;19:335-9.

27. Altman $E$, Cadman $E$. An analysis of 1539 patients with cancer of unknown primary site. Cancer 1986;57:120-4.

28. Markman M. Metastatic adenocarcinoma of unknown primary site: analysis of 245 patients seen at The Johns Hapkins Hospital from 1965-1979. Med Pediatr Oncol 1982; 10:569-74.

29. Greco FA, Burris HA, III, Litchy S, Barton JH, Bradof JE, Richards $P$, Scullin DC, Jr, Erland JB, Morrissey LH. Hainsworth JD. Gemcitabine, carboplatin, and paclitaxel for patients with carcinoma of unknown primary site: a Minnie Pearl Cancer Research Network study. J Clin Oncol 2002;20:1651-6.

30. Greco FA, Erland JB, Morrissey LH, Burris HA, III, Hermann RC, Steis R, Thompson D, Gray $J$, Hainsworth $J D$. Carcinoma of unknown primary site: phase II trials with docetaxell plus cisplatin or carboplatin. Ann Oncol 2000;11:211-5.

31. Greco FA, Burris HA, III, Eriand JB, Gray JR, Kalman LA, Schreeder MT, Hainsworth JD. Carcinoma of unknown primary site. Cancer 2000;89:2655 60.

32. Greco FA, Gray J, Burfis $H A_{n}$. III, Erland JB, Morrissey LH, Hainsworth JD. Taxane-based chemotherapy for patients with carcinoma of unknown primary site. Cancer $J 2001 ; 7: 203-12$

33. Hainsworth JD, Erland JB, Kalman LA Schreeder MT, Greco FA, Carcinama of unknown primary sitte: treatment with 1-hour paclitaxel, carboplatin, and extended-schedule etoposide. $\checkmark$ Clin Oncol 1997;15:2385-93.

34. Abbruzzese Jl. Lenzi R, Raber MN, Pathak $S$, Frost $P$. The biology of unknown primary tumors. Semin Oncol 1993,20:238-43

35. Bell $C W$. Pathak $S$, Frost P. Unknown primary tumors: establishment of cell lines, identification of chromosomal abnormalities, and implications for a second type of tumor progression. Cancer Res 1989:49:4314-5.

36. Atkin NB. Chromosome 1 aberrations in cancer. Cancer Genet Cytogenet 1986;21:279-85.

37. Mertens F, Johansson B. Hoglund M, Mitelman F. Chromosomal imbalance maps of malignant solid tumors: a cytogenetic survey of 3185 neoplasms. Cancer Res 1997;57: 2765-80.

38. Motzer RJ, Rodriguez E, Reuter VE, Samaniego F, Dmitrovsky E, Bajorin DF, Pfister DG, Parsa NZ, Chaganti RS, Bosl GJ. Genetic analysis as an aid in diagnosis for patients with midline carcinomas of uncertain histologies. J Nati Cancer Inst 1991;83:341-6. 
39. Motzer RJ, Rodriguez E, Reuter VE, Bosll GJ. Mazumdar M, Chaganti RS. Molecular and cytogenetic studies in the diagnosis of patients with poorly differentiated carcinomas of unknown primary site. J Clin Oncol 1995;13:274-82.

40. Summersgill $B_{s}$ Goker $H_{v}$ Osin $P$. Huddart $R_{v}$ Horwich $A_{q}$ Fisher $C$, Shipley J. Establishing germ cell origin of undifferentiated tumors by identifying gain of $12 \mathrm{p}$ materiall using comparative genomic hybridization analysis of paraffin-embedded samples. Diagn Mol Pathol 1998; 7: 260-6.

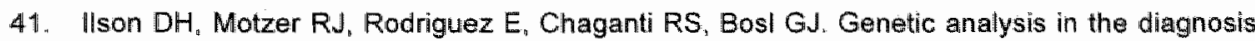
of neoplasms of unknown primary tumor site. Semin Oncol 1993;20:229-37.

42. Sandberg AA, Meloni AM, Suijkerbuijk RF. Reviews of chromosome studies in urological tumors. III. Cytogenetics and genes in testicular tumors. J Urol 1996;155:1531-56.

43. Barlogie $B$, Raber $M N_{n}$ Schumann J, Johnson TS, Drewinko $B$, Swartzendruber DE, Gohde W, Andreeff M, Freireich EJ. Flow cytometry in clinical cancer research. Cancer Res 1983 ; 43:3982-97.

44. Shackmey SE, Shankey TV. Common patterns of genetic evolution in human solid tumors. Cytometry 1997;29:1-27.

45. Williams NN, Daly JM. Flow cytometry and prognostic implications in patients with solid tumars. Surg Gynecol Obstet 1990;171:257-66.

46. Hedley DW, Leary JA, Kirsten F. Metastatic adenocarcinoma of unknown primary site: abnormalities of cellular DNA content and survival. Eur J Cancer Clin Oncoll 1985;21:185-9.

47. Cooper GM. Oncogenes. Baston, Jones \& Bartiett, 1995.

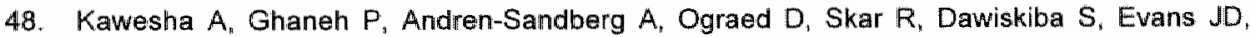
Campbell $F$, Lemoine $N$, Neoptolemos JP. K-ras oncogene subtype mutations are associated with survival but not expression of $p 53, p 16(I N K 4 A), p 21(W A F-1)$, cyclin D1, erbB-2 and erbB-3 in resected pancreatic ductal adenocarcinoma. Int J Cancer 2000;89:469-74.

49. Deming SL, Nass SJ, Dickson RB, Trock BJ. C-myc amplification in breast cancer: a metaanalysis of its occurrence and prognostic relevance. $\mathrm{Br} J$ Cancer 2000;83:1688-95.

50. Kim YJ, Ghu HD, Kim DY, Kim HJ, Kim SK, Park CS. Expression of cellular oncogenes in human gastric carcinoma: C-myc, c- erb B2, and c-Ha-ras. J Surg Oncol 1993;54:167-70.

51. Bland $\mathrm{KI}$, Konstadoulakis MM, Vezeridis MP, Wanebo HJ. Oncogene protein co-expression. Value of Ha-ras, c-myc, c-fos, and p53 as prognostic discriminants for breast carcinoma. Ann Surg 1995;221:706-18.

52. Miller F, Heimann TM, Quish A, Pyo DJ, Szporn A, Martinetli G, Fasy TM. ras and c-myc protein expression in colorectal carcinoma. Study of cancer-prone patients. Dis Colon Rectum 1992;35:430-5.

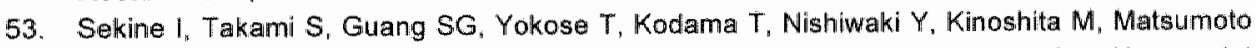
$H$, Ogura $T$, Nagai K. Rale of epidermal growth factor receptor overexpression "K-ras point mutation and $\mathrm{c}$-myc amplification in the carcinogenesis of non-small cell lung cancer. Oncol Rep 1998;5:351-4.

54. Jansen RL, Joosten-Achjanie SR, Volovics A, Arends JW, Hupperets PS, Hillen HF, Schouten HC. Relevance of the expression of bcl-2 in combination with p53 as a prognostic factor in breast cancer. Anticancer Res 1998;18:4455-62

55. Pavlidis $\mathbb{N}$. Briassoulis $E$, Bai $M$. Fountzilas $G$, Agnantis $\mathbb{N}$. Overexpression of C-myc "Ras and $\mathrm{C}$-erbB-2 oncoproteins in carcinoma of unknown primary origin. Anticancer Res 1995;15: 2563-7.

56. Hainsworth JD, Lennington WJ, Greco FA. Overexpression of Her-2 in patients with poorly differentiated carcinoma or poorly differentiated adenocarcinoma of unknown primary site. $J$ Clin Oncol 2000;18:632-5. 
57. Briasoulis $E$. Tsokos M. Fountzilas $G$. Bafaloukos D. Kosmidis P. Samantas $E$, Skarlos $D$, Nicolaides $C$. Pavlidis $\mathbb{N} . B c 12$ and $p 53$ protein expression in metastatic carcinoma of unknown primary origin: biological and chinical implications. A Hellenic Co- operative Oncology Group study. Anticancer Res 1998:18:1907-14.

58. Kaklamanis L, Savage A, Mortensen $N$. Tsiotos P, Doussils-Anagnostopoulou I, Biddolph S, Whitenouse $R_{\text {, Harris }} \mathrm{AL}_{\mathrm{L}}$, Gatter $\mathrm{KC}$. Early expression of bcl-2 protein in the adenomacarcinoma sequence of colorectal neoplasia. J Pathol 1996;179:10-4.

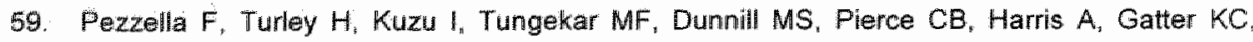
Mason DY. bcl-2 protein in non-small-cell lung carcinoma. N Engl I Med 1993;329:690-4.

60. Haldar $\$$, Basu A, Croce CM. Bcl2 is the guardian of microtubule integrity. Cancer Res 1997; $57: 229 \cdot 33$.

61. Hollstein $M_{1}$ Sidranisky D, Vogelstein B. Harris CC. p53 mutations in human cancers. Sicience $1991: 253: 49-53$

62. Soong $R$, Robbinis PD, Dix BR, Grieu F, Lim B, Knowles $S$, Williams KE, Turbett GR, House AK, lacapetta BJ. Concordance between p53 protein overexpression and gene mutation in a large series of common human carcinomas. Hum Pathol 1996;27:1050-5.

63. Vousden KH, Woude GF. The ins and outs of p53. Nat Cell Biol 2000;2:E178-E180.

64. Bar-Eli M. Abbruzzese JL, Lee-Jackson D. Frost P. p53 gene mutation spectrum in human unknown primary tumors. Anticancer Res 1993;13:1619-23.

65. Speel EuM, Claessen S, van Mierio A, et al. Genetic characterization of different distant metastases in patients with cancer of unknown primary site. proceedings of the american association for cancer research 2001;42:194. (Abstract)

66. Casey G, Lopez ME, Ramos JC. Plummer SJ, Arboleda MJ, Shaughnessy M, Karlan B, Slamon DJ. DNA sequence analysis of exons 2 through 11 and immunohistochemical staining are required to detect all known p53 alterations in human malignancies. Oncogene 1996;13:1971.81.

67. Baas 10 , van den Berg FM, Mulder JW, Clement MJ, Slebos RJ, Hamilton SR, Offerhaus GJ. Potential false-positive results with antigem enhancement for immunohistochemistry of the p53 gene product in colorectal meoplasms. J Pathol 1996;178:264-7.

68. Yoshida BA, Sokoloff MM, Welch DR, Rinker-Schaeffer CW. Metastasis-suppressor genes: a rewiew and perspective on an emerging field. J Natl Cancer Inst 2000; 92:1717-30.

69. Vermeulen PB, Gasparini G, Fox SB, Toi M, Martin L, MaCulloch P. Pezzella F, Viale G, Weidner $N$. Harris AL. Dirix LY. Quantification of angiogenesis in solid human tumours: an international consensus on the methodology and criteria of evaluation. Eur J Cancer 1996 : $32 A: 2474-84$.

70. Hillen HFP, Hak LE, Joosten-Achjanie SR. Arends JW. Microvessel density in unknown primary tumors. Int J Cancer 1997;74:81,5.

71. Yuhas JM, Pazmino NH. Inhibition of sulbcutaneously growing line 1 carcinomas due to metastatic spread. Cancer Res 1974;34:2005-10.

72. Riethmuller G, Kein CA. Early cancer cell dissemination and late metastatic relapse: clinical reflections and biological approaches to the dormancy problem in patients. Semin Cancer Biol 2001:11:307-11. 


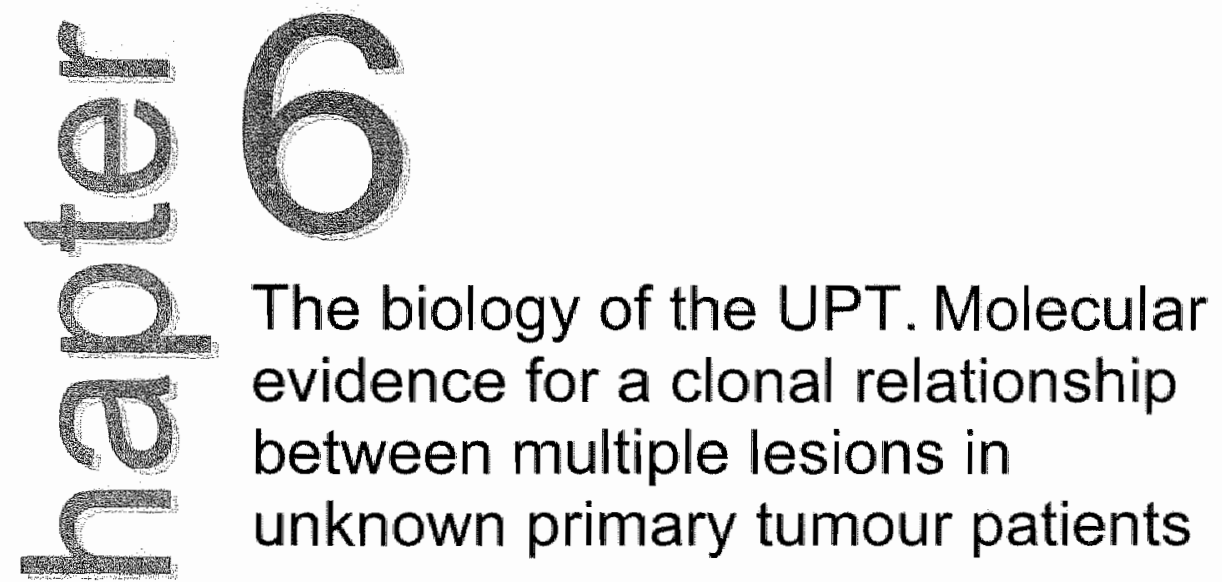

EJM Speel, AJ van de Wouw, SMH Claessen, A Haesevoets, AHN Hopman, AAM van der Wurff, R Osieka, R Buettner, HFP Hillen, FCS Ramaekers 


\section{Abstract}

\section{Purpose}

To determine whether or not a clonal relationship exists between multiple tumours within individual unknown primary tumour (UPT) patients. A molecular resemblance would argue for an early clonal outgrowth of tumour cells from the primary lesion, a mutual feature observed within this group of neoplasms.

\section{Patients and methods}

In 14 patients with adenocarcinoma of unknown primary origin multiple tumours, obtained at autopsy, were analysed by molecular allelotyping and immunohistochemistry. In addition, tumours of 4 patients could be analysed by comparative genomic hybridisation $(\mathrm{CGH})$. Similar genetic and phenotypic profiles were used as indicator for a clonal relationship, whereas different profiles implicate independent tumours.

\section{Results}

The molecular data indicated that the multiple lesions in the 14 UPT patients, including the primary tumours, are clonally related. In agreement with the theory of tumour progression, some metastatic lesions showed additional genetic alterations besides the characteristics that were shared with the primary tumour. Furthermore, 8 UPT patients had tumours with a high frequency of allelic loss and/or imbalance (FALI; 43-71\%), while 6 patients demonstrated a lower FALI (14-29\%), suggesting the occurrence of chromosomal instability in the former group.

\section{Conclusion}

Our data provide molecular evidence for a clonal relationship between multiple metastases and the primary tumour within individual UPT patients, independent of the anatomical origin of the cancer. This finding is in agreement with the suggestion that tumour progression is rapid in UPT patients, limiting the chance of clonal divergence. The identification of two groups of UPT with either a high or low FALI indicates that chromosomal instability is not the only driving force behind early tumour cell dissemination. Thus, other molecular mechanisms must underlie the common biology of these tumours. 


\section{Introduction}

Cancer of unknown primary origin occurs in approximately $3-5 \%$ of all newly diagnosed patients with a malignancy. ${ }^{1.5}$ Unknown primary tumour (UPT) is defined as biopsy-proven metastasis in the absence of an identifiable primary site. The diagnosis is made after complete history and physical examination, basic laboratory studies, chest $X$-ray and additional directed studies indicated by positive findings during the initial work-up and/or in search for treatable subgroups. ${ }^{4}$ UPT is predominantly classified as adenocarcinoma $(50-60 \%)$, or poorly differentiated (adeno)carcinoma $(30-40 \%)$. Only $5-8 \%$ of UPT is squamous cell carcinomas and $2-5 \%$ is undifferentiated malignancies. ${ }^{1,2}$ The clinical features of patients with UPT are heterogeneous and, apart from the identification of some treatable subsets of UPT ${ }^{5-8}$, many patients suffer from cancers that respond poorly to available therapies. As a consequence, the clinical course of UPT is mostly progressive and fatal. ${ }^{1-5}$ Hence, new (molecular) tools to trace their primary site, to predict their biological behaviour and to identify UPT-specific genotypic and phenotypic characteristics are urgently required to improve the current, ineffective treatment strategies. ${ }^{5,6,9012}$

Despite the varying origin and clinical history of UPT, this tumour also appears to have specific characteristics that argue for a common biology. Patients present with a short history of non-specific complaints (anorexia, weight loss, etc). The primary tumour remains in most cases unidentified during life, but if found during life or by autopsy, it is a small asymptomatic tumour often localised in lung or pancreas. ${ }^{15,13,14}$ Even after thorough evaluation at autopsy, only $80 \%$ of the primaries have been found. ${ }^{13.14}$ About $30 \%$ of the patients with UPT present with 3 or more organs involved..$^{1,5}$ This obvious differs from the percentage of patients with 3 or more involved organs in metastasised known primaries, which is below $15 \% .{ }^{15}$ An unusual metastatic pattern is reported by Nystrom et al. and by Chevalier et al. ${ }^{13,14}$ A relative high number of metastases in UPT are found in kidney, adrenal gland, skin and heart, when compared with expected sites of metastases. ${ }^{15}$ From a molecular and cell biological point of view UPT 1) grows from early disseminated cancer cells, 2) grows autotrophically, independent of the paracrine control of the homing organ, 3) is mostly aneuploid and exhibit chromosomal abnormalities with, amongst others, chromosome 1,6,7 and 11 alterations frequently involved, and 4) show a low frequency of p53 mutations and c-erbB2 (HER-2/neu) overexpression. 11, 12,16-23 In many tumour types, such as those from colon, uterine cervix and head and neck, a wealth of molecular data exists on the emergence of clonal populations of cells undergoing successive (epi)genetic alterations during the transition from a premalignant to a malignant lesion. ${ }^{24-28}$ This results in a malignant phenotype with a selective growth advantage. This classical view of tumour progression does not seem to apply to UPT, because there is no evidence of 
histopathological progression and the primary site is (by definition) not identified or only accidentally found e.g. by patient surveillance or during autopsy. ${ }^{3,5}$ It is therefore of clinical and tumour biological interest to investigate UPT patients in which a possible anatomical origin has eventually been identified and to compare this primary lesion to the different distant metastases with respect to tumour evolution. A genotypic and phenotypic resemblance between the primary and metastatic lesions would imply that these lesions are clonally related and that the metastases represent early clonal outgrowths of neoplastic cells from the primary lesion. Such a clonal relationship has so far only been shown in the case of an unknown primary head and neck squamous cell carcinoma, where cervical lymph node metastases genetically resembled histopathologically benign head and neck mucosal biopsies in about half of the patient cases. ${ }^{9}$ Furthermore, the molecular relationship between tumours at various metastatic sites in individual patients can be determined in order to distinguish between true metastases and a probable additional primary tumour. Such conclusions obviously have profound impact for therapeutical management. ${ }^{29}$

In this study, we performed molecular allelotyping and immunohistochemical analyses on multiple tumours of 14 UPT patients, in 12 of which the primary tumour was eventually identified at autopsy. Our aim was to obtain molecular evidence for a clonal relationship between the various metastases within one patient on the one hand, and with the primary tumour on the other. In addition, comparative genomic hybridisation (CGH) analyses allowed further confirmation of a molecular relationship between multiple tumours within 4 patients.

\section{Materials and methods}

\section{Tumour material and patient data}

Formaldehyde-fixed, paraffin-embedded archival autopsy and biopsy material of 56 tumours from 14 patients ( 7 male, 7 female; mean age 70, range 51-86) with adenocarcinoma of unknown primary origin was collected from the archives of the Departments of Pathology, University Hospital Maastricht, the Netherlands (patients 1,10,12,14) and Rheinisch Westfälischen Technischen Hochschule Aachen, Germany (patient 4), and the Laboratory Clinical Pathology Centraal Brabant, Tilburg, the Netherlands (patients 2, 3, 5-9, 11, 13) (table 6.1). From patient 4 also frozen tumour material was available. On basis of medical records and histopathology, these patients were selected due to biopsy-proven UPT with at least 2 organ sites involved and the absence of an identifiable site of tumour origin at the time of diagnosis. Three patients underwent cancer-related therapy (table 6.1). The mean survival time was 9.8 
weeks (range 1-28). By autopsy, in 12 out of 14 patients the primary tumour was identified (patients $1-11$ and 13 ; table 6.3).

Table 6.1 Clinical data of 15 UTP patients.

\begin{tabular}{|c|c|c|c|c|c|c|}
\hline Patient & Gender & Age & $\begin{array}{l}\text { Number of tumour } \\
\text { sites identified }\end{array}$ & Therapy & $\begin{array}{l}\text { Survival } \\
\text { (weeks) }\end{array}$ & $\begin{array}{l}\text { Primary tumour } \\
\text { after autopsy }\end{array}$ \\
\hline 1 & $M$ & 62 & 4 & Radio & 5 & Lung \\
\hline 2 & $F$ & 72 & 3 & No & 13 & Lung \\
\hline 3 & $M$ & 72 & 4 & No & 3 & Lung \\
\hline 4 & $\mathrm{M}$ & 80 & 3 & & & Lung \\
\hline 5 & $M$ & 55 & 3 & No & 3 & Pancreas \\
\hline 6 & $M$ & 62 & 5 & No & 28 & Pancreas \\
\hline 7 & $F$ & 70 & 3 & No & 2 & Pancreas \\
\hline 8 & $F$ & 69 & 3 & Surgery & 6 & Stomach \\
\hline 9 & $F$ & 51 & 3 & No & 28 & Stomach \\
\hline 10 & $F$ & 86 & 6 & No & 2 & Colon \\
\hline 11 & $M$ & 79 & 2 & No & 12 & Rectum \\
\hline 12 & $F$ & 63 & 7 & Radio & 23 & Unknown \\
\hline 13 & $\mathbb{F}$ & 85 & 3 & No & 2 & Uterus \\
\hline 14 & $M$ & 72 & 9 & No & 1 & Unknown \\
\hline
\end{tabular}

Table 6.2 Microsatellite marker information.

\begin{tabular}{|c|c|c|c|c|c|c|c|}
\hline Chromosome & Marker & $\begin{array}{c}\text { Product size } \\
\text { (basepairs) }\end{array}$ & Heterogeneity & Labell & Reference & $\begin{array}{l}\quad \mathrm{PCR} \\
\text { Annealing } \\
\text { Temp }\left({ }^{\circ} \mathrm{C}\right)\end{array}$ & $\begin{array}{l}\mathrm{MgCl}_{2} \\
(\mathrm{mM})\end{array}$ \\
\hline $1 \mathrm{p} 36.33$ & D1S243 & $142-170$ & 0,89 & FAM & GDB & 55 & 1,5 \\
\hline 1036.13 & D1S199 & $94-116$ & 0,84 & TET & $\mathrm{GDB}$ & 60 & 1.5 \\
\hline $3 p 22.2$ & D3S1100 & 179 & 0,82 & TET & $\mathrm{GDB}$ & 58 & 2,0 \\
\hline $3 p 21.31$ & D3S688 & 2110 & 07,3 & FAM & GDB & 60 & 1,5 \\
\hline $8 \mathrm{p} 21.3$ & DBS136 & $71-89$ & 0,88 & FAM & GDB & 52 & 1,5 \\
\hline Sp21.3 & $D 951748$ & $130-150$ & 0,87 & $\mathrm{HEX}$ & GDB & 58 & 1,5 \\
\hline 13014.3 & D13S227 & $81-95$ & 0,83 & FAM & GDB & 58 & 1,5 \\
\hline $17 \mathrm{p} 13$ & TP53CA & $103-135$ & 0,90 & HEX & $\mathrm{GDB}$ & 60 & 2,0 \\
\hline $\mathrm{xq} 12$ & $A R$ & 2216 & 0,90 & TET & GDB & 58 & 1,25 \\
\hline
\end{tabular}

$\mathrm{PCR}=$ polymerase chain reaction; $F A M=$ carboxyfluorescein; $H E X=$ hexachlorofluorescein: $T E T=$ tetra-chlorofturescein; $G D B=$ Genome Database; $A R=$ androgen receptor

A series of $4 \mu \mathrm{m}$-thick sections were cut from the specimens for hematoxylineosin (HE) staining and histopathological reclassification, as well as for immunohistochemistry to visualise (over)expression of $\mathrm{p} 16^{\text {INKA }}, \mathrm{p} 53$, HER$2 /$ neu and CD44v6 proteins. These markers were chosen because accumulation of these proteins has been associated with highly malignant tumours, including UPT. ${ }^{12,20-23,30-35}$ In addition, at least one of the tumours of each patient was subjected to FISH with centromere-1 and 17-specific human DNA probes to detect chromosomal aneusomies, indicating aneuploidy in ali cases. $^{32,36}$ 


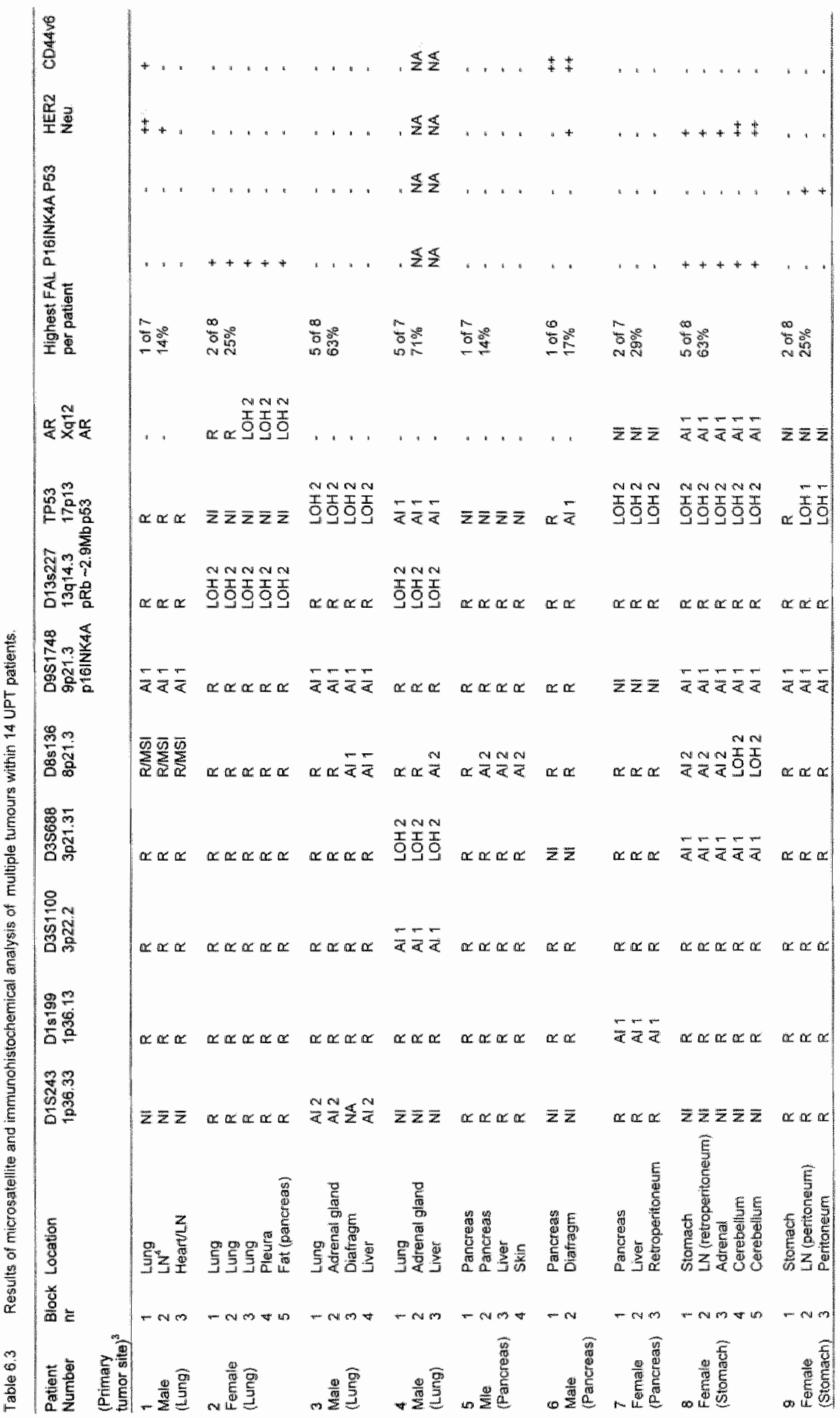




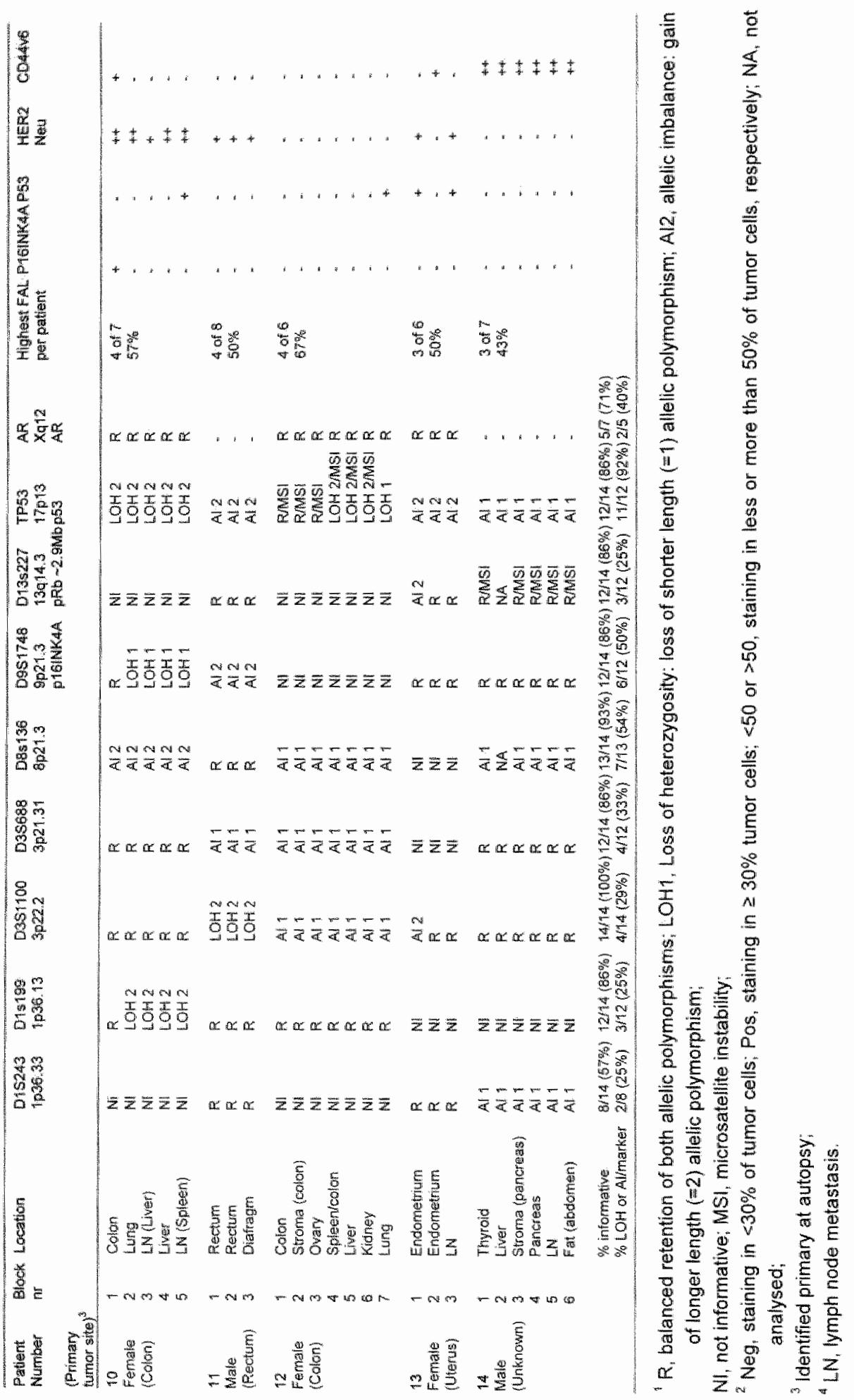


For genomic DNA extraction five to ten 5-10 $\mu$ m-thick paraffin-embedded tissue sections were cut. In case of frozen tissue of patient 5, a $4 \mu \mathrm{m}$-thick section was cut and HE-stained for histopathological analysis in order to check that $>70 \%$ of the cells represented tumour cells. Subsequently, $10 \mu \mathrm{m}$-thick tissue sections were cut for genomic DNA extraction, followed by another $4 \mu \mathrm{m}$-thick section for histopathological examination.

\section{Immunohistochemical staining for p16 ${ }^{\text {INK4A }}, \mathrm{p} 53$, HER-2/neu and CD44v6}

Immunohistochemical protein staining on $4 \mu \mathrm{m}$-thick formaldehyde-fixed, paraffin-embedded tissue sections was performed as described earlier. ${ }^{23,31,32}$ Briefly, sections were deparaffinised by xylene and subsequently pre-treated with $2 \% \mathrm{H}_{2} \mathrm{O}_{2}$ in methanol to quench endogenous peroxidase activity. Antigen retrieval was performed by microwave heating in $0.01 \mathrm{M}$ citrate buffer, $\mathrm{pH} 6.0$ in case of $\mathrm{p} 16^{\mathrm{INK} 4 \mathrm{~A}}, \mathrm{p} 53$ and CD44v6 staining. The monoclonal antibodies $\mathrm{E} 6 \mathrm{H} 4$, DO-7 (both from DAKO A/S, Glostrup, Denmark), HER-2/neu (Novocastra, Newcastle, UK) and CD44v6 ( $R$ \& D Systems, Abingdon, UK) were used to detect $\mathrm{p} 16^{\mathrm{iNK} 4 \mathrm{~A}}, \mathrm{p} 53, \mathrm{HER}-2 /$ neu and $\mathrm{CD} 44 \mathrm{v} 6$ antigens, respectively. After incubation with a biotinylated secondary antibody, immunohistochemical detection was performed by an avidin-biotinylated peroxidase complex (ABC) procedure (Vectastain-Elite-ABC kit; Vector Laboratories, Burlingame, $C A$, USA). Peroxidase activity was detected using diaminobenzidine $/ \mathrm{H}_{2} \mathrm{O}_{2}$. Sections were counter-stained with hematoxylin and mounted in Entellan (Merck, Darmstadt, Germany). In each analysis, negative and positive controls were included. Analysis was performed by two independent observers (E.J.M.S., S.M.H.C.) and consensus was acquired.

Areas of stained tissue (at least 500 cells) that were also used for DNA isolation in consecutive tissue sections (see below) were evaluated as follows:

p16 ${ }^{\text {INK } 4 A}$ : normal expression levels in epithelium are under the detection limit of immunohistochemistry. Strong nuclear and cytoplasmic $p 16^{1 \mathrm{NK} \text {. } A}$ staining in $\geq 30 \%$ of tumour cells was considered as positive and in $<30 \%$ of cells as negative. ${ }^{31}$

p53: the number of cells exhibiting a strong. nuclear staining was scored as negative when $<30 \%$ of the cells showed staining and positive when $\geq 30 \%$ of the cells showed staining. ${ }^{31}$ Although the DO-7 antibody binds to both normal and mutant p53 protein, in general normal levels of wild-type p53 protein are too low to detect by immunohistochemistry.

HER-2/neu and CD44v6: the number of cells exhibiting a strong membrane staining was scored as followed: $<5 \%(-), 5-50 \%(+)$ and $>50 \%(++){ }^{22,23,37}$

\section{DNA isolation}

Genomic DNA from 54 paraffin-embedded and 2 frozen tumour blocks was isolated as described previously. ${ }^{31,38}$ Briefly, $4 \mu \mathrm{m}$-thick HE-stained sections 
served to select tumour parts of the tissue harbouring $>70 \%$ of tumour cells as well as areas of normal tissue (epithelium as well as infiltrating lymphocytes). Selected parts that were easily recognised were scraped with a scalpel from glass slides with unstained $10 \mu \mathrm{m}$-thick sections and collected in $1.5 \mathrm{ml}$ Eppendorf tubes containing 100\% ethanol. This material was spun down (5 min $14000 \mathrm{rpm}$ ) and dissolved in $1 \mathrm{ml} \mathrm{xylol}$. These steps were repeated two times, after which the tissue samples were treated subsequently with $100 \%$ and $70 \%$ ethanol, with centrifugation steps in between (5 min $14000 \mathrm{rpm}$ ), and were air dried prior to proteinase $\mathrm{K}$ digestion. In case of samples that harboured lots of intermingled tumour and normal tissue areas the selected tissue material was carefully and manually scraped under a microscope from 5-10 $\mu$ m-thick tissue sections that were deparaffinised, stained with hematoxylin (according to DelaField; Fluka Chemie, Buchs, Germany), dehydrated and soaked in $5 \%$ glycerol for $5 \mathrm{~min}$.

Tissue collected in $1.5 \mathrm{ml}$ Eppendorf tubes was digested overnight with 1 $\mathrm{mg} / \mathrm{ml}$ Proteinase $\mathrm{K}$ (Sigma) in digestion buffer $(50 \mathrm{mM}$ Tris $\mathrm{pH} 8.0,1 \mathrm{mM}$ EDTA, $0.5 \%$ SDS) at $55^{\circ} \mathrm{C}$. The DNA was purified by either using the QiaAmp DNA mini kit (Qiagen, Hilden, Germany) according to the manufacturer's recommendations or standard phenol-chloroform (PCl; Fluka) extraction, followed by ethanol precipitation and quantification by spectrophotometry.

\section{Microsatellite analysis}

Because the DNA retrieved from the routine processed tissue specimens often was highly degraded, we selected small, highly polymorphic microsatellite markers (70-220 bp) for polymerase chain reaction (PCR) to investigate DNA aberrations (table 6.2; see also Genome Database at www.gdb.org). These markers are located at chromosomal regions known to be frequently deleted in adenocarcinomas, including $1 p, 3 p, 8 p, 9 p\left(p 16^{\text {INKAA }}\right.$ gene at $\left.9 p 21\right), 13 q(p R b$ gene at 13q21), 17p (p53 gene at 17p13) and $X q$ (AR gene at $\mathrm{Xq}_{\mathrm{q} 12)}{ }^{9.11,19,25,26,29.32,38-42}$ For loss of heterozygosity (LOH) analysis, tumour DNA was always compared with normal DNA from the same patient. PCR reactions were carried out in a total volume of $15 \mu \mathrm{l}$ containing $30 \mathrm{ng}$ of genomic DNA, $0.33 \mu \mathrm{M}$ each of forward and reverse (labeled) primer, $0.2 \mathrm{U}$ of AmpliTaq Gold (Perkin Elmer Biosystems, Foster City, CA, USA), 1-2 mM $\mathrm{MgCl}_{2}, 1 \mathrm{mM}$ dNTPs in PCR Gold buffer (Perkin Elmer Biosystems). After a primary heating step of $12 \mathrm{~min}$ at $94^{\circ} \mathrm{C}$, PCR was performed for $30-35$ cycles (denaturation at $95^{\circ} \mathrm{C}$ for 30 seconds, annealing at $52-60^{\circ} \mathrm{C}$ (table 6.2) for $1 \mathrm{~min}$, and extension at $72^{\circ} \mathrm{C}$ for $1 \mathrm{~min}$ ) in a Biometra thermocycler (Biometra, Göttingen, Germany). A final extension was carried out at $72^{\circ} \mathrm{C}$ for $10 \mathrm{~min}$. 1-3 $\mu$ l of PCR product and $0.5 \mu$ TAMRA-labelled size standard (Applied Biosystems, Warrington, UK) were added to $12 \mu$ deionised formamide. This solution was denatured at $95^{\circ} \mathrm{C}$ for $4 \mathrm{~min}$, cooled on ice and analysed on the 
ABI PRISM 3100 GeneScan System (Perkin Elmer Biosystems). The ratio of peak heights of both alleles was calculated for each tumour and normal DNA. For informative cases, $\mathrm{LOH}$ was scored if the ratio between tumour and normal DNA was $>1.5$ or $<0.5$ and the lower peaks were evidently disappearing. In all other cases with these ratios an allelic imbalance (Al) was considered.

\section{Comparative genomic hybridisation and digital image analysis}

Comparative genomic hybridisation (CGH) was performed essentially as described earlier. ${ }^{38}$ Briefly, 2 ug tumour DNA was labelled with Spectrum Green-dUTPs (Vysis, Downers Grove, IL) by nick translation (BioNick kit, Life Technologies, Basel, Switzerland). Spectrum Red-labelled normal reference DNA (Vysis) was used for co-hybridisation. The hybridisation mixture consisted of $800 \mathrm{ng}$ Spectrum Green-labelled tumour DNA, $800 \mathrm{ng}$ of Spectrum-Red labelled normall reference DNA and 10-15 $\mu \mathrm{g}$ of human Cot-1 DNA (Life Technologies) dissolved in $12 \mu \mathrm{l}$ of hybridisation buffer $(50 \%$ formamide, $2 \times S S C, p H 7.0)$. Hybridisation was carried out for 3 days at $37^{\circ} \mathrm{C}$ to denatured ( $2 \times S S C$ and $70 \%$ formamide, $2 \times S S C, p H 7$, each for 5 min at $75^{\circ} \mathrm{C}$ ) normal male human metaphase spreads (Vysis). Slides were washed at $45^{\circ} \mathrm{C}$ two times for 5 min in $50 \%$ formamide/2xSSC followed by short washes in PBS and double distilled water. The chromosomes were counterstained with $0.2 \mu \mathrm{g} / \mathrm{ml}$ DAPI in Vectashield for identification.

Digital images were recorded from six to ten metaphases using the Metasystems Image Pro System (black and white CCD camera; Sandhausen, Germany) mounted on top of a Leica DM-RE fluorescence microscope equipped with appropriate filter sets for DAPI, Spectrum Green and Spectrum Red fluorescence. At least four observations per chromosome were included in each analysis. In a subset of cases, the fluorochrome labels for tumour and reference DNA were reversed in the $\mathrm{CGH}$ to confirm the reproducibility of the detected chromosomal abnormalities.

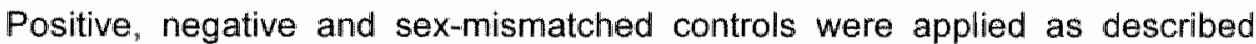
earlier. ${ }^{35}$ Gains and losses of DNA sequences were defined as chromosomal regions where both the mean green-to-red fluorescence ratio and its standard deviation were above 1.20 and below 0.80 , respectively. Overrepresentations were considered amplifications when the fluorescence ratio values in a subregion of a chromosomal arm exceeded 1.5. In negative control hybridisations, the mean green-to-red ratio occasionally exceeded the fixed 1.2 cut-off level at the following chromosomal regions: 1 p32-pter, $16 p, 19$, and 22 . Gains of these known $\mathrm{G}-\mathrm{C}$-rich regions were therefore excluded from all analyses. 


\section{Results}

\section{Microsatellite analysis}

We tested 56 tumour samples of 14 UPT patients for $\mathrm{LOH}$ and $\mathrm{Al}$ at 9 different chromosomal loci by microsatellite analysis (tables 6.1-6.3). In 12 patients the anatomical origin of the UPT was indicated by autopsy and included lung $(4 x)$, pancreas $(3 x)$, stomach $(2 x)$, colon-rectum $(2 x)$ and uterus (1x) (patients 1-11 and 13 ; tables 6.1 and 6.3 ). In patient 14 the primary site was not identified and in patient 12 a negative cytokeratin 7 and a positive cytokeratin 20 staining (data not shown), as well as CGH analysis (see below) suggested colon to be the anatomical origin. The microsatellite markers were informative in $57-100 \%$ (for D1S243 and D3S1100, respectively) of patient cases, showing a frequency of allelic loss and/or imbalance (FALI) ranging from 25\% (D1S243) to $92 \%$ (TP53). In all patients, $\mathrm{LOH}$ or Al for at least 1 of the markers was detected in at least 1 of the tumours (see table 6.3 and figure 6.1 for representative examples). Only the primary tumours of patients 5 and 6 showed no $\mathrm{LOH}$ or $\mathrm{Al}$, despite histopathological proof for the presence of $>70 \%$ tumour cells in the tissue area used for DNA extraction. Furthermore, large differences were seen in the highest FALI comparing the tumours of the 14 UPT patients. When considering the assumed anatomical origin in the 14 patients, the 3 pancreasderived UPTs demonstrated a low FALI (14-29\%), the 2 stomach-derived UPTs either a low $(25 \%)$ or high $(63 \%) \mathrm{FALI}$, and the 3 colorectal-derived UPTs as well as the uterus-derived UPT a high FAl.I (50-67\% and $50 \%$, respectively). The 4 lung-derived UPTs showed a large spread in FALI, ranging from 14-71\%. Patients presenting with tumours with a high FALI showed a shorter mean survival time compared to those with a low FALI ( 7 vs. 13.2 weeks, respectively), although this finding did not reach statistical significance using the Analysis of Variance test (data not shown).

$\mathrm{LOH}$ or Al was regarded as identical in different tumours from the same patient, when the same markers demonstrated loss or Al of the same allele. LOH or Al was considered to be different, when different markers showed LOH or Al in different tumours from the same patient or when the same markers showed loss of different alleles or LOH and Al of the same allele. In all UPT patients, corresponding genetic alterations were observed in the multiple tumours identified (table 6.3). Comparison of the tumours within individual patients, excluding the primary sites, revealed that: 1 ) in 7 cases the $\mathrm{LOH} / \mathrm{Al}$ signature and retention of heterozygosity (R) was identical (patients 1, 2, 5, 9-11, 14);2) in 3 cases there was only a difference between LOH/AI and $R$ for 1 marker (D8S136 in patients 3 and 4 and D1S199 in patient 7); and 3) in 2 cases there was a different $\mathrm{LOH} / \mathrm{Al}$ result for 1 marker, i.e., $\mathrm{Al}$ and $\mathrm{LOH}$ for the longer allele of marker D8S136 in patient 8 and $\mathrm{LOH}$ for both alleles of marker TP53 in patient 12 (table 6.3). 


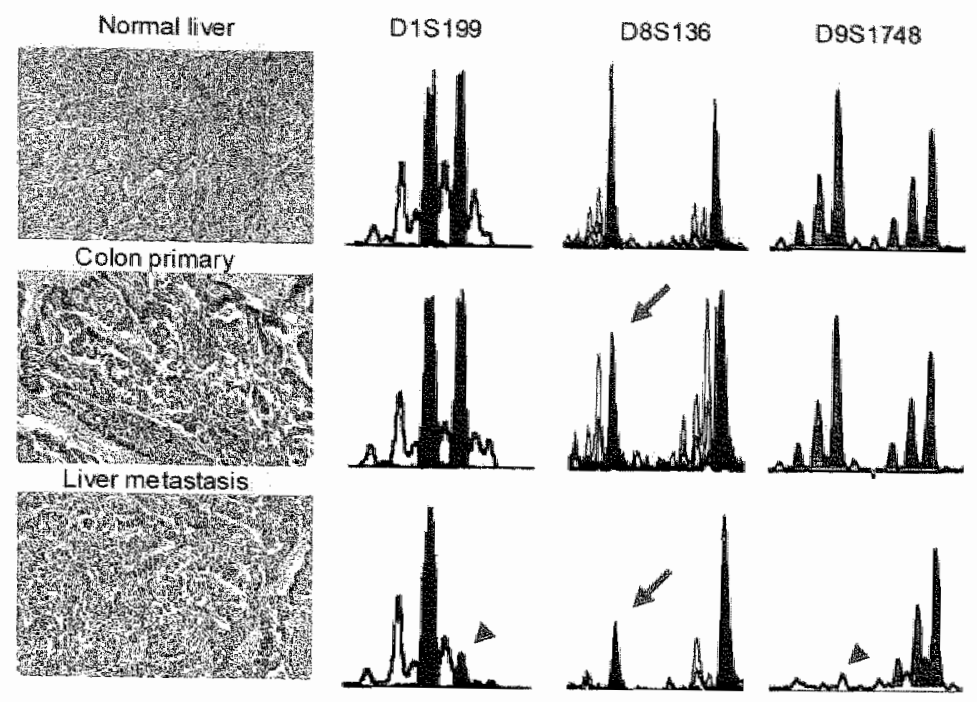

Figure 6.1 Routine histologic sections from patient 10 , stained with hematoxylin (left side), and results of microsatellite analysis of DNA extracted from these tissues (right side; see also table 6.3). LOH is shown for the markers D1S 199 and D9S1748 in the liver metastasis, indicated by loss of the higher length allele $(\mathrm{LOH} 2)$ and shorter length allele (LOH1), respectively. Al is observed for D8S136 in both the colon primary and liver metastasis, indicated by an increase of the higher length allele over the shorter length allele (AI2) without disappearance of the latter allele.

The latter finding suggests that the lung metastasis in patient 12 represents a tumour clone that is genetically different from those of the spleen/colon, liver and kidney (figure 6.2). Nevertheless, the further identical genetic profile of these 4 tumours, as well as the remaining 3 tumours of patient 12 indicates a common origin. These data provide evidence that multiple metastases at different sites in individual UPT patients are clonally related on basis of their molecular allelotype, and only sporadically show aberrant genetic alterations indicating clonal divergence during metastatic progression. Comparison of the metastases with (one or more) tumours of the primary site in patients $1-13$ revealed, that: 1) in 5 cases the LOH/Al signature and $\mathrm{R}$ was identical (patients $1,2,5,11,13) ; 2$ ) in 7 cases there was only a difference between LOH/Al and $R$ for 1 marker, i.e. 5 times $R$ in the primary tumour (patients $3,4,6,9,12$ ) and 2 times $\mathrm{Al}$ in the primary with $\mathrm{R}$ (patient 7) or $\mathrm{LOH}$ (patient 8) in part of the metastases; and 3) in patient 10 markers D1S199 and D9S1748 showed R in the primary tumour, but $\mathrm{LOH}$ in all metastases (figure 6.1). These results strongly indicate that the multiple metastases in the UPT patients are clonally 
related to and derived from the primary tumour, harbouring identical or additional genetic alterations occurring during progression.

A
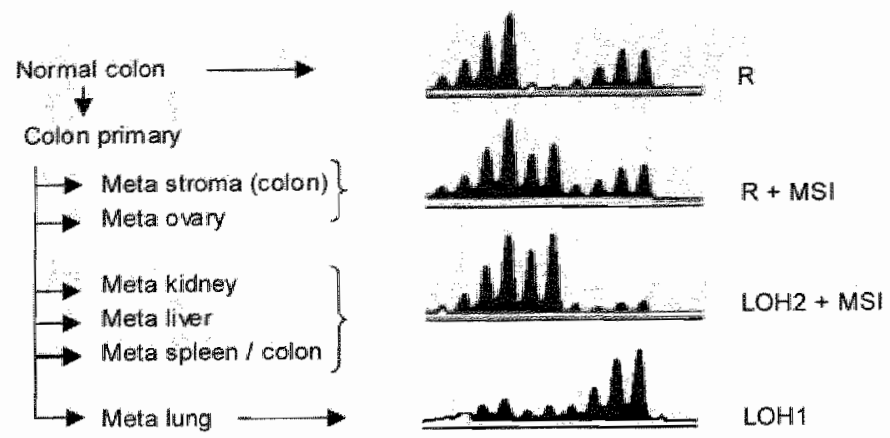

B
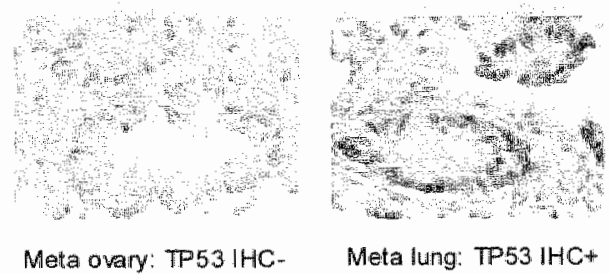

Figure 6.2. A. Results of microsatellite analysis of marker TP53 in multiple tumors of UPT patient 12. In comparison with the presence of two alleles in normal colon tissue ( $R=$ retention of both alleles), 1) microsatellite instability (MSI), identified as two extra peaks of the shortest length allelic polymorphism, is observed in the indicated primary tumor and metastases (meta), except for the lung metastasis, and 2) the metastasas of the spleen/colon, liver and kidney show loss of the longer allele (LOH2) whereas the lung metastasis harbors a loss of the shorter allele (LOH1). Arrows indicate a common origin of the multiple metastases despite these different genetic alterations for TP53, as discussed in the results section. B. Immunohistochemical staining for $p 53$ showing nuclear accumulation of 053 in the lung metastasis $(1 \mathrm{HC}+$ ) while the remaining tumors, including the ovary metastasis, were negative (IHC-; table 6.3).

\section{Comparative genomic hybridization analysis}

In order to further substantiate the data obtained by molecular allelotyping, a subset of tumours of 4 UPT patients $(1,4,10$, and 12), of which enough DNA of acceptable quality was available, was genetically analysed by $\mathrm{CGH}$. The results and hypothetical clonal evolution pathways are shown in figure 6.3 , depicting chromosomal gains and losses in the 10 tumours that were investigated. It is evident that multiple copy number changes occurred in all tumour samples, and that the tumours with a relatively high FALI (from patients 4,10 and 12) also showed significantly more aberrations than those with a low 
FALI (from patient 1). Identical chromosomal alterations were detected in the primary tumour and metastasis derived from UPT patients 1 and 4, indicating a monoclonal origin of the tumour cells. The genetic profile of these lung-derived tumours in both patients, however "completely differed from each other, suggesting different genetic pathways involved in tumourigenesis amongst patients. This finding is in agreement with the LOH/Al data described above. In patient cases 10 and 12 colon-derived metastases from different organ sites could be compared to each other. In both cases similar aberrations were detected in each of the tumour specimens (shared changes), next to additional changes in individual tumour samples. The chromosome alteration signatures of the three tumours of patient 10 indicate that the liver and lymph node (near liver) metastases represent closely related clones with many copy number changes which are with high probability deviated from the lung metastasis on basis of the shared chromosomal changes identified by CGH. The LOH/Al data in table 6.3 underscore the clonal relationship of these tumours. In UPT patient 12 an identical situation can be seen, where the ovary and liver metastases have identical chromosome profiles and the lung tumour only harbours one third of these alterations, however, all shared with both other tumours. Based on the $\mathrm{CGH}$ and $\mathrm{LOH} / \mathrm{Al}$ data (table 6.3 and figure 6.2) a clonal evolution is implicated in which a primary tumour clone shows metastatic progression, after which it acquires LOH1 for TP53 in the lung, or additional chromosomal alterations at other organ sites, including $\mathrm{LOH}_{2}$ for TP53 in some cases. Despite the high number of DNA copy changes in the colon-derived tumours of patients 10 and 12 , the chromosome profiles show high similarities, such as gains of chromosomes $7,13 q$ and $20 q$ and losses of chromosomes $1 p, 3,8 p$, $14 q$ and $18 q$, indicating related pathways of tumourigenesis.

\section{Immunohistochemical analysis}

All tumour samples except for the two metastases of patient 4 (not enough tissue material available) were subjected to immunohistochemistry for the determination of overexpression of four cancer-related antigens, i.e., p16 ${ }^{\mathrm{INK} 4 \mathrm{~A}}$, p53, HER-2/neu and CD44v6 (table 6.3). Accumulation of these antigens was detected in at least one tumour of $3(21 \%), 4(29 \%), 6(43 \%)$ and $5(33 \%)$ of the cases, respectively. In general, identical staining results were observed in the tumours within one patient, with 7 of the 13 patient cases showing no differences between their individual samples at all. 


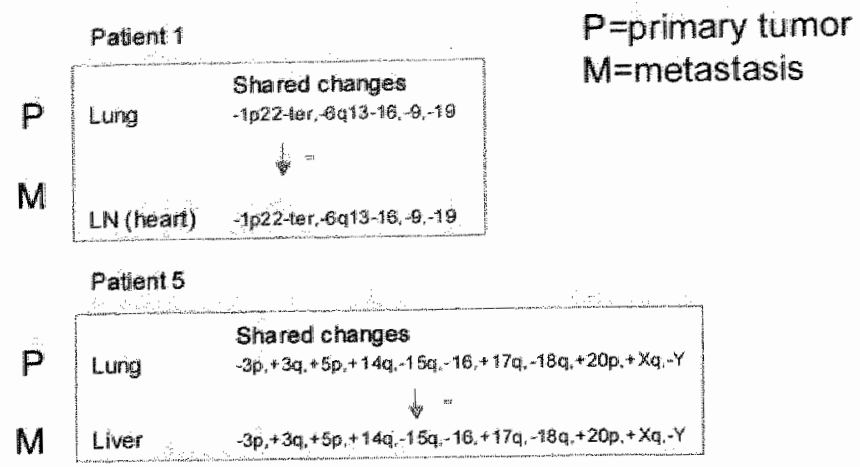

Fatient 11

\begin{tabular}{|c|c|c|}
\hline \multicolumn{3}{|c|}{ P (colorij) } \\
\hline & Shared changes & Additional changes \\
\hline \multicolumn{3}{|c|}{ 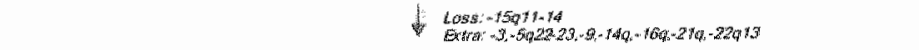 } \\
\hline \multicolumn{3}{|c|}{ 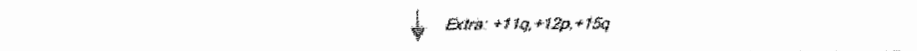 } \\
\hline Lilver & $-1 p,+6 q p-q, 16,11,+7 p,-8 p,+13 q,-18 q,+20 q$ & $\begin{array}{l}3,-5 q 22-23-q_{0}+11 q_{2}+12 p-14 q+15 q \\
-6 q q_{1}-21 q_{m}-22 q 13\end{array}$ \\
\hline
\end{tabular}

Patient 15

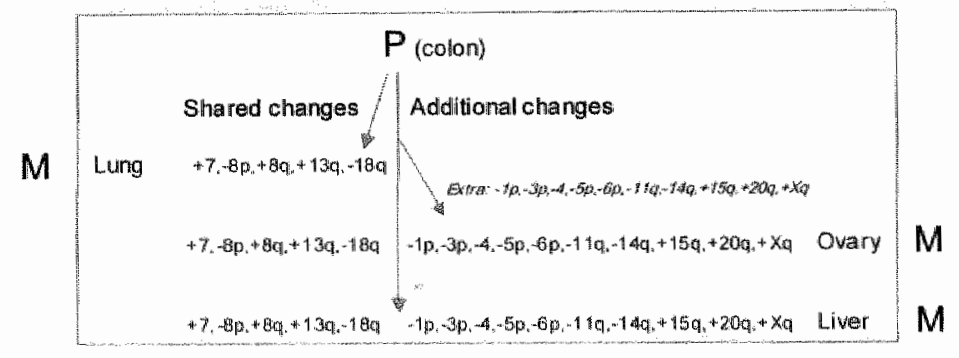

Figure 6.3 Comparison of chromosomal alterations as identified by CGH and hypothetical clonal evolution pathways in different tumors of 4 UPT patients. Additional acquired alterations are in italic.

In five cases there were differences in staining patterns seen when comparing the primary tumour with one or more of the metastases analysed, i.e., in patient 1 HER-2/neu and CD44.v6 expression declined in the metastases, in patient 6 HER-2/neu expression was upregulated in the diaphragm metastasis, in patient 9 accumulation of p53 was observed in both metastases, in patient $10 \mathrm{p} 16^{\mathrm{INKAA}}$ 
and CD44v6 expression was downregulated in all metastases, whereas p53 was upregulated in the LN (near spleen) metastasis, and in patient 12 p53 upregulation was observed in a lung metastasis. The latter finding coincided with LOH1 for the TP53 microsatellite marker, suggesting the occurrence of a p53 mutation resulting in a stabilised p53 protein (figure 6.2 ). Only in the tumours of case 13 the results of $p 53, \mathrm{HER}-2 /$ neu and CD44v6 expression were not in line with the obtained LOH/AI data, because immunohistochemistry points to a clonal relation between tumour 1 and the $L N$ metastasis, while the $\mathrm{LOH} / \mathrm{Al}$ results rather show a closer relationship between tumour 2 and the metastasis. All in all, however, our immunohistochemistry data further support a clonal relationship between multiple tumours within individual UPT patients.

\section{Discussion}

In this study, we evaluated the clonal relationship between multiple adenocarcinomas within 14 individual UPT patients. In 12 of the 14 cases we could include the primary tumour in our analyses, because it was found during autopsy, and in one patient (case 12) the primary tumour was found to originate from the colon on basis of our $\mathrm{CGH}$ and immunohistochemical cytokeratin 7 and 20 staining data. Information on the relationship between the individual tumours per patient was acquired by identifying LOH/Al at 9 microsatellite loci on different chromosomes with molecular allelotyping and detection of changes in the expression of 4 tissue antigens using immunohistochemistry. In 4 patient cases, moreover, CGH analysis allowed a genome-wide overview of DNA gains and losses in at least two tumours per case. Our data provide evidence that multiple lesions in UPT patients, including sites of origin, are molecularly related.

\section{Clonal relationship between UPT metastases and the primary lesion}

Tumour progression is believed to involve the development of a selective growth advantage in a clonal population of cells resulting from the multistep accumulation of (epi)genetic alterations in a certain temporal order. ${ }^{24-28}$ This process is generally accompanied by histopathological changes ultimately leading to morphological proof of invasiveness and the expression of a malignant phenotype. A tumour progression model thus relies on the comparison of premalignant or benign lesions to malignant ones in order to establish genetic progression. In UPT patients, however, such studies are lacking, because the anatomical origin of the tumour is only detected in a minority of cases in a late stage of the disease. This may be due to the fact that the primary lesion is of minute size at presentation and, as a consequence, escapes clinical detection or remains unobserved by sampling error, or even 
disappears after tumour cell dissemination. ${ }^{3,17}$ Proof of the former explanation comes from work on unknown primary squamous cell carcinoma in the head and neck, demonstrating that histopathologically normal mucosa epithelium may harbour cell populations with critical genetic alterations that molecularly resemble cell populations present in distant metastases. ${ }^{9}$ Such studies are more difficult to perform in UPT patients with metastatic adenocarcinoma, because these tumours can originate from many sites in the body, particularly the gastrointestinal tract and lung, for which diagnosis is more invasive and therefore not recommended without any clinical sign of involvement. For adenocarcinomas we show here for the first time that primary lesions detected during autopsy molecularly resemble their previously and/or synchronously detected distant metastases in UPT patients, indicating the presence of clonal populations of cells progressing to clinically detectable metastatic cancer in an early phase of the disease.

\section{Molecular evolution of tumour clones within UPT patients}

In agreement with this theory of tumour progression, some metastatic lesions may contain additional genetic and/or phenotypic alterations not observed in the primary lesions. Such a clonal evolution was evident in 8 out of 13 UPT patients, in which predominantly an extra LOH/Al was identified in the metastatic lesion(s) as compared to the primary tumour by microsatellite analysis. In 5 out of 13 patients this was also illustrated by a difference in staining pattern between the primary tumour and at least one of the metastases for the 4 immunohistochemical markers. Four of those cases were among the 8 patients showing clonal evolution by microsatellite analysis. Also between different metastases within one patient microsateliite analysis could detect genetic differences in 5 out of 13 cases, although always for only 1 of the 9 markers. Interestingly, the acquired CGH data on multiple metastases of patients 10 and 12 demonstrate that the number of chromosomal alterations per tumour may further increase during outgrowth of the malignant clonal cell populations in the different organs. Nevertheless, because the metastasis with the least genetic alterations shares virtually all its changes with the other metastases, these data still underscore the clonal relationship of these tumours, as do the microsatellite and protein expression data.

\section{Frequency of genetic changes in UPT lesions}

The presence of additional molecular alterations in the metastases of some UPT patients not necessarily needs to be related to tumour progression. It may also point to chromosomal instability (CIN), an abnormal cell state with elevated chromosomal gains and losses, which is often observed in epithelial cancers, including UPT. ${ }^{11,43.44}$ We noticed a large spread in the highest FALI per patient as determined by microsatellite analysis, ranging from $14-71 \%$. 
Eight UPT patients showed tumours with a relatively high FALI (43-71\%) while the remaining 6 cases had a lower FALI (14-29\%), suggesting the presence of $\mathrm{CIN}$ in the former group. This observation is in agreement with our $\mathrm{CGH}$ results, which demonstrate much more DNA copy number changes in the tumours of patients 4,10 and 12 (high FALI) in comparison with those of patient 1 (llow FALI). The presence of CIN has recently been associated with a poor prognosis in UPT patients, and also in our patient group cases with a high FALI ( $\geq 43 \%$ ) showed a shorter mean survival time than those with a low FALI $(\leq 29 \%$ ) (7 vs. 13.2 weeks, respectively). "This finding, however, did not reach statistical significance, most probably due to the limited number of patients included in this study. Our data also imply the existence of a group of UPT with much less chromosomal alterations (low FALI). This finding is in agreement with the results of Pantou et al., and indicates that the development and progression of UPT are not merely the result of an accumulation of chromosomal events. " There might be other molecular mechanisms underlying the acquisition of a metastatic phenotype early in tumourigenesis as well as the potential for easy homing in different organs. An interesting hypothesis in this respect suggests that in UPT patients a primary lesion develops with already from the start a "molecular signature of metastasis and poor prognosis", which is angiogenically incompetent and stays clinically undetected, but can metastasise to various organs. ${ }^{3.45}$ Indeed, recent studies implicate that primary tumours already exhibit gene expression profiles of metastatic potential in the bulk of tumour cells as well as alternatives to neoangiogenesis, such as vasculogenic mimicry, which may be challenging subjects for further study in UPT. ${ }^{46.47}$

\section{Molecular classification of UPT}

Apart from demonstrating $\mathrm{CIN}$ in multiple tumours of 3 of the 4 patients, our $\mathrm{CGH}$ analyses clearly demonstrated a chromosome profile pointing toward a colon origin (i.e., gain of $7 p, 13 q$ and $20 q$ and loss of $18 q$ ) in the tumours of patients 10 and 12 . This was further substantiated by analysing these tumours for cytokeratin 7 and 20 expression, which had not been carried out on these samples at the time of diagnosis. CK7- and CK20+ immunostaining further classified the adenocarcinomas in patients 10 and 12 to be of colon origin. These findings thus confirmed the diagnosis in patient 10 , and classified the UPT of patient 12 to be of colon origin. Combining a genomic profile with current immunohistochemical markers, therefore, may help establishing an accurate tumour diagnosis, which if followed by appropriate therapeutic regimens can positively affect outcome..$^{3,5,6,11,12}$ In the near future more results may be expected from genomic approaches in predicting the anatomical origin of UPT as well as deregulated genetic pathways to be targeted by novel therapies. ${ }^{48-50}$ 


\section{Conclusion}

In conclusion, we present here molecular evidence that distant metastases within individual UPT patients are molecularly related to each other and to the indicated primary adenocarcinoma, independent of the tumour origin. This finding argues for an early clonal outgrowth of tumour cells from the primary lesion in UPT patients followed by rapid tumour progression thereby limiting the chance of clonal divergence. Besides chromosomal instability also other molecular mechanisms must underlie UPT pathogenesis. The presence of monoclonal tumour cell populations in UPT patients implicates good chances for therapeutic interventions if tumour origin and/or gene targets can be identified. 


\section{References}

1. Greco FA, Hainsworth JD. Cancer of unknown primary site, in DeVita Jr VT. Hellman $S$. Rosenberg SA (eds): Cancer: Principles and practice of oncology $5^{\text {th }}$ ed. Philadelphia, PA, Lippincott, 1995:2072-92.

2. Hammar SP. Metastatic adenocarcinoma of unknown primary origin. Hum Pathol 1998:29: $1393-402$.

3. Varadhachary GR, Abbruzzese JL. Lenzi R. Diagnostic strategies for unknown primary cancer. Cancer 2004;100:1776-85.

4. van de Wouw AJ, Janssen-Heijnen ML, Coebergh JW, Hillen HFP. Epidemialogy of unknown primary tumours; incidence and population-based survival of 1285 patients in Southeast Netherlands, 1984-1992. Eur J Cancer 2002;38:409-13.

5. Hillen HF. Unknown primary tumours. Postgrad Med J 2000:76:690-3

6. Motzer RJ, Rodriguez E, Reuter VE, Bosl GJ, Mazumdar M, Chaganti RS. Molecular and cytogenetic studies in the diagnosis of patients with poorly differentiated carcinomas of unknown primary site. Slin Oncol 1995;13:274-82.

7. Ayoub JP, Hess KR, Abbruzzese MC, Lenzi R, Raber MN, Abbruzzese JL. Unknown primary tumors metastatic to liver. J Clin Oncol 1998;16:2105-12.

8. Greco FA, Burris HA, III, Litchy S, Barton JH, Bradof JE, Richards P, Scullin DC, Jr, Erland JB, Morrissey LH, Hainsworth JID. Gemcitabine, carboplatin, and paclitaxel for patients with carcinoma of unknown primary site: a Minnie Pearl Cancer Research Network study. J Clin Oncol 2002;20:1651-6.

9. Califano J, Westra WH, Koch W, Meininger $G$, Reed A, Yip L, Boyle JO, Lonardo $F$, Sidransky $D$. Unknown primary head and neck squamous cell carcinoma: Molecular identification of the site of origin. J Natl Cancer Inst 1999;91:599-604.

10. Kaufmann $O$, Fietze $E$, Dietel $M$. Immunohistochemical diagnosis in cancer metastasis of unknown primary tumor. Pathologe 2002;23:183-97.

11. Pantou D, Tsarouha $H_{*}$ Papadopoulou $A_{v}$ Mahaira L, Kyriazoglou I, Apostolikas N, Markidou $S$, Trangas $T$, Pandis $N$, Bardi $G$. Cytogenetic profile of unknown primary tumors: clues fior their pathogenesis and clinical management. Neoplasia 2003;5:23-31.

12. van de Wouw AJ, Jansen RLH, Speel EJM, Hillen HFP. The unknown biology of the unknown primary tumour: a literature review. Annal Oncoll 2003;14:191-6.

13. Nystrom JS, Weiner JM, Heffelfinger-Juttner J, Irwin LE, Bateman JR, Wolf RM, Metastatic and histologic presentations in unknown primary cancer. Semin Oncol 1977:4:53-8.

14. Le Chevalier T, Cvitkovic E, Caille P. Harvey J, Contessa G, Spieimann M. Rouesse J. Earlly metastatic cancer of unknown primary origin at presentation. A clinical study of 302 consecutive autopsied patients. Arch Intern Med 1988;148:2035-9.

15. Gilbert HA, Kagan AR. Metastases: incidence, detection, and evaluation without histologic confirmation, in Weiss L (ed): Fundamental aspects of metastasis. Amsterdam, the Netherlands, 1976:385-405.

16. Abbruzzese $\mathrm{J}$. Lenzi $\mathrm{R}$, Raber MN, Pathak $S$. Frost $P$. The biology of unknown primany tumors. Semin Oncol 1993;20:238 43 .

17. Riethmuller $G$, Klein $C A$. Early cancer cell dissemination and late melastatic relapse: clinical reflections and biological approaches to the dormancy problem in patients. Semin Cancer Biol 2001:11:307-11.

18. Hedley DW. Leary JA, Kirsten F. Metastatic adenocarcinoma of unknown primary site: abnormalities of cellular DNA content and survival. Eur $\mathrm{J}$ Cancer Clin Oncol 1985;21:185-9.

19. Bell $C W$, Pathak $S$, Frost $P$. Unknown primary tumors: establishment of cell lines. identification of chromosomal abnormalities, and implications for a second type of tumor progression. Cancer Res 1989;49:4311-5. 
20. Bar-Eli M. Abbruzzese JL, Lee-Jackson D. Frost P. p53 gene mutation spectrum in human unknown primary tumors. Anticancer Res 1993;13:1619-23.

21. Gottschlich S, Schuhmacher O, Gorogh T. Hoffmanin M, Maune S. Analysis of the p53 gene status of lymph node metaistasis in the head and neck region in accult primary cancer. Laryngol Rhinol Otol 2000;79:434-7.

22. Hainsworth JD, Lennington WJ, Greco FA. Overexpression of Her-2 in patients with poorty differentiated carcinoma or poorly differentiated adenocarcinoma of unknown primary site. $J$ Clin Oncol 2000;18:632-5.

23. wan de Wouw AJ, Jansen RLH, Griffioen AW, Hiflen HFP. Clinical and immurnohistochemical analysis of patients with unknown primary tumour. A search for prognostic factors in UPT. Anticancer Res 2004:24:297-302.

24. Garcia SB, Novelli $M$, Wright $N A$. The clonal origin and clanal evolution of epithelial tumours. Int J Exp Pathol 2000;81:89-116.

25. Markowitz SD, Dawson DM, Willis J, Willson JKV. Focus on colon cancer. Cancer Cell 2002; $1: 233-6$.

26. Forastiere $A$, Koch $W$. Trotti $A$, Sidransky D. Head and neck cancer. N Engl J Med 2001; $345: 1890-1900$.

27. Hermam JG, Baylin SB, Gene silencing in cancer in association with promoter hypermethylation. N Engl J Med 2003;349:2042-54.

28. Hantahan D, Weinberg RA. The hallmarks of canceir. Cell 2000;100:57-70.

29. van der Sijp JRM, van Meerbeeck JPAM, Maat APWM, Zondervan PE, Sleddens HFBM, van Geel AN. Eggermont AMM, Dinjens WNM. Determination of the molecular relationship between multiple tumors within ane patient is of clinical importance. J Clin Oncol 2002;20:1105-14.

30. Begum S, Gillison ML. Ansari-Lari MA. Shah $K$, Westra WH. Detection of human papillomavirus in cervical lymph modes: a highly effective strategy for localizing site of tumor origin. Clin Cancer Res 2003:9:6469-75.

31. Hafkamp HC, Speel EJM, Haesevoets A, Bot FJ, Dinjens WNM, Ramaekers FCS, Hopman AHIN "Manni JJ. A subset of head and neck squamous cell carcinomas exhibits integration of HPV $16 / 18$ DNA and overexpression of $p 16^{\text {NKK4a }}$ and $p 53$ in the absence of mutations in $p 53$ exons 5-8. Int J Gancer 2003;107:394-400.

32. Hopman AHN, Kamps MAF, Speel EJM, Schapers RF, Sauter G, Ramaekers FCS. Identification of chromosome 9 alterations and p53 accumulation in isolated carcinoma in situ of the urinary bladder versus carcinoma in situ associated with carcinoma. Am J Pathol 2002* $161: 1119-25$

33. Vousden KH, Prives $\mathrm{C} . \mathrm{p} 53$ and prognosis: new insights and further complexity. Cell 2005; $120: 7-10$.

34. Heider KH, Kuthan H, Stehle G, Munzert G. CD44v6: a target for antibody-based cancer therapy. Cancer Immund Immunother 2004;53,567-79.

35. Emens LA. Davidson NE. Trastuzumab in breast cancer. Oncology (Huntingt). 2004; 18: 1117-28.

36. Wessels PH, Twijnstra A. Kubat B. Ummelen MIJ, Claessen SMH, Sciot R, Merlo A, Ramaekers FCS, Speel EuM, Hopman AHN. 10q25.3 (DMBT1) copy number changes in astrocytoma grades II and IV. Genes Chromosomes Cancer 2004;39:22-8.

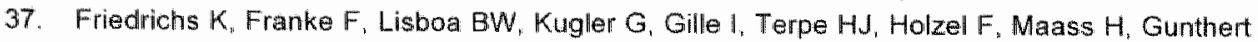
U. CD44 isoforms correlate with cellular differentiation but not with prognosis in human breast cancer. Cancer Res 1995;55:5424-33.

38. Speel EJM, Richter U, Moch H, Egenter $G$, Saremaslani P, Rütimann $K$, Zhao J, Barghorn A, Roth $\Downarrow_{n}$ Heitz PU, and Komminoth $P$. Genetic differences in endocrine pancreatic tumor subtypes detected by comparative genomic hybridization. Am J Pathal 1999:155:1787-94. 
39. Perren A, Roth J, Muletta-Feurer S, Saremaslani P, Speel EJM, Heitz PU, Komininoth P. Clonal analysis of sporadic pancreatic endocrine tumours. J Pathol 1998; 186:363-71.

40. Mertens F. Johansson B, Mitelman F. Chromosomal imbalance maps of malignant solid tumors: a cytogenetic survey of 3185 neoplasms. Cancer Res 1997:57:2765-80.

41. Knuutila $S$, Aalto $Y$, Autio $K$, Bjorkqvist AM, El-Rifai $W$, Hemmer $S$, Huhta $T$, Ketturen $E$. Kiuru-Kuhlefelt $S$, Larramendy ML, Lushnikova $T$, Monni $O$, Pere H, Tapper J, Tarkkanen M, Varis A, Wasenius $V M$, Wolf $M$, Zhu $Y$. DNA copy number losses in human neoplasms. Am $J$ Pathol 1999;155:683-94.

42. Gebhart $E_{\text {i }}$ Liehr $T$. Patterns of genomic imbalances in human solid tumors. Int 10 ncol 2000 ; $16: 383-99$.

43. Vogelstein B, Kinzler KW. Cancer genes and the pathways they control. Nat Med 2004; 10:789-99.

44. Draviam VM, Xie S, Sorger PK. Chromosome segregation and genomic stability. Current opinion in Genetics \& Development 2004:14:120-5.

45. Naresh $\mathrm{KN}$. Do metastatic tumours from an unknown primary reflect anglogenic incompetence of the tumour at the primary site? A hypothesis. Med Hypotheses 2002; $59: 357-60$.

46. Ramaswamy $S$, Ross $K N$, Lander $E S$, Golub TR. A molecular signature of metastasis in primary solid tumors. Nature Genet 2003;33:49-54.

47. van der Schaft DW, Seftor RE, Seftor EA, Hess AR, Gruman LM, Kirschmann DA, Yokoyama $Y$, Griffioen AW, Hendrix MJ. Effects of angiogenesis inhibitors on vascular network formation by human endothelial and melanoma ceils. \& Natl Cancer Inst 2004;96:1473-7.

48. Buckhaults $P$, Zhang $Z$, Chen $Y-C$, Wang $T-L$, St. Croix $B$, Saha $S$, Bardelli $A$, Morin PJ, Polyak $K_{n}$ Hruban $R H$, Velculescu VE, Shih $1-M$. Identifying tumor origin using a gene expression-based classification map. Cancer Res $2003 ; 63: 4144-9$.

49. Su Al, Welsh JB, Sapinoso LM Kern SG, Dimitrow P, Lapp H, Schultz PG, Powell SM, Moskaluk CA Frierson HF Jr, Hampton GM. Malecular classification of human carcinomas by use of gene expression signatures. Ciancer Res 2001;61:7388-93.

50. Aibertson DG. Pinkel D. Genomic microarrays in human genetic disease and cancer. Hum Mol Genet 2003:12:R145-52.

51. Hillen HFP, Claessen SMH, van Mierto A, Haesevoets A, Hopman AHN, Ramaekers FCS, van der Wurff AAM, Joosten S, van de Wouw AJ, Speel EJM: Genetic analysis reveals evidence for a clonal relationship between multiple tumors in individual patients with unknown primary tumor. Proc ASCO 2002:21:453a (Abstract). 


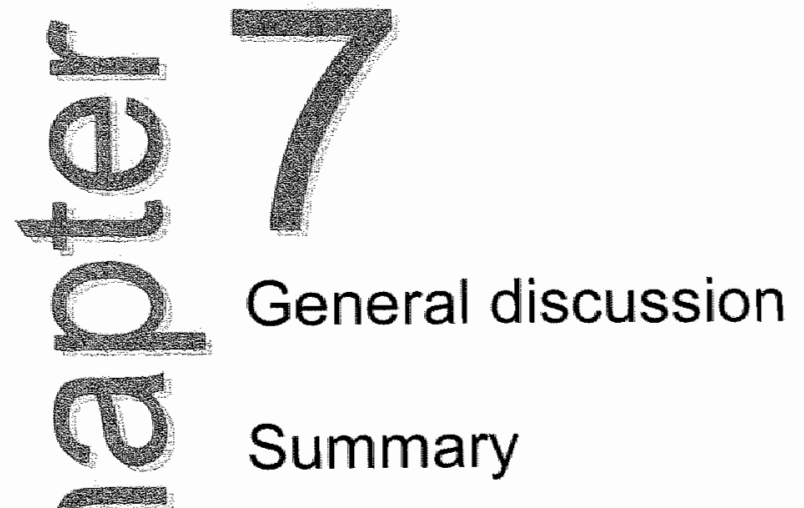




\section{General discussion}

The diagnosis of an unkmown primary tumour (UPT) is impressive and intriguing. Impressive because of the short survival in patients with widespread metastases of an unknown origin. Intriguing because of the unknown genetic make-up and unknown biology of this disease.

The hallmark of UPT is metastasis. Research of the mechanism underlying early metastasis in UPT might also lead to insight in the progression of common tumours. Insight in this process is important for a better understanding and treatment of cancer.

\section{Incidence and diagnosis}

In a general hospital, UPT is a common phenomenon which accounts for $4 \%$ of all newly diagnosed cases of cancer. Approximately 2500 new patients are diagnosed annually in the Netherlands, which means that it is more common than non-Hodgkin's lymphoma (Chapter 2 ). In older studies the diagnosis was made more often $(5-10 \%){ }^{1-3}$ On the other hand, studies, performed in selected populations, found UPT in $0.5-1.8 \%$ of all newly diagnosed cases of cancer. ${ }^{4.5}$ The definition is made per exclusionem based on clinical examination and radiological and pathological work up. By patient selection, evolution of knowledge on tumour biology and availability of new investigational tools the definition and, along with that, the incidence will change.

In recent years, the diagnostic strategy in UPT has changed, from searching the primary tumour with all available methods, to a limited work up directed at the search for treatable subgroups of UPT. The principle of performing only those investigations which can cause a change in patient management seems right. However, patients can think differently on this subject. They already have many problems with accepting the bad news of having a fatal form of cancer; this is even more difficult to cope with, when the origin of the fatal cancer is unknown. An important step in the care of patients with an unknown primary tumour is therefore to prepare the patient for the fact that, in UPT, the primary tumour usually cannot be revealed, and that this fact is not decisive for prognosis or treatment decisions in this particular type of tumour in contrast to other tumours. The examination of patients with UPT not belonging to favourable subgroups should include complete history and physical examination, basic laboratory studies, chest $X$-ray, additional studies indicated by positive findings during the initial work-up, and in case of an adenocarcinoma an endoscopy of the colon and a mammography in women. The pathologist can be helpful in suggesting the diagnosis of the treatable subsets of UPT, using such immunohistochemical markers as CK 7, CK 20 , TTF-1, PSA, ER, PR, thyroglobulin, and alpha-fetoprotein. Unfortunately, no immunohistochemical test is $100 \%$ specific. Although it is important to use 
these markers for guidance, no definite diagnosis of the primary can be made. Nowadays a computer tomography of the abdomen has often already been performed at diagnosis. There is no evidence that this is an effective examination, though it can be used to indicate tumour load. ${ }^{6-8}$ Sometimes the primary tumour is found on CT-scan, usually a pancreatic tumour. But this finding does not change the prognosis of the patient. Therefore CT-scan should only be performed in patients with abdominal complaints. PET scanning has no role yet in UPT: although more primaries are discovered $(25 \%)$, this does not lead to improved survival. ${ }^{9-13}$ There is some evidence for the effective use of PET in UPT localised in cervical lymph nodes, where finding the primary (25-30\%) might lead to improved therapy. ${ }^{14-18}$

\section{Prognosis and therapy}

Prognosis is very poor for UPT. In a population-based study, overall median survival was 3 months, and one-year survival 15\% (Chapter 2 ). This is similar to earlier mentioned survival of $3-5$ months and less than $20 \%$ of patients alive after one year. ${ }^{19-23}$ However, in more recent studies median survival of 7-11 months was reached (Chapter 4).,24-33 These studies used selected patients who had to be well enough to undergo chemotherapy. Demographics of the prognostic favourable patients in the unselected population resembled the patients from these studies (Chapter 2).

Though some treatable subgroups with better prognosis can be identified (table 1.3), UPT comprises mainly patients with adenocarcinoma of unknown primary (ACUP) and poor prognosis. Until now, no specific chemotherapy regimen has proved to be beneficial in this group. Only three phase III studies have been performed (including our study), all without showing benefit for one of the treatment arms (Chapter 4). ${ }^{34,35}$ No studies are performed comparing chemotherapy with best supportive care. Best supportive care is a realistic option, in patients with UPT, especially when one keeps in mind that many patients with UPT are elderly, with comorbidity. On the other hand, in all studies with ACUP, patients are found with a relatively favourable prognosis, independently of which treatment was used. Clinical characteristics of these patients are young age, good performance status, normal LDH and no liver metastases (Chapter 2 and Chapter 3 ). It seems useful to identify these patients beforehand, because these patients will probably benefit from therapy. At this moment no standard or specific therapy can be recommended in UPT. There is need for clinical trials in these patients. These trials are rare in the literature and it is also our experience that accrual for these trials is difficult. For those patients not treated in clinical trials, FUFA may be a reasonable choice, given the side-effects and the effectivity. In search for better prognostic factors to identify patients who do benefit from therapy, some studies have been performed. ${ }^{36,37}$ The clinical characteristics identifying a favourable prognosis, 
described by Culine and also by van der Gaast, were supported by the results of our study (Chapter 3 ). ${ }^{36,37}$ The immunohisto-chemical factors we examined (p53, MIB-1, HER-2/neu, CD34, CD44v6, and VEGF) apparently did not contribute to a better prediction of prognosis of our patients. But, because of insufficient biopsy material in over $30 \%$ of the patients, this conclusion should be considered with some caution (Chapter 3). However, also, others found no prognostic significance of $\mathrm{p} 53, \mathrm{bcl}-2$, and HER-2/neu, solely, though patients with a high immunoreactivity index for $p 53$ and bcl-2 tended to respond better to cisplatin-based therapy. Far more interesting are the findings by Pantou et al. ${ }^{38}$ They show a significantly shorter survival, in cases displaying massive chromosome changes, as compared with those having few changes. This indicates that the cytogenetic pattern might be used as a tool to assess prognosis in UPT. New studies are needed to investigate whether the patients with few changes have their favourable prognosis solely on the basis of their tumour biology, or that this prognosis can be even further improved by treatment. The use of modern genomic analysis techniques will probably provide better prognostic tools, as in known primaries. 39,40

\section{Biological aspects}

For a better understanding of UPT, more information on the biology of the tumour is needed. At present several different explanations have been put forward to describe the heterogeneous UPT syndrome. One can consider LIPT as metastasised cancer in patients in whom the primary just has not been found, without any biological differences from metastasised tumours from known origin. More likely, but still without evidence, is that UPT represents a separate group of cancers harbouring genetic and phenotypic characteristics that underlie its unique clinical presentation. Satisfactory explanations of why primary tumours in UPT remain microscopically small or disappear after seeding have not yet been found. It is hypothesised that the primary tumour has a molecular signature of poor prognosis from the start, and is angiogenically incompetent to present clinically (either because of failed angionesis or because of locally secreted antiangiogenic factors), but can metastasise to various organs. ${ }^{41}$ Indeed, recent studies suggest that primary tumours already exhibit gene expression profiles of metastatic potential in the bulk of tumour cells. ${ }^{42}$ Others have suggested that the primary stays small because of inborn errors within the primary, leading to involution or an extremely slow growth rate, or by metastases inhibiting the growth of the primary tumour. ${ }^{4}$

Another elegant option is the suggestion of vascular mimicry. UPT creates direct access to the blood flow, by vascular mimicry without angiogenesis. This can explain the presence of tumour metastasis with a small primary tumour (unpublished data). 
In the search for a specific genetic profile in UPT, all metastatic tumour sites and the primary in UPT patients who were autopsied, were examined (Chapter 6). Distant metastases within individual UPT patients were molecularly related to each other and to the indicated primary lesion, independently of the tumour origin. This finding is in line with the idea that UPT has a common biology, showing rapid tumour progression, thereby limiting the chance of clonal divergence.

By unravelling the biology of the tumour, two directions can be followed. First, the primary may be identified by genetic analysis. Although not the most important issue, it can in some cases lead to tumour-specific therapy and can bring peace of mind to the patient. Since several months ago a micro-array is available which can predict the primary tumour in over $80 \%$ of the cases. ${ }^{46}$

Second, insight into the biology of UPT can lead to more precise prognosis and a more specific therapy. I presume that, in a few years, specific therapy for a tumour will no longer solely be directed by the origin of the primary, but mainly by the genetic characteristics of that tumour.

\section{Conclusion}

UPT remains a heterogeneous group of tumours with similar clinical aspects but an unknown biological behaviour. Patients have a poor prognosis, except for some favourable subgroups. Chemotherapy does not seem to contribute to improving survival, however, patients with better prognosis and better responses to systemic therapy can be identified. Yet clinical features are the only tools, immunohistochemical markers have not proved to be useful. Though it seems likely that different tumours with similar clinical aspects exhibit similar genetic profiles, this still is just a hypothesis. Indirect evidence exists, but the true biology of UPT is still unknown. 


\section{References}

1. Greco FA, Hainsworth JD. Tumors of unknown origin. CA Cancer J Clin 42, 96-115 (1992).

2. Bitran,J.D. \& Ultmann,J.E. Malignancies of undetermined primary origin. Dis Mon $1992 ; 38: 213-60$.

3. Krementz ET, Cerise EJ, Foster DS, Morgan LR Jr. Metastases of undetermined source. Curr Prob Cancer 1979:4:4-37.

4. Blaszyk $H$, Hartmann A, Bjornsson J. Cancer of unknown primary: clinicopathologic correlations. APMIS 2003;111:1089-94.

5. Abbruzzese JL, Abbruzzese MC, Hess $K R_{\text {, }}$ Raber MN, Lenzi $R_{n}$ Frost $P$. Unknown primary carcinoma: natural history and prognostic factors in 657 consecutive patients. I Clin Oncol $1994: 12: 1272-80$.

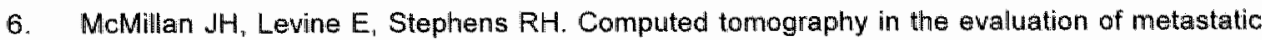
adenocarcinoma from an unknown primary site. A retrospective study. Radiology $1982 ; 143: 143-6$.

7. Pavlidis $N$, Briasoulis E, Hainsworth J, Greco FA. Diagnostic and therapeutic management of cancer of an unknown primary. Eur J Cancer 2003;39:1990-2005.

8. Karsell PR, Sheedy PF, O'Connell MJ. Computed tomography in search of cancer of unknown origin. JAMA 1982;248:340-3.

9. Kole AC, Nieweg OE, Pruim J, Hoekstra HJ, Koops HS, Roodenburg JL, Vaalburg W, Vermey A. Detection of unknown occult primary tumors using pasitron emission tomography. Cancer 1998;82:1160-6.

10. Delgado-Bolton RC, Fernandez-Perez C, Gonzalez-Mate A, Carreras JL. Meta-analysis of the performance of $18 \mathrm{~F}$.FDG PET in primary tumor detection in unknown primary tumors. J Nucl Med 2003;44:1301-14.

11. Rades $D$, Kuhnel $G$, Wildfang I, Borner AR, Schmoll HJ, Knapp W. Localised disease in cancer of unknown primary (CUP): the value of positron emission tomography (PET) for individual therapeutic management. Ann Oncol 2001:12:1605-9.

12. Lassen $U$, Daugaaird $G$, Eigtved A, Damgaard K, Friberg L. 18F-FDG whole body positron emission tomography (PET) in patients with unknown primary tumours (UPT). Eur J Cancer $1999 ; 35: 1076-82$.

13. Gutzeit A, Antoch $G$, Kuhl $H$, Egelhof $T$, Fischer $M$, Hauth, E, Goehde $S$, Bockisch A, Debatin J. Freudenberg L. Unknown primary tumors: detection with dual-modality PET/CT-minitial experience. Radiology 2005;234:227-34.

14. Assar OS, Fischbein, NJ, Caputo GR, Kaplan MJ, Price DC, Singer MI,Dillon WP, Hawkins RA. Metastatic head and neck cancer: role and useffulness of FDG PET in locating occult primary tumors. Radiology 1999;210:177-81.

15. Braams JW, Pruim J Kole AC, Nikkels PG. Vaalburg W, Vermey A, Roodenburg JL. Detection of unknown primary head and neck tumors by positron emission tomography. Int $J$ Oral Maxillofac Surg 1997;26:112-5.

16. Fogarty GB, Peters Lل, Stewart J, Scott C, Rischin D, Hicks RJ. The usefulness of fluorine 18-labelled deoxyglucose positron emission tomography in the investigation of patients with cervical lymphadenopathy from an unknown primary tumor. Head Neck 2003;25:138-45.

17. Jereczek-Fossa BA, Jassem J, Orecchia R. Cervical lymph node metastases of squarnous cell carcinoma from an unknown primary. Cancer Treat Rev 2004;30:153-64.

18. Johansen $\mathrm{J}$. Eigtved A, Buchwald $C$. Theilgaard SA, Hansen HS. Implication of 18F-fluoro-2 deoxy-D-glucose positron emission tomography on management of carcinoma of unknown primary in the head and neck: a Danish cohort study. Laryngoscope 2002:112:2009-14.

19. Altman $E$, Cadman $E$. An analysis of 1539 patients with cancer of unknown primary site. Cancer $1986 ; 57: 120-4$. 
20. Le Chevallier T, Cvitkovic E, Caille P. Harvey J Contesso G, Spieimann M. Rouesse J. Early metastatic cancer of unknown primary origin at presentation. A clinical study of 302 consecutive autopsied patients. Arch Intern Med 1988;148:2035-9.

21. Levi $F$, Te VC. Erler $G$, Randimbison $L$, La Vecchia $C$. Epidemiology of unknown primary tumours. Eur J Cancer 2002;38:1810-2.

22. Kirsten $F$, Chi $\mathrm{CH}$, Leary JA, Ng AB, Hedley DW, Tattersall MH. Metastatic adeno or undifferentiated carcinoma from an unknown primary site-natural history and guidelines for identification of treatabile subsets. $Q$ U Med $19 ; 87 ; 62 ; 143-61$.

23. Markman M. Metastatic adenocarcinoma of unknown primary site: analysis of 245 patients seen at The Johns Hopkins Hospital from 1965-1979. Med Pediatr Oncol 1982;10. 569-74.

24. Hess KR, Abbruzzese MC, Lenzi R, Raber MN, Abbruzzese JL. Classification and regression tree analysis of 1000 consecutive patients with unknown primary carcinoma. Clin Cancer Res 1999;5:3403-10.

25. Hainsworth JD, Greco FA. Management of patients with cancer of unknown primary site Oncology (Huntingt) 2000;14:563-74.

26. Greco FA, Burris HA 3rd, Litchy $S$, Barton JH, Bradof JE, Richards $P_{i}$ Scullin DC Jr. Erland

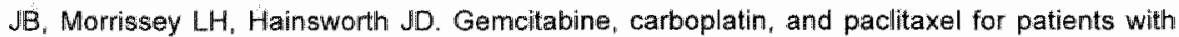
carcinoma of unknown primary site: a Minnie Pearl Cancer Research Network study. J Clin Oncol 2002;20:1651-6.

27. Greco FA, Erland JB, Morrissey LH, Burris HA 3rd, Hermann RC, Steis R, Thompsion D, Gray J. Hainsworth JD. Carcinoma of unknown primary site: phase II trials with docetaxel plus cisplatin or carboplatin. Ann Oncoll 2000;11:211-5.

28. Greco FA, Gray J, Burris HA 3rd, Erland JB, Morrissey LH, Hainsworth JD. Taxane-based chemotherapy for patients with carcinoma of unknown primary site. Cancer $\mathrm{J} 2001 ; 7: 203-12$.

29. Greco FA, Burris HA 3rd, Erland JB, Gray JR, Kalman LA, Schreeder MT, Hainsworth JD. Carcinoma of unknown primary site. Cancer 2000;89:2655-60.

30. Lenzi $R$, Hess KR, Abbruzzese MC, Raber MNN, Ordonez NG, Abbruzzese JL. Poorly differentiated carcinoma and poorly differentiated adenocarcinoma of unknown origin: favorable subsets of patients with uniknown-primary carcinoma? $J$ Clin Oncol 1997;15: 2056-66.

31. Culine S, Fabbro M, Ychou M, Romieu G, Cupissol D, Pujol H. Chemotherapy in carcinomas of unknown primary sitte: a high-dose intensity policy. Ann Oncol 1999;10:569-75.

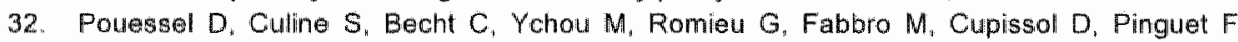
Gemcitabine and docetaxel as front-line chemotherapy in patients with carcinoma of an unknown primary site. Cancer 2004;100:1257-61.

33. Briasoulis $E$, Kalofonos $H$, Bafaloukos D, Samantas $E$, Fountzilas $G$, Xiros $N$, skarlos D, Christodoutou $\mathrm{C}$, Kosmidis $\mathrm{P}$. Pavlidis N. Carboplatin plus paclitaxel in unknown primary carcinoma: a phase II Hellenic Cooperative Oncology Group Study. J Clin Oncol 2000;18: $3101-7$.

34. Assersohn L. Norman AR, Cunningham $D$, Iveson $T$, Seymour M, Hickish $T$, Massey A, Prior $Y$. Hill ME. A randomised study of protracted venous infusion of 5-fluorouracil (5-FU) with or without bolus mitomycin $C$ (MMC) in patients with carcinoma of unknowm primary. Eur $J$ Cancer $2003 ; 39: 1121-8$.

35. Milliken ST, Tattersall MH, Woods RL, Coates AS, Levi JA, Fox RM, Raghavan D. Metastatic adenocarcinoma of unknown primary site. A randomized study of two combination chemotherapy regimens. Eur J Cancer Clin Oncol 1987:23:1645-8.

36. Culime $S$, Kramar A. Saghatchian $M$, Bugat $R$, Lesimple $T$, Lortholary A, Merrouche $Y$, Laplanche A, Fizazi K. Development and validation of a prognostic model to predict the length of survival in patients with carcinomas of an unknown primary site. $J$ Clin Oncol $2002 ; 20: 4679-83$. 


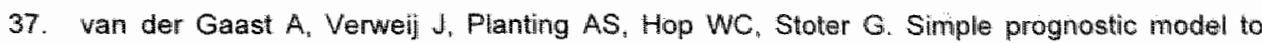
predict survival in patients with undifferentiated carcinoma of unknown primary site. $J$ Clin Oncol 1995; 13:1720-5

38. Pantou D, Tsaroutha $H$, Papadopoulou A, Mahaira L, Kyriazoglou li, Apostolikas $N$, Markidou

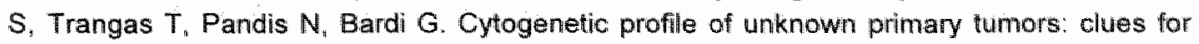
their pathogenesis and clinical management. Neoplasia 2003;5:23-31

39. Lossos IS, Czenwinski DK, Alizadeh AA, Wechser MA, Tibshirani R, Botstein D, Levy R. Prediction of survival in diffuse large-B-cell lymphoma based on the expression of six genes. N Engl J Med 2004; 350:1828-37.

40. van de Vijver MJ, He YD, van't Veer LJ, Dai H, Hart AA, Voskuil DW, Schreiber GJ, Peterse JL, Roberts C, Marton MJ, Parrish M, Atsma D. Witteveen A, Glas A, Delahaye L, van der Velde T, Bartelink H, Rodenhuis $S$, Rutgers ET, Friend SH, Bernards R. A gene-expression signature as a predictor of survival in breast cancer. N Engl J Med 2002;347:1999-2009.

41. Naresh $\mathrm{KN}$. Do metastatic tumours from an unknown primary reflect angiogenic incompetence of the tumour at the primary site?-a hypothesis. Med Hypotheses 2002;59: $357-60$.

42. van "t Veer LJ, Weigelt B. Road map to metastasis. Nat Med 2003;9:999-1000.

43. Frost $P$, Raber MN, Abbruzzese $J L$. Unknown primary tumors-are they a unique subgroup of neoplastic disease? Cancer Bull 1987;39:216-8.

44. Bell CW. Pathak $S$. Frost $P$. Unknown primary tumors: establishment of cell lines, identification of chromosomal abnormalities, and implications for a second type of tumor progression. Cancer Res $9989 ; 49: 4311-5$.

45. Yuhas $\mathrm{JM}$, Pazmino $\mathrm{NH}$. Inhibition of subcutaneously growing line 1 carcinomas due to metastatic spread. Cancer Res 1974;34:2005-10.

46. Erlander MG, Moore MW, Cotter $P$, et al. Molecular classification of carcinoma of unknown primary by gene expression profiling from formalin-fixed paraffin-embedded tissules. J Clin Oncol 2004 ASCO Annual Meeting Proceedings (Post-Meeting Edition). 22(14S), 2004:9545. (Abstract) 
Dhispter 7 


\section{Summary}

Unknown primary tumour (UPT) is defined as biopsy-proven metastasis of a malignancy in the absence of an identifiable primary site after the patient has undergone a complete history and physical examination, basic laboratory studies, chest $X$-ray and additional studies indicated by positive findings during the initial work-up or in a search for a treatable malignancy.

UPT is a relatively common tumour with a very poor prognosis. In order to improve the prognosis, it is very important to better understand this tumour. To achieve this goal several clinical and biological studies were performed which are described in this thesis.

In Chapter 1 an overview of the clinical knowledge and characteristics of UPT is presented. Furthermore a general introduction to the different studies in this thesis is described.

Data on survival and prognostic factors of UPT are mostly based on selected patients series from specialised institutions. Population-based data on incidence, histology and determinants of survival for patients with UPT are not available. Chapter 2 describes a study analysing incidence and populationbased survival of UPT in Southeast Netherlands. UPT was diagnosed in 1285 patients, accounting for $4 \%$ of al cancer patients. In 1024 patients the diagnosis was confirmed histopathologically; adenocarcinoma $(47 \%)$, poorly differentiated carcinoma or adenocarcinoma (44\%), squamous cell carcinoma $(7.4 \%)$ and undifferentiated malignant neoplasm (1.6\%). In $261 \quad(20 \%)$ diagnosis was made only clinically. In $26 \%$ of the patients with UPT the tumour was already widely disseminated at presentation. The majority of patients $(67 \%)$ received only supportive treatment. Overall survival was very poor in the biopsied group with a median of 11 weeks and a 1 -year survival rate of $15 \%$. Favourable subgroups comprised young patients and patients with metastases localised in lymph nodes. The 261 patients in whom the diagnosis was made clinically were evaluated separately. They were older than the biopsyconfirmed patients, received less cancer-directed therapy and their prognosis was even worse (median survival of 7 weeks).

In a comparison with data from a tertiary referral centre in the USA Dutch patients were older, received less therapy and had a poorer prognosis, but the Dutch favourable subgroup showed identical demographics with respect to the patients from the American study. The differences were most likely caused by the difference in patient population. In conclusion this population-based study demonstrates that UPT is a relatively common diagnosis with a prognosis which is even more unfavourable than suggested in most clinical studies. 
Besides the traditional favourable subgroups described in the introduction (table 1.3) some patients with adenocarcinoma of unknown primary (ACUP) show a better prognosis than others. It is important to identify these patients because they may be the ones who benefit from treatment. To verify clinical prognostic factors and to identify new ones, a detailed clinical and immunohistochemical analysis of 70 patients with the diagnosis of ACUP was undertaken (Chapter 3). Statistical analyses were performed with clinical variables. Patients with a younger age $(<60$ years), a good performance score (0-1), no liver metastases, or normal LDH-levels, were found to have a better prognosis. The prognostic model published by Culine using performance status and the presence or absence of liver metastases was confirmed as a valuable tool for predicting prognosis also in patients with ACUP. Univariate analyses of protein expression data (MIB-1, p53, VEGF, CD34, CD44v6 and HER-2/neu) indicated no evident association with prognosis. Thus, so far only clinical markers appear to be valuable in predicting prognosis of patients with UPT

Treatment of UPT is still evolving. A minority of patients presents with characteristics that have been recognised as favourable, based on responsiveness to therapy and better prognosis (table 1.3). Unfortunatelly, most patients with UPT (predominantly adenocarcinoma) do not fit in a favourable subgroup. Many different chemotherapeutic regimens containing cisplatin and/or 5-fluorouracil have been studied in phase II trials. Because of the positive results of a phase $I I$ trial with carboplatin, etoposide and paclitaxel (CEP) a phase III study was performed in patients with ACUP (Chapter 4). Treatment with CEP was compared to treatment with folinic acid followed by 5-fluorouracil in a continuous schedule (FUFA). The objective of this study was to determine whether treatment with CEP improved survival, response and toxicity profile in patients with ACUP compared to treatment with FUFA. Fortysix patients were enrolled; 23 in both treatment arms. Baseline characteristics were well ballanced between both arms. No significant differences in survival were observed. The median survival for the CEP arm was 7.0 vs. 6.4 months for the FUFA arm $(p=0.76)$ and median time to progression was 3.5 vs. 3.3 months $(p=0.79)$. Eighty-three percent (38/46) of the above patients were evaluable for response. Complete remission (CR) or partial remission (PR) in CEP vs. FUFA arm was recorded in 30 vs. $9 \%(p=0.036)$ and $C R$ or $P R$ or stable disease (SD) in 60 vs. $48 \% \quad(p=0.14)$. Two drug-related deaths were reported in the CEP and none in the FUFA arm. CEP caused more frequently grade 3 or 4 neutropenia ( 9 vs. 1 patients), thrombocytopenia ( 5 vs. 0 patients) and neutropenic fever (4 vs. 0 patients). Incidences of anaemia and nonhaematological adverse events were similar in the two groups. Remarkably, $30 \%$ of the patients in the CEP and $26 \%$ in the FUFA arm were long survivors. A major problem, undermining the strength of this study, was the small number of patients. Because of lack of accrual, the study was closed before reaching 
the beforehand estimated necessary number of 120 patients. With 46 patients only a difference in median survival of 6.5 months or more could be demonstrated.

In conclusion this study indicates that treatment with CEP improves response rates but does not prolong overall survival or time to progression and is more toxic compared to FUFA in patients with ACUP. Furthermore, there seems to be a subgroup of ACUP patients with prolonged survival, irrespective of the therapy used. Thus based on this study, no standard treatment can be advised, despite the presence of patients with clinical favourable prognostic factors who respond better to therapy and show improved prognosis. It is unclear if this is due to therapy or to their favourable condition beforehand. New studies treating solely UPT patients with favourable factors could answer this question.

It is unclear whether UPT forms a distinct biological entity with specific genetic and phenotypic characteristics, or whether it is merely a clinical presentation of metastases in patients in whom the primary tumour cannot be detected and does not result in any clinical signs. Understanding the basic biology of UPT may shed light on this issue and moreover, may have a direct impact on clinical care. A review of the literature shown in Chapter 5 revealed only a limited number of publications describing the genetic and phenotypic features of UPT, most of which focus only on the potential of these markers to predict prognosis. Karyotypic abnormalities of the short arm of chromosome 1 were recurrently observed in UPT. Aneuploidy was found in $70 \%$ of the tumours. Furthermore, overexpression of HER-2/neu and p53 mutation was only found in low frequencies. These features were however not unique to UPT, since many malignant solid tumours harbour such molecular alterations. Moreover, these findings were of no prognostic value, however patients with a high immunoreactivity index for $\mathrm{p} 53$ and bcl-2 tended to respond better to cisplatinbased chemotherapy.

A mutual feature of UPT is the rapid and early malignant progression as compared to that of tumours with known origin. This would imply that multiple tumours within individual UPT patients are clonally related (Chapter 6). Therefore, a molecular study was undertaken in which 14 patients with ACUP and multiple tumour sites, including the eventually during autopsy identified primary tumour (12), were analysed by molecular allelotyping and immunohistochemistry. In addition 4 tumours could also be analysed by comparative genomic hybridisation $(\mathrm{CGH})$. The molecular determinations indicated that the multiple lesions in all UPT patients, including eventually detected sites of anatomical origin, were clonally related. In agreement with the theory of tumour progression, some metastatic lesions showed besides shared characteristics also additional genetic alterations in comparison with the primary tumour. Furthermore, 8 UPT patients had tumours with a high frequency of loss of heterozygosity and/or allelic imbalance (FALI 43-71\%) 
while 6 demonstrated lower FALI (14-29\%), suggesting the presence of chromosomal instability in the former group. These data provide molecular evidence that multiple metastases within individual UPT patients are clonally related to each other and to the identified primary tumour, independent of its anatomical origin. This finding is in agreement with the idea that tumour progression is a rapid process in UPT patients limiting the chance of clonal divergence.

The results thus argue for a common biology of UPT. A further unravelling of the biology of this heterogeneous group of tumours might be expected in the near future by the application of genomic approaches to analyse UPT.

In the general discussion in Chapter 7 the incidence, the diagnosis, the prognosis, the therapy and the biological aspects of UPT are discussed. UPT is a relatively common tumour with a poor prognosis, except for some favourable subgroups. Investigations to identify the location of the primary are only valuable when they are likely to provide therapeutic or prognostic information for the patient. In patients, not belonging to favourable subgroups, independent clinical prognostic favourable factors are young age, good performance status, normal LDH level and absence of liver metastases. In this respect immunohistochemical analyses of some known cancer genes were of no prognostic value. Except for treatable subgroups no specific therapy for UPT is available. Most new treatment schemes were evaluated by phase II trials and none of the three phase III trials performed, showed an improved outcome. Thus, at this moment no standard chemotherapeutic treatment for UPT can be advised, except may be for patients with favourable factors, who should be preferably treated in a trial. Although molecular data argue for a common biology of UPT, the use of modern genomic analysis techniques is needed to further substantiate this hypothesis. Moreover, these approaches will help to discover the primary tumour in UPT and probably more important will help to identify new targets for treatment.

\section{Conclusion}

UPT remains a heterogeneous group of tumours with mutual clinical aspects but an unknown biological behaviour. Patients have a poor prognosis, except for some favourable subgroups. Chemotherapy does not seem to contribute to improving survival, however, patients with better prognosis and better responses to systemic therapy can be identified. Yet clinical features are the only tools, immunohistochemical markers have not proved to be useful. Though it seems likely that different tumours with similar clinical aspects exhibit similar genomic features explaining their aggressive progression, this hypothesis needs a stronger basis. 
Samenvatting 


\section{Samenvatting}

$\mathrm{Er}$ is sprake van een onbekende primaire tumor (OPT) wanneer bij een patiënt pathologisch bewezen uitzaaiingen zijn vastgesteld zonder dat er een primaire tumor wordt gevonden. De diagnose OPT kan pas worden gesteld na volledig anamnestisch en lichamelijk onderzoek, basaal laboratorium onderzoek, een thorax foto, aanvullend onderzoek gericht op afwijkingen, die bij deze onderzoeken aan het licht zijin gekomen of aanvullend onderzoek gericht op een behandelbare maligniteit.

OPT is een regelmatig voorkomende maligniteit met een uiterst sombere prognose. Om de prognose te verbeteren is het van belang deze maligniteit beter te begrijpen dan wiij nu doen. Meerdere onderzoeken, waarin het klinische en biologische gedrag van OPT is bestudeerd, worden daarom in dit proefschrift beschreven.

In Hoofdstuk 1 wordt een overzicht van de literatuur over OPT gegeven. Verder wordt in dit hoofdstuk een inleiding gepresenteerd op de verschillende studies in dit proefschrift.

Gegevens over het voorkomen, de prognostische factoren en de overleving van patiënten met OPT zijn voornamelijk afkomstig uit geselecteerde patiëntengroepen in gespecialiseerde, veelal tertiaire klinieken. Hoofdstuk 2 beschrijft een studie gebaseerd op een ongeselecteerde patiëntengroep in het zuidoosten van Nederland. Er werden 1285 patiënten beschreven; dit was 4\% van alle nieuw gediagnosticeerde kankergevallen in de populatie uit die regio. Bij 1024 patiënten werd de diagnose gesteld door middel van een cytologische punctie of een histologisch biopt. Bij $47 \%$ betrof het een goed of matig gedifferentieerd adenocarcinoom, bij $44 \%$ een ongedifferentieerd carcinoom of een slecht gedifferentieerd adenocarcinoom, bij $7,4 \%$ een plaveiselcel carcinoom en bij $1,6 \%$ betrof het een ongedifferentieerde maligniteit. Bij 261 $(20 \%)$ van de patiënten was de diagnose alleen op klinische gronden gesteld, zonder microscopische bevestiging.

De tumor bleek bij de diagnose al in $26 \%$ van de gevallen uitgebreid te zijn uitgezaaid. De meerderheid van de patiënten $(67 \%)$ werd alleen palliatief behandeld. De mediane overleving was kort (11 weken), de éen-jaars overleving was slechts $15 \%$. Prognostisch gunstige groepen die langer dan één jaar overleefden waren gemiddeld jongere patiënten en patiënten met uitzaaiingen in de lymfeklieren als enige lokalisatie. De 261 patiënten, bij wie geen pathologische maar alleen een klinische diagnose werd gesteld, werden apart geanalyseerd. Het bleek dat zij ouder waren dan de andere patiënten, nog minder antitumor therapie hadden ontvangen en gemiddeid nog korter overleefden ( 7 weken). 
De gegevens van de Nederlandse populatie werden vergeleken met een Amerikaanse groep OPT patiënten. Hieruit bleek dat de Nederlandse patiënten ouder waren, minder vaak werden behandeld met anti-tumor therapie en een slechtere prognose hadden. De prognostisch gunstige Nederlandse groep kwam goed overeen met de Amerikaanse groep. Waarschijnlijk kunnen de verschillen in overleving dan ook verklaard worden door een selectie van patiënten in de Amerikaanse publicaties. Er kan geconcludeerd worden dat in een ongeselecteerde populatie de diagnose OPT relatief vaak wordt gesteld en dat de overleving nog slechter is dan in menig ander studie wordt vermeld.

Er bestaan binnen OPT prognostisch gunstige groepen, die met de juiste benadering gemiddeld langer overleven (tabel 1.3). Dit zijn onder andere vrouwen met een okselkliermetastase van een adenocarcinoom, vrouwen met een peritonitis carcinomatosa van een adenocarcinoom, mannen met een osteoblastische botmetastase en/of een verhoogde PSA. Daarnaast blijkt er binnen de overgebleven patiënten ook een groep te bestaan die zich klinisch gunstiger gedraagt. Het is van belang deze patiënten te identificeren omdat bij deze subgroepen gunstige resultaten van de behandeling bereikt worden. Op zoek naar nieuwe prognostische factoren werden in eén centrum de biopten van 70 opeenvolgende patiënten met adenocarcinoma van OPT retrospectief klinisch en immunohistochemisch onderzocht. (Hoofdstuk 3) Statistische analyse van klinische kenmerken liet zien dat een jonge leeftijd ( $<60$ jaar), een goede 'performance status' (0-1), de afwezigheid van levermetastasen en een normaal lactaat dehydrogenase $(\mathrm{LDH})$ gehalte prognostisch gunstige factoren waren. Het prognostische model van Culine waarin gebruik werd gemaakt van de 'performance status' en het LDH gehalte, bleek toepasbaar op onze OPT populatie. Statistische analyse van de immunohistochemische kenmerken (MIB-1, p53,VEGF, CD34, CD44v6 en HER-2/neu) liet geen relatie zien met de prognose. Tot nu toe blijken dus ook in onze studie alleen de bekende klinische kenmerken gebruikt te kunnen worden als prognostische factoren voor de overleving bij patiënten met OPT.

De behandeling van OPT staat nog steeds in de kinderschoenen. Slechts een klein deel van de patiënten presenteert zich met een zogenaamde behandelbare OPT (kliermetastasen oksel, peritonitis carcinomatosa, etc.). Het merendeel van de patiënten behoort niet tot deze gunstige groep, dit zijn voornamelijk de patiënten met een adenocarcinoom van OPT. Deze patiënten zijn in fase II onderzoek behandeld met diverse chemotherapie schema's waarbij vooral de nieuwere middelen (taxanen en gemcitabine) van toegevoegde waarde lijken te zijn. In een fase II onderzoek met carboplatin, etoposide en paclitaxel (CEP) werd een mediane overleving van 11 maanden bereikt. Dit leek een goede reden om deze combinatie in een fase III studie te 
anderzoeken. In Hoofdstuk 4 is deze studie beschreven waarbij als controle arm de combinatie van continue 5-fluorouracil infusie en leucovorin (FUFA) wordt gebruikt. Het doel van deze studie was om te bepalen of behandeling met CEP tot langere overleving en een betere respons zou leiden bij patiënten met adenocarinoma van OPT dan behandeling met FUFA.

Zesenveertig patiënten werden geïncludeerd; in beide armen 23. De kenmerkende gegevens van de patiënten in beide armen van de studie waren vergelijkbaar. Er werden geen significante verschillen gevonden qua overleving in beide groepen. De mediane overleving in de CEP groep bedroeg 7,0 maanden versus 6,4 maanden in de FUFA groep $(p=0,76)$ en de mediane tijd tot progressie bedroeg 3,5 versus 3,3 maanden $(p=0,79)$. Van de 46 patiënten waren er $38(83 \%)$ evalueerbaar volgens de van tevoren vastgestelde criteria voor het beoordelen van de therapieresultaat. Complete en partiële remissie werd bij 30\% van de patiënten, die met CEP waren behandeld, gevonden en bij $9 \%$ van de patiënten, die met FUFA waren behandeld. Dit leverde een significant verschil op $(p=0,036)$. Wanneer de patiënten met stabiele ziekte meegenomen werden in de respons berekening dan verviel de significantie ( 60 versus $48 \%, p=0,14)$. Toxiciteit was veel ernstiger in de CEP groep; twee patiënten overleden ten gevolge van de chemotherapie, terwijl in de FUFA groep geen patiënten overleden ten gevolge van de behandeling. CEP veroorzaakte daarnaast vaker neutropenie, neutropene koorts en trombopenie dan FUFA. (Respectievelijk 9 versus $1 ; 4$ versus $0 ; 5$ versus 0 patiënten) Anemie en niet-hematologische bijwerkingen kwamen in beide groepen even vaak voor. Opvallend was dat in beide behandelarmen een prognostisch gunstige groep van ruim $25 \%$ van de patiënten te onderscheiden was. Een groot bezwaar van deze studie was het kleine aantal patiënten. Tevoren was berekend dat er om een verschil van vier maanden overleving aan te tonen 120 patiënten nodig waren. Met 46 patiënten konden verschillen van kleiner dan 6,5 maanden statistisch niet aangetoond worden.

Concluderend laat deze studie zien dat CEP de respons verbetert, maar geen verlenging van de overleving geeft. Daarnaast geeft CEP veel meer toxiciteit. $E r$ is binnen beide behandelarmen een prognostisch gunstige groep te vinden die het dus onafhankelijk van de soort therapie beter doet. Op basis van de gegevens uit deze studie kan geen specifiek therapie schema geadviseerd worden. Er lijkt wel een prognostisch gunstige groep te bestaan die beter respondeert op chemotherapie en langer overleeft. Het is onduidelijk of dit ten gevolge van de therapie is of door het gunstige prognostische profiel dat deze patiënten al hebben. Een nieuwe studie waarin alleen patiënten met prognostisch gunstige factoren worden behandeld zal deze vraag kunnen beantwoorden. 
Het blijt de vraag of OPT een aparte biologische entiteit is met specifieke genetische en fenotypische kenmerken, of dat OPT de klinische uiting is van een toevallig niet gevonden primaire tumor. Het verder uitdiepen van de biologie van deze tumor zal tot een beter begrip van de OPT leiden en hopelijk vandaar uit tot een betere behandeling. Een overzicht van de literatuur over het biologische gedrag van OPT wordt weergegeven in Hoofdstuk 5 . Het bleek dat er slechts weinig kennis was over de genetische kenmerken van OPT. Het merendeel van de studies verdiepte zich in het zoeken naar prognostische factoren.

Er werden afwijkingen aangetroffen op de korte arm van chromosoom 1, in $70 \%$ van de OPT bleek er sprake te zijn van aneuploidie en slechts een laag percentage van de OPT bracht p53 mutatie en HER-2/neu tot expressie. Deze kenmerken waren echter zeker niet OPT-specifiek en werden ook in vele andere gemetastaseerde tumoren gevonden. In OPT waren deze factoren niet van prognostische waarde.

Het lijkt dat de OPT zich in een vroeg stadium snel verspreidt door het lichaam. Dit impliceert mogelijkerwijs dat de verschillende uitzaaiingen genetisch op elkaar zouden moeten lijken (clonaal zijn) omdat er zich nog weinig mutaties hebben voorgedaan. Om deze hypothese verder te onderzoeken is een moleculaire studie opgezet die wordt beschreven in Hoofdstuk 6 . Van 14 patiënten met adenocarcinoom van OPT werden de verschillende uitzaaiingem en (als die gevonden was bij obductie) de primaire tumor geanalyseerd door middel van moleculaire allelotypering en immunohistchemie. Verder konden vier tumoren ook bestudeerd worden met behulp van 'comparative genomic hybridisation' $(\mathrm{CGH})$. Uit deze studie bleek dat de verschillende uitzaaiingen en grotendeels ook de primaire tumor clonaal gerelateerd waren, ongeacht de primaire lokalisatie. Daarnaast werden in de uitzaaiingen ook nieuwe afwijkingen gevonden, die de primaire tumor niet bezat. In 8 van de 14 patiënten was er duidelijk sprake van chromosomale instabiliteit. Deze bevindingen bevestigen de hypothese dat OPT een snel gemetastaseerd proces is waarbij de kans op clonale divergentie beperkt is. Dit zou kunnen passen bij het feit dat OPT gemeenschappelijke genetische afwijkingen heeft die zorgen voor het afwijkende gedrag. Op niet al te lange termijn valt te verwachten dat mett nieuwe technieken (zoals micro-array en proteomics) de biologie van OPT nog verder ontrafeld kan worden.

In Hoofdstuk 7 worden de bevindingen, die beschreven zijn in dit proefschrift, bediscussieerd. OPT is een relatief vaak voorkomend fenomeen met een uiterst sombere prognose, met uitzondering van enkele behandelbare subgroepen. Aanvullende diagnostiek naar de primaire tumor wordt alleen aanbevolen wanneer dit therapeutische consequenties heeft, zoals het vinden van een tumor in de borst of dikke darm. Klinische prognostische factoren zijn 
jonge leeftijd, goede 'performance status', slechts eén of twee organen aangetast, een normale lactaat dehydrogenase spiegel en geen levermetastasen. Enkele bekende kanker genen blijken zonder enige prognostische waarde te zijn bij OPT. Op dit moment kan voor OPT geen specifiek chemotherapeutisch schema worden geadviseerd, misschien met uitzondering van de prognostisch gunstige groep. Hoewel er momenteel enkele argumenten bestaan die pleiten voor een specifieke biologie van OPT, zullen deze eerst verder bewezen moeten worden. De OPT doet in dat opzicht zijn naam eer aan. Er wordt veel verwacht van de nieuwe genetische onderzoekstechnieken. Zodra de biologie van OPT beter begrepen wordt zal dit zeer waarschijnlijk ook leiden tot een betere behandeling en een betere prognose. 
Dankwoord 


\section{Dankwoord}

De totstandkoming van dit proefschrift is een ware bevalling geweest die zich over vele jaren heeft uitgestrekt. Zonder de hulp en support van velen zou ik het nilet gered hebben. Vandaar dat ik op deze plaats enkele mensen, die een stukje van dit ei hebben helpen leggen, will bedanken.

Prof. dr. H.F.P. Hillen, tijdens de opleiding in Maastricht heb ik veel geleerd van uw klinisch en analytisch denken. Verder is het uw aanstekelijk enthousiasme geweest waardoor ik geïnteresseerd ben geraakt in de onbekende primaire tumor. We hebben er beide niet aan getwijfeld dat het er ooit van zou komen, maar het voelt toch wel erg goed dat er nu een proefschrift valt te verdedigen.

Dr. R.L.H. Jansen, beste Rob, jij hebt mij bij het schrijven van dit proefschrift met de voor jouw typerende precisie begeleid. Dat was nou juist wat ik nodig had; iemand die mij bijstuurde als ik op papier weer eens te kort door de bocht probeerde te gaan. Een betere co-promotor kan iemand zich niet wensen.

Dr. E.J.M. Speel, beste Ernst-Jan, je bent altijd enthousiast en vol nieuwe ideeën. Je hebt me wegwijs gemaakt in de $\mathrm{LOH}, \mathrm{Al}, \mathrm{CGH}$ en warm doen lopen voor de moleculaire biologie.

Sandra Claessen door jouw onaflatende inzet zijn alle proeven uiteindelijk goed gelukt en de gegevens betrouwbaar en reproduceerbaar. Hiervoor mijn grote dank, dit had ik nooit zelf kunnen doen.

Het angiogenese lab in het azM. Arjan Griffioen, bedankt voor het inwijden in de wereld die vaatnieuwvorming heet. Je hebt me eerst door de literatuur en later ook door het laboratorium geleid. Suzan Joosten, je hebt me enorm veel werk uit handen genomen. Je hebt alle immunohistochemische kleuringen uitgevoerd en hebt ook nog eens alle tellingen opnieuw verricht als tweede onderzoeker.

Het St. Elisabeth ziekenhuis Tilburg. De internisten, in het bijzonder de opleider, Cees van der Heul, en de arts-assistenten van de 'rode bankjes'-tijd hebben voor een gedegen maar ook niet te vergeten interne opleiding gezorgd. In deze goede en stimulerende sfeer is dan ook de basis voor dit proefschrift gelegd. Anneke van der Wurff, bedankt dat je ondanks je nieuwe drukke baan al het histologische materiaal opnieuw hebt willen beoordelen. Daarnaast ook mijn dank aan de medewerkers van het pathologisch laboratorium voor het leren snijden en kleuren en voor het uitzoeken van alle lijsten en biopten. 
Maatschap interne geneeskunde uit het Slingeland Ziekenhuis Doetinchem. Beste maten, bij jullie in de Achterhoek heb ik een superplek gevonden waar ik me enorm op mijn plaats voel. Het is fantastisch om met zulke kundige en plezierige collega's te kunnen samenwerken.

Tiny Wouters. ledere doctor van de interne geneeskunde in Maastricht weet het: JE KUNT HET NIET ZONDER TINY.

Mijn paranimfen. Karin van Assen, als voorganger (in opleiding, promotie, moederschap, noem maar op) en bovenal goede vriendin ben ik blij dat ik jou aan mijn zijde heb. Marie-José Walenkamp, wie had dit twee jaar geleden kunnen denken en nog wel synchroon ook. Ik hoop dat jij aan mijn andere zijde veel inspiratie opdoet en over niet al te lange tijd ook je ' $s$ ' verliest.

Ik wil ook alle andere 'paranimfen' bedanken die in de zaal zittend mij bijstaan.

Pap en mam, jullie hebben mij, Gilles en Branka op een geweldig mooie manier in het leven gezet. Ik houd van jullie!

En dan mijn liefste Aernout, Floris, Liselotte en Myrthe. Jullie zijn mijn allerbelangrijkste drijfveer geweest om het ei dan nu te leggen. Jongens, ik ben er weer! 


\section{List of abbreviation}




\section{List of abbreviation}

\section{"What's upt doc?"}

$\begin{array}{ll}\text { UPT } & \text { Uiver Promoot Thesis } \\ \text { UPT } & \text { Ultimate Personal Trainer } \\ \text { UPT } & \text { UltraPhonics Tutor } \\ \text { UPT } & \text { Ultrapräzision Technische Optik } \\ \text { UPT } & \text { Unattended Payment Terminal } \\ \text { UPT } & \text { Undergraduate Pilot Training } \\ \text { UPT } & \text { Unieke Perifere Toko } \\ \text { UPT } & \text { Uniform Particulier Tarief } \\ \text { UPT } & \text { UniPartners Twente } \\ \text { UPT } & \text { Unique Play Therapy } \\ \text { UPT } & \text { Unit Pelaksana Teknis } \\ \text { UPT } & \text { United Petroleum Transports } \\ \text { UPT } & \text { United Product Tankers } \\ \text { UPT } & \text { Universal Personal Telecommunications } \\ \text { UPT } & \text { Universita Popolare Trentina } \\ \text { UPT } & \text { Universitaire ProfileringsThema's } \\ \text { UPT } & \text { University of Pittsburgh at Titusville } \\ \text { UPT } & \text { University Physical Therapy } \\ \text { UPT } & \text { Unknown Primary Tumour } \\ \text { UPT } & \text { Unpenttrium 153 } \\ \text { UPT } & \text { Unreal Performance Test } \\ \text { UPT } & \text { Uptown } \\ \text { UPT } & \text { Urenco Power Technologies } \\ \text { UPT } & \text { Urinary Pregnancy Test } \\ \text { UPT } & \text { USB Port Tester } \\ \text { UPT } & \text { User Preferred Trajectory } \\ \text { UPT } & \text { Utrechtse Party Tijger }\end{array}$

